\title{
American Dairying
}

\author{
2y 4. 3. CURLER.
}




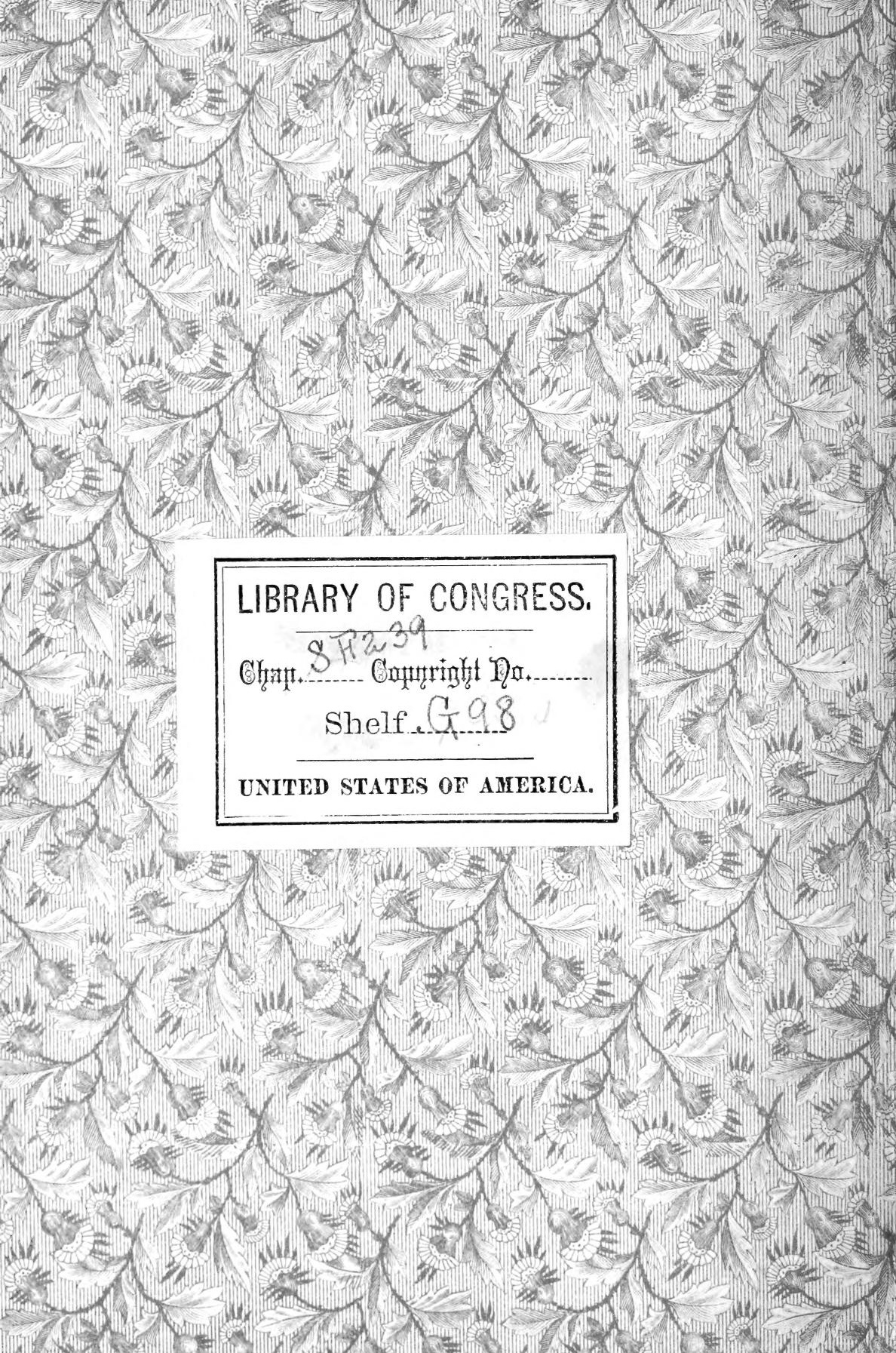





\section{AMERICAN DAIRYING}

A PRACTICAL TREATISE ON

\section{Dairy Farming and the Management of Creameries.}

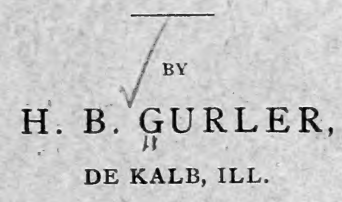

CHICAGO :

Breeder's Gazette Print.

I894.

$$
49225-2
$$


Copyright, 1894,

BY THE J. H. SANDERS PUB. CO.

(All rights reserved.) 


\section{PREFACE.}

This book is dedicated to those interested in the dairy and creamery business in America.

The work is undertaken at the urgent request of men with whom I have worked in this great field. I shall undertake to weave into its pages all my experience that I think will be of value to the readers of my book. My mistakes will be put to the front when I think they will be of value in preventing some brother dairyman or creamery man from mak ing similar mistakes.

I expect to use much information secured from the work of our experiment stations and other reliable sources. A. H. Barber, Chicago; the Cornish, Curtis \& Greene Co., Fort Atkinson, Wis.; the Creamery Package Co., Chicago; the Vermont Farm Machine Co., Bellows Falls, Vt.; P. M. Sharpless, Elgin, Ill., and Mr. Decker, Fond du Lac, Wis., have offered to loan me cuts to illustrate the work. Mr. E. H. Farrington, the World's Fair Chemist, has prom- 
ised to write for the book about the Babcock test.

If I can give my brother workers some ideas that will enable them to do better work, and can induce a small percentage of the dairymen to apply the scale and Babcock test to their individual cows and dispose of the unprofitable ones, I shall feel that I have accomplished some good.

De Kalb, Ill.

H. B. Gurler. 


\section{TABLE OF CONTENTS.}

\section{PART I.-PRIVATE DAIRYING.}

ChAPTER I.-The Dairy Herd, Selection, Breed and

Breeding. . . . . . . . . . . . 9

ChaPter II.-Feed and Management. . . . . . 30

ChAPTER III.-Care of Dairy Utensils. . . . . . 62

ChaPTER IV.-Milking. . . . . . . . . . . . 65

Chapter V.-Milk from Cow to Cream Vat. . . . 81

CHAPTER VI.-Ripening and Churning. . . . . . . 94

CHAPTER VII.-Salting, Working, Packing and Print-

ing. . . . . . . . . . . . . 103

CHAPTER VIII.-Marketing Dairy Butter. . . . . 110

CHAPTER IX.-Skim-milk. . . . . . . . . . 116

\section{PART II.-CREAMERY MANAGEMENT.}

Cha Pter I.-Care of Milk by Patrons. . . . . . 147

CHAPTER II.-Receiving Milk at Creamery. . . . 154 ChAPter III.-The Babcock Milk Test (by E. H. Farrington). . . . . . . . . . . . 160

CHAPTER IV.-Tempering and Separating. . . . 169 CHAPTER V.-Ripening and Churning Cream. . . . 182

CHAPTER VI.--Salting, Working, Packing and Marketing. .. . . . . . . . . . . . . 204

CHAPTER VII.-Care of Skim-milk at the Creamery. . 214 CHAPter VIII.-Care of Buildings and Utensils. . . 217 CHAPTER IX. - Suggestions to Those About to Build a

Creamery. . . . . . . . . . . . 226 ChaPter X.-Gathered-Cream Work. . . . . . 238 ChaPTER XI.-A Talk With Creamery Employés. . . 249 APPENDIX.-An Acid Test of Cream. . . . . . . 257 



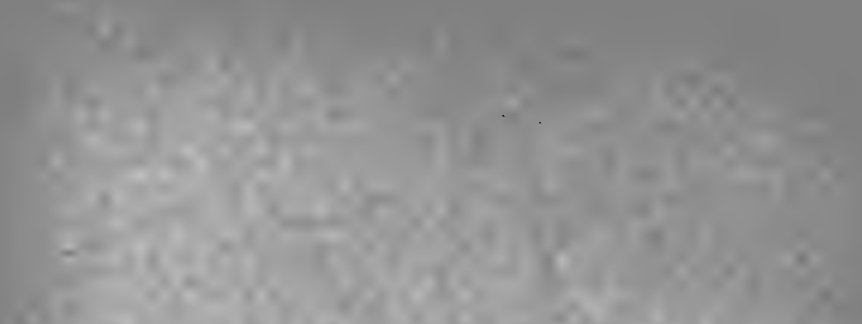

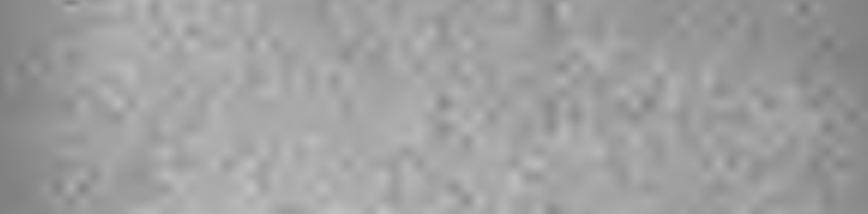

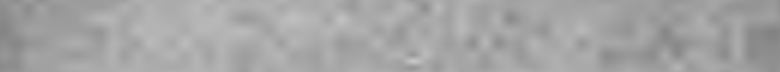

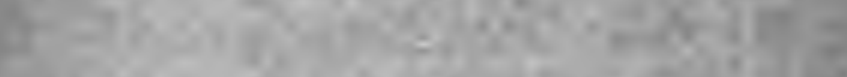

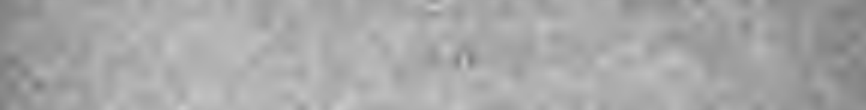

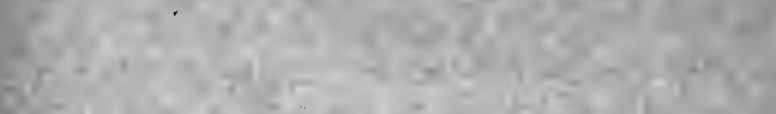

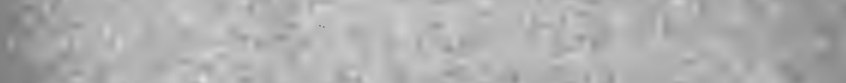

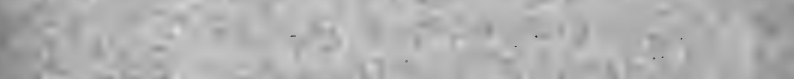

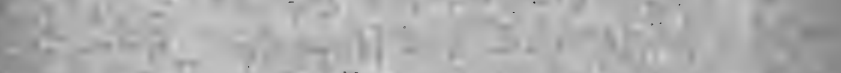

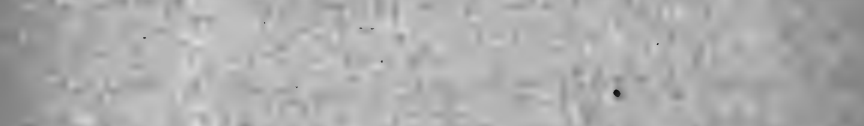
- 10

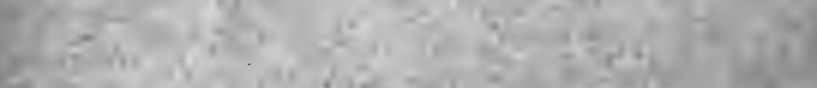

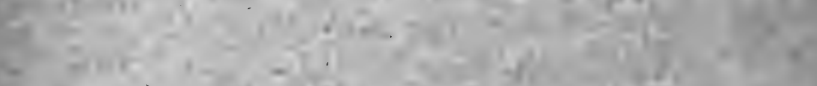

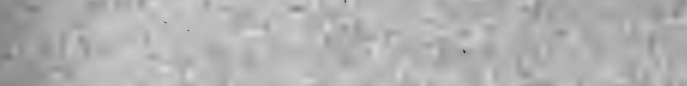

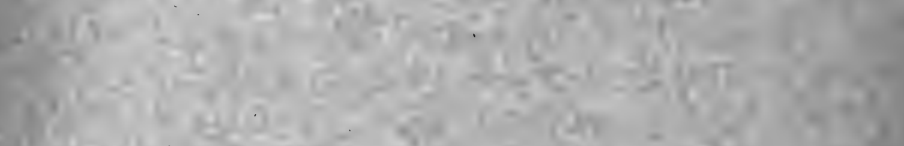
.

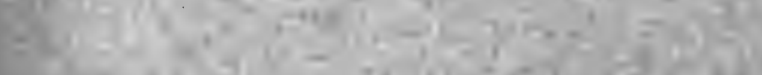

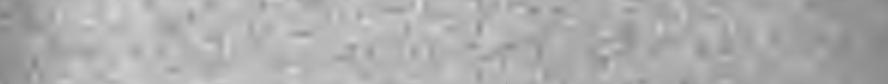

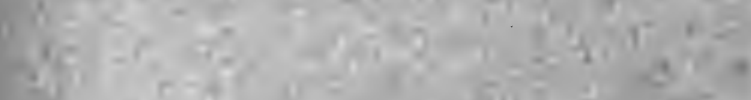

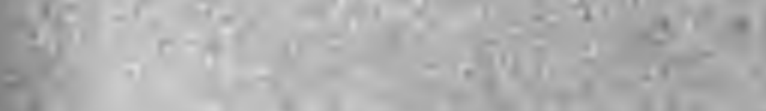

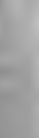




\section{CHAPTER I.}

\section{THE DAIRY HERD, SELECTION, BREED AND BREEDING.}

Here is the foundation of the whole dairy business. Success depends more on the herd than on any other one point. Much, of course, depends on the feed and care, but the best of feed and care will not make a cow that has a capacity for only $125 \mathrm{lbs}$. of butter annually a profitable cow.

Average cow in the United States.-When we think that the average of the $16,500,000$ cows in the United States is only $130 \mathrm{lbs}$. of butter annually, according to the last census, is it not time to be thinking how to improve in this work? There is no doubt as to there being room to improve, as there are herds in the United States that average $400 \mathrm{lbs}$. and above per cow annually, and herds in nearly every community in the dairy sections that average $300 \mathrm{lbs}$. of butter per cow annually.

Object lessons. - These 300 to 400 -lb. dairies should be object lessons to all dairymen. What one dairyman or dairywoman has done another 
can do, and probably a little better can be done. It is certainly well for us to try to excel in whatever line we are working. I shall not advise all dairymen to sell their present herds and buy registered cows of some of the dairy breeds. This is all right for those who can see their way clear to do so. I believe it is wise to breed registered animals when a person is so situated that he can.

How to improve the herd. - What every dairyman can do to improve his herd is to test individual cows and dispose of such as do not come up to a profitable standard. This standard will vary in different localities, depending on the cost of feed and labor and on the value of the products.

Cost of feeding cows. - We should not take any other person's figures or estimates for this, but should know from our own work what it costs to feed a cow one year. To the cost of feed add labor and the interest on the investment in the cow. We will suppose it costs $\$ 35$ to feed the cow a year and $\$ 12.50$ for labor to care for her and $\$ 2.50$ to pay interest. We now have $\$ 50$ charged up against the cow. Now, what shall we find to put on the other side of the account? It is very plain to be seen that the $130-\mathrm{lb}$. cow is not in this race, as her butter will have to sell for 33 cents per pound to leave a profit. 
Value of skim-milk.-We will allow $\$ 10$ per cow for the skim-milk and we have a balance of $\$ 40$ to be paid for by the butter before we have any profit. We will suppose as much butter is made in winter as summer, in which case the average price after paying for making at the creamery will be about 21 cents per pound. Now it will require 190 lbs. of butter at 21 cents per pound to balance the $\$ 40$ and leave us whole. In this case the cow that makes 190 lbs. of butter per year does not make us any profit. In my experience I find no profit in a $200-1 b$. cow. I might have 100 of them on my farm and not make $\$ 250$ per year on the whole lot of them.

Man, horse and cow.-Now please tell what is the sense in keeping such cows? We would not keep a horse that could only do work enough to pay for feed, neither would we keep a man who could only do enough to pay for his board. But yet most of us keep a dairy of cows onefourth of which actually run us in debt. There is no excuse for this at this period of the dairy work. Before the introduction of the Babcock test there was some excuse for a dairyman not knowing what each individual cow was doing for him, though even then there was not sufficient excuse for this condition, as the cows could be tested by the churn. That required a great amount of work, but it paid. 
Cream test.-The first test I applied to my cows was the test for cream, and this was twenty-five years ago. At that time it was generally supposed that the percentage or depth of cream that raised on samples of milk set in glass test tubes or dishes of uniform size and depth was a correct basis on which to judge of the butter value of the different cows' milk. I soon learned, as have hundreds of others in this line of work, that this test was not reliable, as I found that there was in some instances a difference of 25 per cent in the butter value of milk that showed the same percentage of cream in the glass tubes.

The Connecticut Experiment Station found cream furnished by different patrons of a cream. ery who set their milk in deep or submerged cans for twelve to twenty-four hours to contain from 13.8 to 24.9 per cent of fat. I proved the cream test to be unreliable by applying the cream test and the churn test to the same milk. The results of these comparisons caused me to abandon the cream test and start anew with the churn.

Churn test.-This plan cost me much time and labor, each cow's milk being set separately and skimmed and churned separately. For this work I had a gang of six small churns of the rlasher pattern, with the dashers attached to a 
horizontal bar, so I could operate the six at one time. This work paid me in several ways. It paid me to know my individual cows, so I could dispose of the unprofitable ones. It caused me to think better of my business and of myself. It opened a great field for improvement in the line of selection and breeding - a field large enough to give room for the most ambitious and progressive person.

Percentages of cream and fat.-The following table shows the percentage of cream in fourteen different patrons' milk; also the percentage of fat found in the same milk by the Babcock test:

TABLE I.-MILK FROM DIFFERENT DAIRIES.
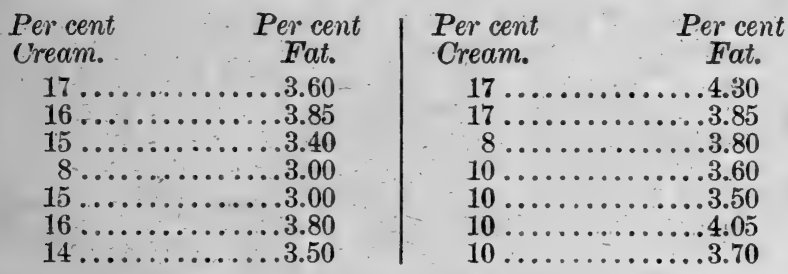

And the second and third tables show the different cows in two dairies, the first column being the percentage of cream and the second column the percentage of fat by the Babcock test. A study of these two tables will show the unreliability of the cream test in judging the butter value of milk: 
'IABLE II.-MILK' FROM FIRST DAIRY.

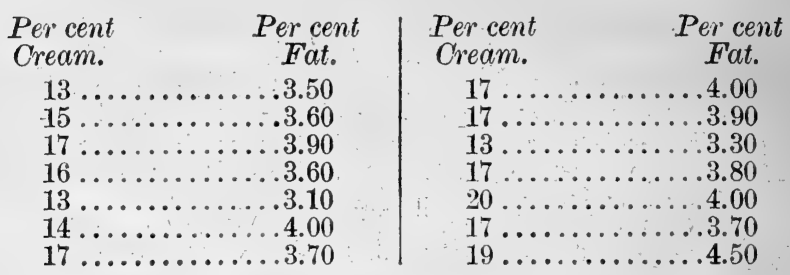

TABLE III.-MILK FROM SECOND DAIRY
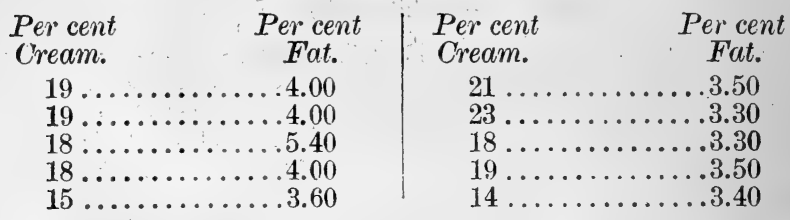

Unimproved opportunities. - Why more dairymen do not improve this opportunity to help themselves I am at a loss to understand. No manufacturer could withstand the competition he has to contend with if he left unimproved opportunities like many dairymen are leaving in not testing and knowing what their individual cows are doing for them. With the Babcock test it is a very simple matter to tell what each cow is doing at any time, and there is now no excuse for a dairyman's not knowing just where each individual cow stands.

In the estimate we have made we find that it requires 190 lbs. of butter and the skim-milk to pay for feed, labor and interest. This being a fact we must have cows that will make at 
least 200 lbs. annually. Now let us test each cow and learn what she is doing.

Testing the cows.-There are many ways of applying the test. So far as frequency of applying it is concerned if a person wishes to know exactly what a cow is doing the milk must all be weighed and a sample taken from every milking and tested. The composite test (which will be referred to elsewhere) can be used for this work. A reasonably reliable test can be secured by testing one day in each month; a more reliable one by testing twice per month. For the past year's work I have adopted the plan of making three tests with four months between each test, each test to cover three days' time, a record of each milking to be kept, and a sample of milk from each milking to be put in a bottle that is to be marked with the name or number of the cow the milk is from. For taking the samples have your tinsmith make you a little cup one inch in diameter and two and a half inches deep. This will hold about one ounce and is sufficient. When a cow is milked first weigh and record the weight of the milk, then pour it from one pail to another back and forth three times, then take the little ounce cup full and put it into the sample bottle or jar. A pint fruit jar can be used for this purpose, or an eight-ounce bottle can be used by having a small funnel to fill with. 
Care of samples.-If this test is being made in warm weather care should be used to preserve the samples sweet for three days. This can be done by setting them on the floor of a cool cellar or by the use of bichromate of potash, which can be bought at the drugstore in a pulverized form and put into each jar or bottle in quantities the size of a pea. This will prevent souring and keep the cream in a liquid condition so that it will mix with the milk with but little agitation. At the end of the three days the samples should be tested.

How to get testing done.-If you are a patron of a creamery that has a Babcock tester get your creamery man to make the test for you. He will not ask you much for it and possibly will do it for nothing. When the test is worked and you have the weight of the milk it is an easy matter to get at the butter the cow is making daily.

Estimating butter from test.-We will suppose that she gave $70 \mathrm{lbs}$. of milk in the three days and it tested 3.8 per cent of fat. This would give $2.66 \mathrm{lbs}$. of fat, to which we will add $12 \frac{1}{2}$ per cent, or one-eighth, to get the amount of butter this fat will make. We do this because butter is not pure fat and we find in actual work that we can make one-eighth more butter from 100 lbs. of milk than the test shows of fat, though to secure this increase it 
is necessary to do efficient work both in the creaming and churning.

The average work done by the gravity system of cream raising would not warrant us in adding one-eighth to the fat found by the test to secure the probable butter, but with the separator this increase of butter over fat should be obtained, and if it is not the cause should be looked for and removed. By adding oneeighth to the $2.66 \mathrm{lbs}$. of butter-fat we get 2.99 lbs. of butter in the three days, or practically one pound per day.

Simplest way to test.-A simpler form may be used. It will not give as accurate results as the three tests, but is very much better than no test.

I have learned by following my individual cow tests that my cows averaged for 8.4 months the same as the average of the first six months. In other words, if a cow averaged $30 \mathrm{lbs}$. per month for the first six months she would make 8.4 times that for the year's work and drop her calf at the same time as the previous year. She should give enough milk after the 8.4 months to make the 2.4 months average with the first six months. I have proved this work in my dairy. This does not prove that it would be a reliable rule in all cases.

When a cow is judged on a single test it should cover one week, the milk being weighed 
at each milking and a sample added to the composite jar from each milking. This test should be made at about the end of three months, as that will give an average of the first six months. When a cow is to be judged on a single test there is need of some thought and good judgment-more than when she is judged on three tests at intervals or on monthly tests. We will suppose a cow is fresh Jan. 1 and is tested April 1. This will give a fair basis on which to judge her if she has had uniform feed and care. But if she is fresh March 1 and tested June 1 we shall secure too high a basis on which to judge her as she will be judged at her highest point of production, for she will produce more milk and butter June 1 on pasture than she would May 1 on dry feed; in fact more than she would at any previous or subsequent time.

We will suppose a cow gives 154 lbs. of milk in seven days and it tests 4.3 per cent of fat. This will make $6.612 \mathrm{lbs}$. of butter-fat in the seven days. To this we will add one-eighth for increase of butter over fat and we have $7.72 \mathrm{lbs}$. of butter in seven days, or $1.1 \mathrm{lbs}$. per day. This we will multiply by 252 , the number of days in 8.4 months, and we have 277 lbs. of butter for the cow's yearly work.

A better way.--I would recommend this plan of testing only to those who will not take the 
necessary time to make a more reliable test. I know how the average dairyman dreads to undertake this work and I offer this as the simplest way I know of to get facts that have value, feeling confident that when a dairyman has applied this test he will have become so much interested that he will apply a more thorough one.

The benefit that a dairyman derives from testing his herd is much greater than one would at first suppose. We will call 200 lbs. of butter annually the line between profit and loss. This will hold good in the Central and most of the Western States. The Eastern States may need to put this line up to 225 lbs. on account of feed being higher. This is a point that every dairyman must figure out for himself, whether he lives East or West, North or South.

Comparative profit.-What I wish to bring out is the comparative profit of cows that make $250 \mathrm{lbs}$. and those that make more. The 250-lb. cow leaves $50 \mathrm{lbs}$. for profit and a $300-\mathrm{lb}$. cow leaves $100 \mathrm{lbs}$. for profit, or twice as much as the 250-1b. cow, and is worth twice as much. The 350-lb. cow is worth three times as much as the 250-1b. cow and six times as much as the 225-1b. cow. This is supposing that one cow consumes as much food as the other. This may or may not be tne case, but whether it is or not it does not in any case make an argument 
of sufficient weight to be considered when comparing $250-1 b$. cows with 350 to $400-1 b$. cows.

The question of the ability of cows to produce the most from the food consumed is an important one and should be followed as soon as we can reach it.

Cows in debt to us.-But let us first weed out the cows that are getting in debt to us, and the number of such cows in the country is alarming. I believe a majority of the cows in the United States could be made profitable by proper feed and care, but the majority as now fed and cared for are evidently not profitable. The last United States census estimates the average amount of milk per cow annually at 2,883 lbs., which, it would be fair to suppose, would make 130 lbs. of butter. I do not know of a place in the United States where a 130-1b. cow can be made profitable.

Buy a Babcock tester.--If you have no convenient way of getting your samples of milk tested buy a Babcock test machine and do your own testing. The dealers send full instructions with the machines and any person with average intelligence can learn in a short time to operate one. This will be the most satisfactory way in the end and the cost will not be great. Every dairyman with ten cows can afford to have one. In fact no dairyman can 
afford to go long without having his cows tésted.

When you buy a Babcock test machine go and see one operated, if there is one in your vicinity. This will show you the simplicity of it and give you confidence. When you are ready to do some testing get a sample of milk and do some trial work with it. Work with it until you can get a half-dozen tests of the same milk to read alike or nearly so. The bottles having been bought of some reliable dealer who guarantees them accurate you will soon find your readings of the same milk very near alike. I remember one instance when our lady bookkeeper made twenty-four tests of the same milk and they all read alike. There was not enough difference to change the reading. This work will not only prove profitable but instructive and interesting to a person that is cut out for a dairyman. It must be taken hold of with a grip that will allow of no slipping, and when a cow is found that does not pay a profit sell her for beef, as you are better off without her than with her. I found cows in my dairy that would eat up the profit of another cow that made 265 lbs. of butter annually.

One cow better than two.-When I had the two cows I made nothing from the two, but when the poor one was sold I had a profit of $\$ 13.65$ from the best one. There are thousands 
of such instances in the dairy work of our country. This is a matter in which we do not need to ask our legislatures for assistance unless it is for legislation compelling us to improve our opportunities.

In 1892 I set my standard at 200 lbs. of butter per cow and found twenty-one cows out of sixty-four to be below that standard and they were sold for beef. In 1893 I raised my standard to $210 \mathrm{lbs}$. and had eighteen to sell for beef. In 1894 I raised the standard to $225 \mathrm{lbs}$. and had six to sell for beef. I hope in a very few years to be able to replace all cows that do not make $250 \mathrm{lbs}$. of butter annually with better ones of my own raising. I can see no reason why persistent work on the part of any intelligent dairyman will not take him up to the point where he can dispose of all cows that do not make 300 lbs. of butter annually and secure an average for the herd of $400 \mathrm{lbs}$. or more.

Intelligent breeding.-When we have once learned what each cow is doing for us we are in a position to do intelligent work in the line of breeding, and we are not in position to do the best work until we know each individual cow. We will admit the fact that the bull is half the herd so far as offspring is concerned, and he is a half that should be thoroughly looked after. Look well after the butter record of his ancestors, especially his dam. Do not let a few dol- 
lars prevent your securing the best you can find. It will be a good investment.

Now that you know the butter record of each cow and you have a bull from some choice butter-making family, you are in position to grow some heifers that will do you good. These heifers should be grown on skim-milk after they are from one to two weeks old. This subject will be treated in the chapter on skim-milk. They must be kept growing continually, as any check in their growth is a cause of loss in size and development of the digestive organs, and consequently affects the future value of the animal.

Age to breed.-I practice breeding my heifers so that they drop their first calves at two years of age. I am confident that they make better cows to come in milk at two years of age than later. They should be handled from the time they are calves, so that they may not be afraid of the person caring for them. Where this is done there is very little trouble when they drop their calves, but if they have not been so handled and are afraid of the person caring for them, and of their surroundings, they suffer much from fear; and much patience will be required to overcome their fear and teach them to be quiet while being milked.

Establish the milking habit.-Care should be exercised during their first milking period 
to establish or fix the habit of milking as long as desirable. If they are allowed to go dry too early in their first year of milking they are more likely to do the same the succeeding year, and the habit is soon fixed. They should be milked to within two months or less of the time of dropping their calves. This is the kind of work that has developed and made it practicable to secure the large yields of butter from cows that we now so frequently obtain.

Do not force a cow dry. If she persists in milking the whole time let her have her way about it. Drying off a persistent milker requires more care than the average milker will give to it. I have had such cows forced dry and when fresh again found a part of the udder injured so as to be useless, and I had a threeteated cow as the result.

Buying cows.-As time passes and the Babcock test comes into more general use it will become more and more difficult to buy cows that will make a profit, as the farmers, becoming acquainted with their cows, will not sell their best ones. This is as it should be, and we should be prepared to meet this gradual change that is sure to come.

What breed to select for dairy purposes I shall not undertake to tell you, only let it be some one of the special dairy-purpose breeds. Study this sulject thoroughly and select the 
breed you think best suited to your wants. I have grade Jerseys that are excellent cows, also grade Holstein-Friesians, grade Short-horns, and registered Jerseys.

Prof. W. H. Caldwell of New Hampshire, who was superintendent of the Guernsey cows in the great breed contest at the Columbian Exposition, in writing on this subject uses the folTowing language:

This law of natural selection applies with equal force to the dairy cow. The progressive dairyman wants a dairy cow whose lines of temperament and functions are for milk or butter, as may be desired. It does not necessitate fancybred stock.- Don't, however, believe I wish to raise one word against pedigreed stock. There is place for it, and it should be more generally distributed than it now is and farmers should be more eager for its influence. My object now is to take the problem confronting the hundreds of dairymen whose conditions have not led to the same. Competition and economy are forcing them to improve their stock. This lesson of individuality should be a most encouraging one to them. They undoubtedly have many a fine profitable dairy cow in their own herds. What is needed is to have some plan of improvement.

The Illinois Experiment Station has recently been purchasing cows for a dairy. The scale and Babcock test have been applied to every cow and no cow purchased that did not promise to make 300 lbs. of butter annually. The fact that we were able to purchase $300-1 b$. cows in the vicinity of the experiment station was a source of gratification to me. It shows very conclusively to me that there are good cows in 
all localities. What is needed is to become acquainted with them.

I now have on my farm sixty-five heifers that are from grade Holstein-Friesian cows and registered Jersey bulls. They are a very promising lot of heifers and I feel confident they will do me good work. They have the Jersey markings mostly and are open and roomily built, with good size and large digestive organs. A pony-built heifer is pretty to look at but I pass them when looking for the future cow. My business brings me in contact with dairymen daily, and in conversation with them I often feel that they do not realize the opportunities there are for improvement on our present work in our dairies. It is very hard to realize what a delicate piece of machinery the cow is. We have a great deal to learn about her yet, and the more I learn the more I see I need to learn. Raising calves will be treated under the head of skim-milk.

Test before buying.-When buying cows it is best to test them before buying and avoid unprofitable cows. This can easily be done if the cow is giving milk. With the present low price of beef a discarded cow will not sell for beef without considerable loss from the price paid for her as a milch cow. Several years ago when fat cows would sell to the butchers for from four to five cents a pound, live weight, we 
could dispose of them without loss, but now it is quite different, as cow beef is very low priced.

Disposing of unprofitable cows.-The best way I have learned to dispose of cows that are below standard is to feed heavy and milk at the same time. After three or four months most cows will improve in condition, and may be fattened while being milked and sold for beef soon after being dry. Fattening dry cows is unprofitable work. I have never been able to do it without loss. I advise to fatten while milking always, and sell as soon as possible after the cow is dry, as a dry cow cannot be fed at a profit with the present low price of cow beef.

Cost of cow beef.-The Maryland Experiment Station reports a comparison of the cost of fattening cows nine to ten years old and those five to six years old, feeding corn-meal, wheat middlings, linseed-meal and Hungarian hay or corn stover. In eight weeks the two older cows gained 105 lbs., at a cost for food of $\$ 20.65$, or nearly twenty cents per pound of gain, and the two younger cows gained 209 lbs., at a cost of $\$ 21.95$, or about ten and onehalf cents per pound. Some European work in this line has shown it to be very unprofitable.

Cost of feeding individual cows. - When we have got our cows tested pretty thoroughly for 
butter it is time for us to test to learn what feed each individual cow consumes. The Pennsylvania Experiment Station has done some work in this line, and with results that are interesting, instructive and valuable. This work is reported in "Bulletin No. 24." On page 11 of this bulletin we find that the cow Marguerite produced 6,512 lbs. of milk and $296 \mathrm{lbs}$. of butter, and the cow Ramona 5,459 lbs. of milk and 279 lbs. of butter.

Judging these cows on the basis of the butter made we would call Marguerite the best cow, but when the cost of feed is deducted we find that Marguerite has left to her credit $\$ 31.50$ and Ramona has $\$ 61.50$. In closing this bulletin they say:

The reader may regard these as extreme cases, and yet they were selected from the ten animals used in this experiment and we have no reason to doubt that as great differences might be found in any ordinary herd.

Unquestionably the presumption is in favor of the animal producing the largest quantity of butter per year. On the average this is true, but the most successful dairyman has to deal with individuals rather than averages, otherwise it will be impossible for him to derive the greatest possible profit from his business.

These facts are in no way applicable to the farmer who has yet to learn what each animal in his herd is producing. To him the use of the Babcock test and milk scales is of paramount importance. But to the careful, thoughtful dairyman there is undoubtedly an opportunity for a great saving by applying the feed test to each animal, as well as the butter test, and weeding out those animals that do not make satisfactory return for the food consumed. It is true that 


\section{THE DAIRY HERD.}

this involves some labor and pains, but requires a small outlay of money. While making such a test he will also be able to determine the quantity of food that each animal requires for the greatest profit, and bə thereby doubly repaid for his labor. 


\section{CHAPTER II.}

\section{FEED AND MANAGEMENT.}

In feeding cows the point that attracts my attention more frequently than any other is palatability of the food. This point must be looked after with great care, as it is the key to the situation. It matters but little how much nutriment there is in any kind of food; if it is not palatable the cows will not eat enough of it to make a satisfactory profit.

The cow a machine.-The cow is a machine for manufacturing our coarse fodder and grain into milk. This machine requires a certain amount to keep it in running order, and our profit comes from what she consumes after she has taken care of herself. A food may be so lacking in palatability that she will only consume enough to sustain herself, in which case our profit is a minus quantity. The question of digestibility enters into the problem, but $\mathrm{my}$ experience has caused me to think that palatability and digestibility go together, or at least a palatable food is a digestible food. Palatahility we must have as we cannotsucceed with- 
out it. How shall we secure it? With our hay it can be attained by cutting at the proper time and curing and protecting it in a proper manner. My experience teaches me that the clovers, and especially the medium clover, make the best hay for milch cows when cut at the proper time and well cured and secured.

Make hay early.-Only a small percentage of farmers commence making hay as early as they should. A pressure of other farm work is the excuse for this. I say excuse for the reason that many farmers know that they are not doing as well as they know how, but other work is crowding and they postpone haying thinking they will not lose as much by letting clover wait as they will by letting some other crop wait. The fact is we cannot afford to let anything wait, but we sometimes are compelled to, or at least we think we are. Clover should be cut for hay when in full blossom, and the same rule will apply to other grasses when to be made into hay for cows. If we have a large quantity to cut we need to commence before it reaches its best stage, otherwise some of it will become much too far advanced before we can secure it all. The cow cannot overcome our mistakes. It does not matter what the cause of the delay is, when it gets to the cow she is compelled to accept of our excuses for not furnishing a more palatable and nutritious food, 
and we are compelled to accept her excuse for not producing a profitable quantity of milk. This is an inevitable result. The cow is not to blame, for she has done her best. If she could talk English I believe she would make some of us ashamed of ourselves.

Study cow language.-If we would try to learn cow language it would pay us well for the time spent-learn to know as soon as we look the cow over and her surroundings what we have failed to do that we should have done for the comfort and health of the cow and profit to the owner. There are many things here that I cannot describe. We must study the situation and the cows; try to reach the condition that we know intuitively when things are right and when they are not right. This will come with experience and with it will come an increased profit for our work. We cannot cover the loss from poor hay or silage. I have never been able to bridge over the mistakes I have made in not securing the best hay or silage for $m y$ cows. An increase of the ground feed will help, but it will not cover the mistake in full. At the same time it increases the cost of food as a rule, as in most localities the coarse foods are the most economical so far as they can be used. We pay dearly when we fail to secure our hay, corn-fodder and silage in the best possible condition. We lose some- 
thing that we can never recover. We can simply learn not to do it again.

When to cut corn for silage.-I believe I get the most out of my corn crop by cutting it when the grains are beginning to glaze, or between denting and glazing. The large white Southern corn I put in the silo when it is well dented and it makes excellent feed-I think better feed than our native corn. In all cases grow a variety for the silo that will reach the stage of denting or glazing before frosts. One of the early mistakes with the silo was in putting in the corn too immature. It had not the nutriment in it. It had not reached its best. I saw many illustrations of this fact the season of 1893 , which was extremely dry, with very little rain after July 4. The pastures were brown in August and the farmers were compelled to feed green corn or hay to their cows or let them dry up. The corn was not sufficiently matured at this time and we found our yield of butter at the creameries running very low-a large percentage lower than the corresponding tirne the previous season. I made many comparisons between the two years from different patrons. The previous year there was excellent pasture and after-feed for the cows, and as a rule they did not need any extra food. In a comparison of eighteen patrons I found but one with a higher percentage of fat 
that season than the previous one; two with the same, and all others with a lower percentage of fat. The average of the whole list showed 6 per cent less fat in 1893 than during the corresponding time in 1892 . With all points equal we should have expected a little higher per cent of fat in 1893 than in 1892, from the fact that our patrons are all getting pay by the test, and this stimulates them to test their cows and do considerable weeding out. We get a larger butter yield than we did before we paid by the test.

Exposure of silage surface.-A point I wish to speak of in connection with the silo is the amount of surface exposed at one time. Experience has taught me that it should not be more than eight surface feet per cow in cold weather and less in warm weather, as the silage will commence to decay more quickly in warm weather. I am confident that the mistake is oftener made with the silo of exposing too much surface for the stock to be fed than any other. When it is exposed so long that decay commences it will make bad milk, the same as any other decayed food will.

With ten years' experience I firmly believe that sound silage from properly matured corn will produce milk and butter that is above criticism. There will be no fault traceable to the feed. I have frequently been asked why the 
condensed milk factories do not allow their patrons to feed silage if it is all right as a milkproducing food. The Lansing, Mich., factory does allow its patrons to feed silage, and has, moreover, issued a pamphlet urging them to use it and instructing them how to grow, handle and feed silage. There is probably more danger of the cows getting unsound food when. silage is fed than there is when dry food is used. When we learn to make perfect silage, and use proper care in feeding it, so that decay does not commence before it is fed, I believe we shall find the objections to it will gradually wear away and in time disappear.

Silage butter.-I have made butter from silage milk and had it scored by experts, and none of them found anything to cause them to think of silage. I have also had samples of silage milk warmed to 110 deg. to 115 deg. Fah. and examined for flavor daily for weeks, and nothing found to cause us to think of the silo; but we had reason to think of unclean cans, the pig pen, the cow stable and various other things which the milk had absorbed by being exposed after milking. Milk exposed in a silo in an open vessel will absorb from the silage, so that any person acquainted with the silo will know where it has been exposed.

Planting for silage.-I formerly plwited twenty to thirty quarts of corn per acr fur 
silage. I now plant ten quarts, which gives an ear on most of the stalks. I believe this is more economical than to grow more fodder and then feed more ground feed. I find the cows digest all the corn when it is put in the silo at the denting and glazing stage. I do not believe it pays to husk, shell and grind the corn for cows when we have a silo, as I fail to find any loss when put in at the proper time, for the cows, judging from the appearance of the droppings, digest all of the ears.

The cow the best judge.-I believe the best guide as to the proper stage of maturity to have the corn when put into the silo is the cow, and the desirable point is shown by watching the work of the cow. My experience has taught me that it is between the denting and glazing stage. If it goes much past the glazing stage the cow will not digest it all.

A feeding problem.-Frequently when examining my cows and their work in the past when feeding shocked corn, cut ears and fodder together I have noticed the large quantity of undigested corn in the manure and have asked myself the question: "Can we afford to let the cow employ her digestive machinery on food that she does not chew and digest?" $\mathrm{My}$ opinion is that we cannot. I am confident she does not do as profitable work for her owner as when she has the food in a condition that she 
can eat and digest it. I also believe this trying to do what she cannot wears out her digestive machinery, and therefore she will not continue to do profitable work as long as she would if supplied with the food in a digestible condition. There is a difference between a cow and a steer. If the cow is a good one we wish to keep her as long as she is profitable. The steer we expect to dispose of as soon as it reaches maturity, if not before, and his machinery may stand the wear and tear the necessary time, but that of the cow I believe will not. I cannot offer any figures to prove my position on this point. It is an opinion formed from observation.

If a farmer wishes to carry all the cattle possible on his farm and buy ground feed for them he should plant his corn thick enough so that it will not ear, as more fodder can be grown in this way: It is possible that a larger profit can be secured from the farm in this way, but I am confident a larger profit can be secured per cow from feeding silage when the corn is planted so as to grow ears on most of the stalks and when it is put in the silo in the dented stage and before glazing. In the early silo work the corn was put in too green. Now we-or some of us - are at the other extreme and are putting in corn too dry to pack sufficiently close to exclude the air, so as to prevent mold and decay. 
I have known this trouble in my locality in the last two years. Some of my corn got frosted last season before we were through filling the silos and I sprinkled it as it passed from the cutter up the elevator. I accomplished this by conducting water through a hose to the foot of the elevator and spraying the corn as it dropped from the cutter into the foot of the elevator. This should be done with frosted corn or corn that has become too dry from any cause. Do not be afraid the water will do any harm, as it will not, but there is danger of harm if the water is not used. This information cost me enough so that I remember it.

If we put corn into the silo that has not sufficient weight in itself to pack so as to exclude the air we must add water sufficient to accomplish this or provide some other means of doing it, or we will have moldy silage or perhaps find there has been sufficient heat to cause it to be black, and it will smell like burned molasses.

How fast to fill the silo. - When corn has reached the stage of denting to glazing we can safely put it in as fast as cut in the field. In fact I think it best to do so. For a part of my work last season I had a machine that cut one row at a time and elevated it onto the wagon driven by the side. With it two men and five horses cut and load one row as fast as the horses walk. This was a trial machine, but I am hope- 
ful that I shall have a machine for next season that will do this work quite satisfactorily. When this is accomplished the expense of filling our silos will be materially reduced.

Wet chaff for weighting silos.-For three year's I have used chaff to weight my silos, having first made it as wet as possible. In this condition it packs very closely and makes the best covering I have ever used. Twelve inches of it will protect the corn so there will be none of it lost from decay.

Warm the water.-As soon as we get freezing weather I warm the water for my cows. I have a steam boiler at my farm and a reservoir for water on the floor above. The water runs underground to the stables. When we wish to warm the water for the cows we connect the water and steam pipes and inject sufficient steam into the water as it runs to the barn to give the desired temperature- 75 to $80 \mathrm{deg}$. Fah. I find my cows prefer the warm water to cold water. They give more milk when they have warm water; they also look better and are less liable to sickness. It is safe to let a cow drink all the warm water she wants at any time, but it is not safe to let her drink all the cold water she wants. This I know to my cost.

I have heard men argue that warm water is not palatable to stock. This does not agree 
with my experience. I once saw some of my young stock get into a water tank to reach the warm water that was running in from a pipe on the opposite side of the tank where they could not reach it without getting into the tank. I have also watched my cows in the pasture in the summer and fall. I have an eightinch tile discharging into an open ditch forty rods from a stream into which it empties. In warm weather the cows will drink from this open ditch near its outlet into the stream where the water is warmer than at the mouth of the tile. But as soon as it gets cold in the autumn the cows go to the mouth of the tile where the water is the warmest. In both cases they appear to prefer to drink at the point where the water is the warmest.

I believe it is more economical to warm the water before the cow drinks it, with coal at $\$ 3$ or $\$ 4$ per ton, than it is to warm it with hay and grain after she drinks. Hay and grain do not get low-priced enough in Northern Illinois to be used as fuel. I have seen the time when corn was a more economical fuel than coal, but coal is lower and corn higher than at that time. We do not burn it any more.

Watering in the stable.-I have never watered my cows in the stable. I have thought considerable about it. I have seen a number 
of stables fitted with watering devices. I do not believe it is advisable to allow the water to stand exposed in an open vessel in the stable as it will absorb any impurities there may be in the atmosphere. This we all know to be a fact if we will give it thought. Another objection to open water in the manger or within reach of the cow is the liability of the cows dropping feed into it. This will cause the water to get in bad condition in a very short time. When watering in the stable I think it would he safest and best to water twice per day, and after watering empty the water buckets and close them so the stock cannot get any food into them.

I cannot yet believe it is not well for the cows to go into the yard as many at a time as have room to drink, get what warm water they want, and then when cold or stormy be returned to the barn and another lot turned out. When it is warm and pleasant allow the cows to remain a few hours in the yard; it will do them good. A little exercise is good, and fresh or pure air is a necessity if we are to preserve the health of our stock.

About tuberculosis.-Ventilation is a vital question, and is at the present time being forced upon our attention more than it has been in a long time. Tuberculosis having been detected in some prominent herds is sufficient 
warrant for us to be thinking about the cause of this disease developing in some herds and not in others. I believe poor ventilation is the greatest promoter of this disease. I fear some of us have paid more attention to securing warm stables than we have to securing good air or ventilation. This is a question we shall receive information on from our experiment stations in the near future, as at least three of them have found their herds of cows afflicted with this disease. At first I felt it was too bad to have our experiment station herds afflicted in this way, but since giving the subject more thought I have come to the conclusion that it is better to have the station herds afflicted than any other herds, as it will give an opportunity for us to learn more about it through investigation than we otherwise would. The probabilities are that there is no more of this disease in our country than there has previously been. We are discovering more of it, as we have more reliable means of detecting the disease. This is a question that I do not feel competent to write much about, but at the same time there is room for good horse sense to be used. I recently had an interesting conversation with a veterinary professor in one of our agricultural colleges (a man who had had several years' practice before becoming a teacher), in which he said he was fond of milk and expected to 
continue using it, and that if all persons that had used milk from tuberculous cows had died with consumption we would have a much smaller population than we now have. I believe that diseased cows should be killed when discovered, but I do not believe that a large percentage of our cows are afflicted with this disease.

Amount of silage fed.-I feed what corn silage my cows will eat. I also feed some hay once per day as a rule. I find my cows thrive well and do profitable work when they have only the corn silage for coarse food. The amount of ground feed to be given in connection with the silage depends on the amount of corn in the silage. When the silage is made from corn that would husk forty bushels per acre I feed to mature cows five pounds of wheat shorts and five pounds of grano-gluten feed. The latter is a kiln-dried, whisky-distillery feed which has been subjected to a heat that kills all germs of ferment. My cows invariably shrink in the flow of milk and in total fat produced when I change from corn silage to hay, and the cost of feeding the cows just as surely increases.

Can we afford to feed oats?-Oats are an excellent feed for cows, but as a rule it pays me to sell my oats and buy shorts and bran. When oats are comparatively low priced I grind them 
and feed to the cows. At present, with oats worth twenty-seven cents a bushel and wheat bran and coarse middlings $\$ 13$ per ton, it figures as follows: A ton of oats is sixty-two and a half bushels, and at twenty-seven cents equals \$16.87. Grinding at two cents a bushel makes $\$ 1.25$, and this added to $\$ 16.87$ makes a total of $\$ 18.12$. If a farmer has no mill to do his grinding it makes no difference whether he draws his oats to mill and back or draws the oats to market and draws home other feed. The Wisconsin Experiment Station has proved by the cow that oats are worth 10 per cent more than wheat bran to feed cows. When bran is worth $\$ 13$ oats are worth $\$ 14.30$. Now, can I afford to feed them when they are worth $\$ 18.12$ in market?

Rejected food.-The silage and hay left by my cows are removed from the mangers and given to the young heifers, with grain food added, so nothing goes to waste. It will not answer to let rejected food remain in the mangers or feed-boxes, as it will cause a cow to get off her feed and off in her milk, and away goes the profit.

The calving.-My cows drop their calves in the months of September to December and go dry on pasture and milk as long as they ought to-in fact in many cases longer than they ought to. I do not feed these cows ground feed 
after they get full pasture. I am in doubt about there being a profit in feeding ground feed to cows when they are on full pasture. But this is not the vital point here. The main question is the health and usefulness of the cow. My experience has convinced me that there is very little danger at calving time with cows that calve in the fall going dry on pasture and having no grain food after they get full pasturage until they are fresh again. My dairy is very free from troubles at calving time when treated in this way.

Dr. Pierson on cow-feeding.-In January, 1894, I had the pleasure of listening to a lecture by Dr. Pierson of the Philadelphia Veterinary College before the short course class at the Pennsylvania State College, in which he told us of the danger of giving too much grain feed to cows when dry. He said it led to trouble at time of parturition. Plenty of grass or other succulent food puts the cow's system in the best possible condition for this period. Do not understand that I do not feed my cows in case of short pasture from drouth or any other cause. Every farmer should plant corn for this purpose if he is in the corn belt. If not, he should plant some other crop, as the cow must have all she wants of some proper food.

A New York experiment.-The New York (Cornell University) Experiment Station has 
done some very interesting and valuable work covering three seasons $(1859,1890,1891)$, comparing the effects of grain vs, no grain for cows on pasture. The grain consisted of cotton-seed meal and bran fed alone or with malt sprouts or corn-meal. The first two years the pasture was luxuriant and there was no increased yield of either milk or butter from feeding the grain. The yield of butter was practically the same for the lots with and without grain. The first year the milk fell off in yield but became richer in fat on grain. The third year the pasture was at no time very luxuriant. The eight cows receiving grain produced just enough more milk and butter to pay for the cost of the grain. The last two years the changes in live weight were observed and it was found that the cows receiving grain increased more in live weight than those receiving no grain.

Kansas experimental work. - The Kansas Station (report 1858) observed an increased yield of milk and butter when either cornmeal, wheat bran or ground oats were fed in addition to pasture, but this increase did not nearly pay the cost of the grain. In the above experiments no account was taken of the increased value of the manure or the saving of pastures due to the grain feed.

Why should cows freshen in autumn?There are several reasons why I prefer to have 
my cows fresh in the fall. First, they will give more milk in the year than they will if fresh in the spring. When they freshen in the fall they are like fresh cows when they get to pasture in the spring, and they milk as long as they ought to, and in many cases too long. But when they are fresh in the spring they are ready to dry up at the commencement of cold weather, and they will dry up in spite of all the average dairyman will do to prevent it. It also gives the least milking to be done at the time in summer when the farm work is crowding and it distributes the labor so there is work for the same force of help the year around. The moral effect is good, as the farmer must be home at milking time. He cannot remain in town and gossip until bedtime.

Moreover, we secure the largest flow of milk at the time when it brings the best price. The difference in the price of summer and winter milk and butter will probably be less in the future than it has been in the past. Especially will this be the case with butter on account of the improved methods of cold storage. It was formerly thought that butter was injured by a temperature below freezing; now we have learned that it is desirable to have it held at a temperature several degrees below freezing. This will doubtless cause an increased demand for butter to be held in cold storage and put on 
the market in fall and winter. This seems to me a natural result of the changed conditions. At the same time I expect to continue my present method of having my cows fresh in the fall months.

Warm stables.-All stables should be so protected from the cold that the manure will not freeze in them during the coldest weather. A cheap stable can be made frost-proof by nailing boards inside the posts or studs and filling solid with straw between. I practiced this with my first cow stable and kept my cows as comfortable as I have since in more expensive stables. I have plenty of light in the stables and good ventilation.

The following I clip from The Dairy of London, Eng. Comment is unnecessary:

Mr. Alexander Pottie, M. R. C. V. S., Paisley, in a lecture under the auspices of the Glasgow and West of Scotland Agricultural Discussion. Society, on "How to Make the Most of the Cow in Winter," said that there was a great deal of misunderstanding as to what was the proper temperature that should be maintained in byres [barns] in winter. From experiments extending over a considerable period, which he had made in byres, he found that the temperature at which a cow gave the largest amount of milk was $63 \mathrm{deg}$. No artificial heat was necessary-byres should be heated by means of the warmth of the cows in them. In a properly-eonstructed byre the difference in value of milk obtained from twenty-nine or thirty cows in a temperature of $63 \mathrm{deg}$. was about $£ 3$ more per week than when the temperature was 52 deg. Farmers did not seem to be aware of the loss they were sustaining by keeping their cows in cold byres. 
How confine the cows. - I have used neck ties and stanchions, but am discarding them and putting in the Bidwell stall. I do not believe we can afford to use the stanchions, for they do not help us to get past the 300-lb. mark, and that is what we must do if we make it pay.

With a warm stable, well lighted and ventilated, plenty of silage, early-cut clover hay and warm water to drink, I have very little need of a veterinarian in my dairy. The cows must be made comfortable at all times and in all places. Any failure here the cow will account to you for daily by a shortage in milk and butter-fat. The cow can make her wants known to a man that is using his brains in his work. Here is a great field for thought and study to improve on our present methods.

Seeking a milk test.-Several years ago I had an experience with abortion in my dairy. I then had sixty cows that I had worked several years in getting up to my idea of what a cow should be. The first cow lost her calf in July and between that time and the following June thirty-five of the sixty cows aborted. This broke my dairy up badly, as many of the cows failed to breed, became fat and dried up with their milk, and I was compelled to sell them for beef. About this time I commenced to take my milk to one of our creameries and 
pool with every other patron, as we had no practical way to test milk. I bought cows for a few years to keep up my dairy, but could not get satisfaction and went back to my old plan of raising the heifer calves. The only test I applied was the weight of milk. I was forced to do this, as I could not afford to pool grade Jersey milk with other milk that had been produced with quantity alone in view. I was always in open rebellion against this plan and hunting for some practical test that we could apply to our dairies and to the individual cows in the dairies. I felt all the time that I was a backslider in my work and it irritated me terribly.

Credit to the scientists.-When Prof. Short of the Wisconsin Experiment Station brought out his test my firm secured one, and later Prof. Patrick's test was purchased, which was a long step in advance. Next came a letter from Prof. W. A. Henry, asking me to go to Madison and see Dr. Babcock's new test, as he thought he had one that would fill the wants of the dairyman. He was right, as it has now come into use in all dairy countries. I bought such parts as I could at Madison and got up the first machine used outside the Wisconsin Experiment Station, and we are using it now to do the test work for six creameries.

Abortion from ergot--treatment. - The 
cause of my first trouble with abortion I never became fully satisfied about, but connected it with a summer freshet that flooded a part of my pasture. I suspected it was caused by ergotized grass on this flooded land. I do not now know that to have been the cause, but I still think it was. It was three years before my dairy was clear of the trouble, and I had no more of it until the summer of 1992 , when fifteen cows lost their calves, the trouble commencing at the same time in July as in the former case. I had been fearing it, as the conditions were nearly the same as they were when I had the first trouble. I secured some remedies and sought advice from different sources, but it came as I feared it would. The flood water had caused my pasture to be short and I had cut clover from new ground that had grown rye the previous year and had considerable volunteer rye with the clover. The trouble commenced soon after using this clover and rye. Every cow that lost her calf was immediately isolated and treated with vaginal injections of bichloride of mercury, using one part to four thousand of water and using one gallon at a treatment three times per week. The same lotion was used to wash the vulva and tail and any parts necessary. The trouble ended in a few weeks and I had no more of it until the following spring when feeding the hay cut from 
the same rye field of clover. Then three cows aborted and on investigation I found plenty of ergot in the rye. The trouble ended when we stopped feeding this hay.

Now I can say this: I am thoroughly satisfied that ergot caused the abortion in one case. In the other I think it did, but am not sure. I believe I should have lost from onehalf to two-thirds of my calves in the last case if I had not isolated and treated the cows. I am confident that there are several causes of abortion in cows. What I know about it is as nothing in comparison with what I do not know. I often think of what one of the commissioners appointed to investigate the subject by the New York Legislature several years ago said when through with the investigation. He said he did not know as much about the cause of abortion as he thought he did when he commenced the investigation.

Rations.-Here I will draw from the Wisconsin Experiment Station "Bulletin No. 38," entitled, "One Hundred American Rations for Dairy Cows." I do this because I believe it is of more value to dairymen than any other material at my command. I will give the name and post-office address of owner or manager; name of breed; the weight of cow; annual yield of milk; annual yield of butter; percentage of fat in milk, and the ration fed. Prof. 
Woll says: "For the sake of comparison the components of the rations have all been calculated per 1,000 lbs. live weight."

The following selections from the 100 rations in "Bulletin No. 38" include localities from the Atlantic to the Rocky Mountains and a variety of foods, though silage is included in a majority of them:

No. 1-J. W. Goss, Hygiene, Col. Jersey cows; average weight, $900 \mathrm{lbs}$; annual yield of milk, $5,000 \mathrm{lbs}$; ; annual yield of butter, 340 lbs.; percentage of fat in milk, 5. Ration$30 \mathrm{lbs}$. corn silage, $10 \mathrm{lbs}$. alfalfa hay, $10 \mathrm{lbs}$. clover hay, $5 \mathrm{lbs}$. roller bran, 2 lbs. corn-meal.

No. 5-E. S. Henry, Rockville, Conn. Jersey cows; average weight, $900 \mathrm{lbs}$; annual yield of butter, $375 \mathrm{lbs}$. Ration -35 lbs. corn silage, 10 lbs. hay, 3 lbs. bran, 3 lbs. corn-andcob meal, 2 lbs. cotton-seed meal, 2 lbs. Chicago gluten-meal.

No. 6-A. Bourquin, Nokomis, Ill. Brown Swiss cows; average weight, 1,400 lbs.; annual yield of butter, $415 \mathrm{lbs}$. Ration $-7 \frac{1}{2}$ lbs. clover hay, $7 \frac{1}{2}$ lbs. timothy hay, 12 lbs. cornand-cob meal, 8 lbs. bran, $1 \frac{1}{4}$ lbs. linseed-meal, $1 \frac{1}{4}$ lbs. 'cottonseed meal.

No. 11-Mrs. Kate M. Busick, Wabash, Ind. Jersey cows; average weight, $800 \mathrm{lbs}$.: annual yield of milk, 4,500 lbs.; annual yield of butter, 300 lbs.; percentage of fat in milk, 5.9. Ration-30 lbs. corn silage, 5 lbs. clover hay, 3 lbs. cornfodder, $1 \mathrm{lb}$. oat straw, $1 \mathrm{lb}$. wheat straw, 5 lbs. bran, $2 \mathrm{lbs}$. oil-meal, 2 lbs. cotton-seed meal.

No. 14-C. L. Gabrilson, New Hampton, Ia. Jersey and Short-horn cows; average weight, 1,000 lbs.; annual yield of milk, 4,200 lbs.; annual yield of butter, 200 lbs.; percentage of fat in milk, 4.9. Ration-50 lbs. corn silage, 5 lbs. hay, 5 lbs. corn-fodder, $1 \mathrm{lb}$. oat straw, $1 \mathrm{lb}$. barley straw, 5 lbs. earcorn, $2 \frac{1}{2}$ lbs. ground oats and barley.

No. 24-W. J. Boynton, Rockester, Minn. HolsteinFriesian cows; average weight, 1,400 lbs.; annual yield of 
milk, 10,000 lbs.; percentage of fat in milk, 3.6. Ration-50 lbs. corn silage, 8 lbs. hay, 3 lbs. bran, 2 lbs. shorts, 3 lbs. ground rye and oats, 2 lbs. barley.

No. 29-W. D. Baker, Quincy, N. H. Does not name breed; average weight of cows, $900 \mathrm{lbs}$; annual yield of milk, 5,500 lbs.; annual yield of butter, $312 \mathrm{lbs}$. Rations-(a) $10 \mathrm{lbs}$. clover and witch grass hay, 10 lbs. corn-stover, 5 lbs. unthreshed barley, 2 lbs. corn-and-cob meal, 2 lbs. shorts, 2 lbs. cottonseed meal. (b) $11.7 \mathrm{lbs}$. clover and witch grass hay, $3.3 \mathrm{lbs}$. oat straw, 10 lbs. meadow hay, 2 lbs. shorts, 2 lbs. corn-andcob meal, 1 lb. ground peas, 1 lb. oats, 1 lb. barley. (c) 10 lbs. meadow hay, $10 \mathrm{lbs}$. corn-stover, 5 lbs. pea straw, 2 -lbs. middlings, $1 \frac{1}{2}$ lbs. gluten-meal, $1 \frac{1}{2}$ lbs. cotton-seed meal, 2 lbs. corn-and-cob meal. (d) 10 lbs. clover and witch grass hay, 10 lbs. meadow hay, 5 lbs. pea straw, 2 lbs. shorts, 1 lb. glutenmeal, 1 lb. cotton-seed meal, 2 lbs. corn-and-cob meal

No. 34-H. M. Cottrell, Superintendent Ellerslie Stock Farm, Rhinecliff, N. Y. Guernsey cows; average weight of cows, 1,000 lbs.; annual yield of milk, 6,120 lbs.; percentage of fat in milk, 5.3. Ration-25 lbs. corn silage, $7 \mathrm{lbs}$. mixed hay, 4 lbs. corn-meal, 5 lbs. bran, $\frac{1}{2}$ lb. oil-meal, $\frac{1}{2}$ lb. cottonseed meal.

No. 45-Geo. W. Sisson, Jr., Potsdam, N. Y. Jerseys; average weight, $800 \mathrm{lbs}$; annual yield of milk, 5,000 lbs.; annual yield of butter, $300 \mathrm{lbs}$; percentage of fat in milk, 5.2. Ration-30 lbs. corn silage, 12 lbs. clover hay, 8 lbs. wheat midalings, $1 \mathrm{lb}$. oil-meal.

No. 46-Smiths \&'Powell Co., Syracuse, N. Y. HolsteinFriesians; average weight of cows, 1,200 lbs.; annual yield of milk, 12,000 lbs. Ration-40 lbs. corn silage, 15 lbs. hay, 9 lbs. wheat bran, $4 \frac{1}{2}$ lbs. germ-meal, 1 lb. oats, 1 lb. wheat, 1 lb. barley, 1 lb. corn, $\frac{1}{2}$ lb. linseed-meal.

- No. 49-Munzo Wilcox, Milford, N. Y. Devons and natives; average weight, $785 \mathrm{lbs}$; annual yield of milk, 9,200 lbs.; annual yield of butter, 373 lbs. Ration-12 lbs. timothy hay, 1 lb. bran, 1 lb. middlings, 2 lbs. corn-meal, 2 lbs. cottonseed meal, 40 lbs. skim-milk. 
No. 50-A. Doncourt, Manager The Old Brick Farm, Roslyn, N. Y. Guernseys; average weight, 1,000 lbs.; annual yield of milk, 7,300 lbs.; annual yield of butter, $497 \mathrm{lbs}$; percentage of fat in milk, 5.7. Ration -42 lbs. corn silage, $2 \frac{1}{2}$ lbs. clover hay, $2 \frac{1}{2}$ lbs. timothy hay, 8 lbs. corn-and-cob meal, 14 lbs. dried brewers' grains.

No. 55-John Gould, Aurora, Ohio. Grades and natives; average weight, 1,000 lbs.; annual yield of milk, 5,900 lbs.; percentage of fat in milk, 4.2. Ration-50 lbs. corn silage, 8 lbs. clover hay, 5 lbs. "seconds."

No. 61-John McClintock, Meadville, Pa. Jerseys; average weight, $900 \mathrm{lbs}$ : annual yield of milk, 5,565 lbs.; annual yield of butter, $370 \mathrm{lbs}$. Ration-24,lbs. corn-fodder, $5.1 \mathrm{lbs}$. bran, 5.1 lbs. corn-meal, 3 lbs. cotton-seed meal, 2 lbs. oilmeal.

No. 71-L. S. Drew, Burlington, Vt. Ayrshires; average weight, 1,000 lbs.; annual yield of milk, 5, $50 \mathrm{lbs}$; p percentage of fat in milk, 4.3. Ration-20 lbs. corn silage, 14 lbs. hay, 3 lbs. bran, 2 lbs. gluten-meal.

No. 74-C. M. Winslow, Brandon, Vt. Ayrshires; average weight, 1,000 lbs.; annual yield of milk, 6,187 lbs.; percentage of fat in milk, 4.25. Ration-30 lbs. hay, 1.8 lbs. wheat bran, $.9 \mathrm{lb}$. wheat middlings.

No. 72-L. C. Fisher, Cabot, Vt. Jerseys; average weighi, $900 \mathrm{lbs}$; annual yield of butter, $40 \pm$ lbs. Ration-30 lbs. corn silage, $10 \mathrm{lbs}$, hay, 4.2 lbs. corn-meal, 4.2 lbs. bran, .8 lb. linseed-meal.

No. 79-C. P. Goodrich, Fort Atkinson, Wis. Grade Jerseys; average weight, $900 \mathrm{lbs}$; ; annual yield of milk, 5,500 lbs.; annual yield of butter, 320 lbs.; percentage of fat in milk, 5.25. Ration-32 lbs. corn silage, 5 lbs. clover hay, 5 lbs. cornstalks, 8 lbs. bran, 2 lbs. cotton-seed meal, 2 lbs, oat straw.

No. 85-A. X. Hyatt, Sheboygan Falls, Wis. Mostly Shorthorns; average weight, 1,200 lbs.; annual yield of milk, 8,000 lbs.; percentage of fat in milk, 4.1. Ration-25 lbs. roots, 8 lbs. oatmeal, 3 lbs. oil-meal, 15 lbs. hay, 10 lbs. corn-fodder, 4 lbs. oat straw. 
No. 92-Herman Bollert, Canada. Holstein-Friesians; average weight, 1,300 lbs.; annual yield of milk, 10,000 lbs.; percentage of fat in milk, 4. Ration-40 1bs. corn silage, 5 lbs. hay, 5 lbs. straw, $4 \frac{1}{2}$ lbs. bran, $4 \frac{1}{2}$ lbs. oats.

No. $100-$ R. Robertson, Howick, Quebec. Ayrshires. average weight, 1,000 lbs.; annual yield of milk, 8,000 lbs.: annual yield of butter, $360 \mathrm{lbs}$; percentage of fat in milk, 4 . Ration-40 lbs. corn silage, $7 \frac{1}{2}$ lbs. clover hay, 3 lbs. straw, $1 \frac{1}{3}$ lbs. oats, $1 \frac{1}{3}$ lbs. barley, $1 \frac{1}{3} \mathrm{lbs}$. pea-meal, 3 lbs. wheat bran, 1 lb. cotton-seed meal.

TABLE OF NUTRIENTS IN TWENTY-FOUR RATIONS.

\begin{tabular}{|c|c|c|c|c|c|c|}
\hline \multirow{2}{*}{ No. } & \multirow{2}{*}{$\underset{\text { matter. }}{\text { Dry }}$} & \multicolumn{4}{|c|}{ DIGESTIBLE MATTER. } & \multirow{2}{*}{$\begin{array}{l}\text { Nutritive } \\
\text { ratio. }\end{array}$} \\
\hline & & Protein. & $\begin{array}{c}\text { Carbo- } \\
\text { hydrates. }\end{array}$ & Fat. & Total. & \\
\hline 1 & 31.09 & 2.70 & 15.78 & .80 & $19.2 \checkmark$ & $1: 6.5$ \\
\hline 5 & 25.70 & 2.69 & 13.96 & .97 & 17.62 & $1: 6$. \\
\hline 6 & 22.09 & 2.37 & 12.06 & .75 & 15.18 & $1: 5.8$ \\
\hline 11 & 26.08 & 3.24 & 12.94 & 1.07 & 17.23 & $1: 4.7$ \\
\hline 14 & 24.77 & 1.34 & 15.01 & .76 & 17.11 & $1: 12.8$ \\
\hline 24 & 19.09 & 1.40 & 11.10 & .48 & 12.98 & $1: 8.7$ \\
\hline $29 a$ & 25.50 & 239 & 14.37 & .70 & 17.46 & $1: 6.7$ \\
\hline $29 b$ & 28.97 & $1 . \varepsilon 8$ & 15.47 & .53 & 17.88 & 1: 8.8 \\
\hline $29 c$ & 26.12 & 2.24 & 13.65 & .65 & 16.54 & $1: 6.7$ \\
\hline $29 d$ & 28.86 & 2.84 & 13.68 & .82 & 17.34 & $1: 5.5$ \\
\hline 34 & 19.98 & 1.81 & $11.46^{\circ}$ & .66 & 13.93 & $1: 7.1$ \\
\hline 45 & 28.65 & 2.87 & 14.73 & .88 & 18.48 & $1: 5.8$ \\
\hline 46 & 29.16 & 2.41 & 16.98 & .85 & 20.24 & $1: 7.8$ \\
\hline 49 & 25.73 & 3.50 & 14.05 & 1.12 & 18.67 & $1: 4.7$ \\
\hline 50 & 31.30 & 3.37 & 16.31 & 1.31 & 20.99 & $1: 5.7$ \\
\hline 55 & 20.26 & 1.53 & 10.95 & .63 & 13.11. & 1: 8.1 \\
\hline 61 & 26.52 & 2.53 & 15.74 & .90 & 19.17 & 1: 7 . \\
\hline 71 & 20.20 & 1.64 & 11.09 & .48 & 13.21 & $1: 7.4$ \\
\hline 74 & 26.06 & 1.42 & 14.02 & .38 & 15.82 & $1: 10.5$ \\
\hline 72 & 24.23 & 186 & 14.03 & .75 & 16.64 & 1: 8.4 \\
\hline 79 & 27.24 & 2.86 & 13.80 & .92 & 17.58 & 1: 5.5 \\
\hline $8 \pi$ & 26.90 & 2.11 & 14.43 & .70 & 17.24 & $1: 7.6$ \\
\hline 92 & 19.70 & 1.36 & 1060 & .53 & 12.49 & 1: 8.7 \\
\hline 100 & $22 . \longleftarrow 6$ & 2.08 & 12.17 & .71 & 14.96 & $1: 6.6$ \\
\hline
\end{tabular}

The foregoing table gives the nutrients in the twenty-four rations selected from the 100 in 
the Wisconsin bulletin. The numbers in this table correspond to the numbers in connection with the owners' names and name of breed, and the table is quite interesting to a person that wishes to study the feeding question.

Dehorning.-I have deliberated considerably about the question of dehorning. It has been so much discussed in the agricultural and dairy papers that it seems almost an old story, but I have decided to give a little of my experience. I waited and read and watched for several years, dehorning only the ugly cows, before I became thoroughly convinced that it was best to dehorn my whole herd. I now have no cattle with horns except my registered Jerseys. One reason that I leave their horns is to avoid any possibility of getting them mixed with my grades. I employed a man to dehorn my cows that had dehorned over five thousand head, and he did a good job for me. It would require an expert to detect that they ever had horns. He did the work with a saw and cut a little below the skin, setting the saw to cut a little circular in direction. Cutting below the skin caused some bleeding, but he pulled out the little blood vessels with a pair of small forceps, which made the bleeding cease. I think the fright caused by making the cows fast for the operation gave them more suffering than the act of removing the horns. As fast as dehorned they 
were turned into the pasture and they went to feeding in a short time as if nothing had happened. I was very much surprised, and very agreeably so, at the apparent indifference of the cows to the effect of the operation. It caused a very perceptible change in my cows. They soon learned that they could not injure. each other and ceased trying. With the loss of fear of each other came a loss of fear of their attendants, or at least it appeared so to me. There was a change in the herd that was a pleasant surprise to me. I say frankly that I am glad I had my herd dehorned. The shrinkage in milk was very small-no more in fact than I should have expected from having them out of the pasture as long as they were. It was very satisfactory to me in all points and caused me to wish I had had them dehorned earlier.

I now kill the horns of my calves by the use of caustic potash. This is a very simple matter. We cut the hair from around the horns, or where they are to grow, and then wet the button and rub the caustic potash on it. Get the potash in sticks and wrap it in paper or cloth to prevent its eating the hands. This causes the calf no more pain than a blister of the same size. In fact that is just what it is.

- Effects of Exposure.-In the winter of 1892 the Indiana Experiment Station made a very 
valuable experiment to show the effect of exposure on milch cows. I clip the following from that station's "Bulletin No. 47":

The following points of importance are brought out in the bulletin:

1. That cows exposed during the day to the inclemency of winter weather ate more food than those given the shelter of a comfortable barn.

2. That cows thus exposed gave on an average less milk per day than those not so exposed, and much less milk as a total, during the experiment, which extended over forty. eight days in January, February, and March.

3. That the cows which were exposed to the weather during this experiment lost in weight, while those given barn shelter gained in weight.

4. That there is a differenc 3 of $\$ 12.79$ in favor of shelter for cows in winter.

Some of the interesting details of this experiment are herewith quoted:

Grouped by lots each lot ate the following amount of food:

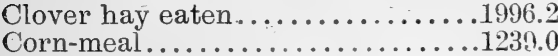
Lot $I$ - lbs.

Lot $I I-l b s$.

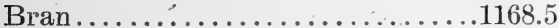

1483.8

1627.0

1536.7

Total...................4403.7

4647.5

Lot II, the exposed one, ate $243.8 \mathrm{lbs}$. more food than lot I, but less hay and much more grain, consuming $388 \mathrm{lbs}$. more of corn-meal and 368.2 lbs. more of bran. The difference in the cost of the total amounts of food eaten has an important bearing on the relationship of expense and income.

The cost of the food eaten is based on current market prices in Lafayette at the time of the experiment. Clover hay is quoted at $\$ 8$ per ton, corn-meal at $\$ 1$ per 100 lbs., and bran at 65 cents per 100 lbs. The cost of labor was no greater for lot I than for lot II, if it was as great, and is not included in the discussion of the experiment. 
Amount and cost of food consumed:

1996.2 lbs. clover hay at $\$ 8$ per ton......... $\$ 7.98$

Lot I. Lot II. 1239.0 lbs. corn-meal at $\$ 1$ per 100 lbs........ 12.39 1168.5 lbs. bran at 65 cents per $100 \mathrm{lbs} . . . .7 .60$

Total cost.................. $\overline{\$ 27.97}$

1483.8 lbs. clover hay at $\$ 8$ per ton...........

$1627.0 \mathrm{lbs}$. corn-meal at $\$ 1$ per $100 \mathrm{lbs} . . . \ldots$
1536.7 lbs. bran at 65 cents per $100 \mathrm{lbs...}$.

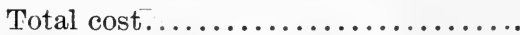

Balance in favor of lot I............. \$4.23

$\overline{\$ 32.20}$

So far as cost of food eaten is concerned the sheltered lot makes the best showing by $\$ 4.23$. This experiment, however, was undertaken on milch cows to note the effect of the conditions of keeping on the milk yield.

Considering this experiment from the financial standpoint, including cost of food eaten, weight of milk secured, and animal weight lost or gained, we get the following results in favor of the sheltered lot:

Saving in cost of feed eaten.................... $\$ 4.23$

Value of difference in milk secured (161.1 lbs. at 15 cents

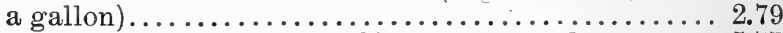

Value of $231 \mathrm{lbs}$. flesh gain at $2 \frac{1}{2}$ cents a pound......... 5.77

Amount saved by sheltering three cows 48 days........12.79

Amount saved by sheltering one cow 48 days......... 4.26

Prof. C. S. Plumb, Director of the Indiana Agricultural Experiment Station, who made this experiment, offers the following observations:

A reasonable amount of exercise should be given farm animals, and pure air ought to be available at all times, but no animal should be exposed to weather conditions that involve suffering, neither ought farmers to expose stock in such a manner as to cause them financial loss. Beef cattle with thick, mellow hides and heavy coats of fine hair may be exposed to outdoor conditions that would cause thin-skinned 
milch cows to suffer and show the injurious effect in the pail and feed account. Dairy cows are more sensitive in temperament and require warmer winter quarters as a rule than do beef cattle. 


\section{- CHAPTER III.}

\section{CARE OF DAIRY UTENSILS.}

Milk pails should always be of tin. When purchasing tinware of any kind have your tinner solder around all rims and open joints where dirt can accumulate. The cost of this will be saved many times over in the labor required to wash them. I never had sufficient patience to fool away my time trying to get a dishcloth into every corner and around the rims and ears of pails when I knew that a few cents spent at the tinshop would put the tinware in such shape that the dishcloth would reach all parts and time did not need to be taken digging dirt out of holes that need not be.

Clean all utensils as soon as possible after using them. The longer they remain without being cleaned the more time will be required to do the work.

Washing tinware.-When washing tinware about the dairy always use first cool or tepid water, as hot water applied to milk vessels cooks the milk onto the tin and gives them an 
appearance that you will not take pride in showing. After they are washed in tepid or cold water, wash with hot water, then scald with boiling water or steam if it is available. When steam is used there is no guesswork about it, as it reaches all parts and does thorough work. When hot water is used there is often too much guesswork about the temperature.

After the scalding the vessels should be put in the sun to dry and air. When thoroughly scalded there is sufficient heat to cause the dishes or vessels to dry without wiping. Have a place for all the tin and woodenware in the sun for a time after cleaning and scalding it. Never put the covers on tin vessels after scalding them, neither will it answer to put them in a position that will prevent a circulation of air. Dead air is far from sweet-smelling.

Churn and worker.-The churn and butterworker and all other wooden utensils should be first washed in hot water, then scalded with boiling water or steam. Wooden utensils must not be left in the sun long enough to cause them to warp or crack.

Preparing wooden utensils.--Before using the churn and all other woodenware it should be scalded and then thoroughly cooled. Scalding wooden utensils and then thoronghly cooling with cold water will prevent the butter 
sticking to them. When the butter sticks to a wooden vessel or utensil it is positive proof that it has not been properly prepared before using, and the only way is to do the work over in a proper manner.

Return milk in barrels.-Great care is necessary in cleansing cans that are used in drawing milk to a creamery, especially if skim-milk or whey is returned in them. The best way is to take the milk back to the farm in barrels and have the cans washed at the creamery before being returned to the patrons.

But in many cases this is not practicable, as the milk comes in loads and the skim-milk must go back in the cans, if it is taken, which it surely should be. These cans should be treated as any other milk vessel, but more care is necessary, as in many cases the milk has become sour before reaching home and adheres to the can. A brush is an excellent tool to use for this work, as it will get at the corners much better than a dishcloth. Lack of care in this line soon gives foul cans and bad milk. All milk vessels miust be kept sweet and clean or there will be serious trouble in a very short time. 


\section{CHAPTER IV.}

\section{MILKING.}

Milking is a trade. Comparatively few dairymen realize the importance of it, or the necessity for kindness, neatness, system and regularity and of securing all of the milk.

The cow must be kindly treated at all times and in all places. It will not answer to bring her from pasture on a run with a dog behind her, and if she in her excitement gets into the wrong stall don't put her out with a blow from a whip or the boot. The owner pays for this immediately in the quantity and quality of the milk from the next milking. Any person who doubts this should use a scale and the Babcock test and satisfy himself. The cows should not fear the person who cares for them. There is a chance for the person to improve so long as this is the case. The feeling between the cows and the person who cares for and milks them should be such that when such person goes among them either in the barn or in the yard or pasture the cows will not only not care to move away from the person but will actually 
appear to enjoy the company of the one who cares for them. When this is the situation there need be no fear so far as kindness is concerned.

Cleanliness.-The cows must be kept clean in the stable and also out of it, so far as is practical, but there are times in wet seasons that it is impractical in some pastures to prevent the cows getting their teats and udders muddy. When this is the case they should be washed when put into the stable. This is the best way I have found to remove the mud or filth, which must be done before milking. My practice was to furnish each milker a pail for water and require them to wash their cows' udders before commencing to milk if they needed to be washed. By the time the milker was through washing the first washed would be dry and ready to milk. This is the quickest and best way I have found to accomplish this object.

Regularity.-Each cow should have her regular stall, be milked by the same milker, and at regular hours, night and morning. It pays just as well to systematize with the cows as it does in any business. A business man that is irregular about his business loses by it. We can all call to mind instances to prove this, and it is just as true and more with the cows, as the business man may not lose every time he fails to open his store until an hour late, but every 
time the cows are milked an hour late or early there is sure to be a loss.

There must be regularity in feeding, watering, salting, and in all work connected with the cow. Never allow promiscuous milking. It is best to milk in the stable in winter and summer. The milkers will suffer no more from heat there than in the yard if the stable is properly ventilated and they commence at the right end of their row of cows, so the animals can be turned out as fast as milked. There will then be no cow back of them to help give them a sweat.

Cause for kicking.-A cow never kicks without cause. She is either hurt or frightened when she kicks. An instance comes to my mind now that illustrates this point. Several years ago, when living on my farm, I was one day in De Kalb and the Mayor spoke to me about his cow. He had an excellent one and had talked with me about her frequently before. At this particular time he was in trouble with her. He said she had contracted a habit of kicking and he could do nothing with her and thought he would be compelled to sell her. I told him there must be a cause, but he said he could find none. I insisted there must be some good cause for it and it should be discovered, and talked with him for some time about his cow and her surroundings. I asked 
him if her teats were not chapped, and he said not. I told him to get some linseed oil and apply a little after milking to her teats. He did so, and the next time I saw him he told me his cow was all right. The oil had performed a cure and helped him to discover what the cause of the trouble was. This was during August when the flies were troublesome, and the cow to get rid of the flies had been in the habit of getting into a pond of water in the pasture, where she kept her teats wet fighting the flies, and caused them to chap, but not enough so the owner who milked her had discovered it until they commenced to heal, when he discovered the trouble.

When you have a kicking cow study the case and learn the cause, and if you cannot learn and remove the cause you should remove the cow, as a kicking cow is too severe a test on the milker's patience and the effect is not good in the stable, as it affects the whole surrounding atmosphere.

Effect of disturbances.-When I first began to apply the Babcock test to separate herds and individual cows I had some experience that was surprising and instructive. I have traced a low daily test of herd milk to the cattle breaking out of their pasture and being chased by men on horseback until they were excited and worried. 
Cows need special care.-There is no farm animal that needs more care than the cow. It will not answer to give her the same treatment that you do a fat steer. She is much more sensitive to cold, as she has not (if she is a dairy cow) an inch or two of fat all over her body to protect her vitals from the cold. The steer will be comfortable in a well-bedded dry shed in cold weather, when the cow would suffer and her flow of milk decrease. It does me good to visit a herd of cows and see the herdsman go among them with a kind word and the cows approach him as though they had an affection for him. On the other hand when I see a herdsman go among the cows with a loud voice and every cow begins to get away from him I think that man is out of place, and he should be put to some work that he is fitted to do-if it can be discovered what that is.

Difference in milkers.-There is a great difference in milkers. This many dairymen have learned and many more have not, judging from the way they act. I have had some milkers that would get enough more from fifteen cows in one year than other milkers I had at the same time to pay their salaries for the year. Perhaps some may not believe this, but it is not guesswork. It is a matter of calculation after weighing the milk from the various milkers' cows periodically for a term of 
months. The difference in milker's in this respect is surprising. There are many milkers whom the owner of the cows cannot afford to have in his employ at any price.

I test all my cows periodically, and at the same time I test the milkers. This takes no extra time, only in the matter of looking it up, as each milker has his regular cows to milk, and at the end of the season it can very readily be calculated how each milker has made his cows "hold out" (as we term it) with their milk. The following figures are from my books having the record of the work done during the winter of $1892-93$ :

Milker No. 1, Dec. 17, 1892, cows gave 356 lbs.; Feb. 28, 1893, 258 lbs.

Milker No. 2, Dec. 17, 1892, cows gave 298 lbs.; Feb. 28, 1893, 244 lbs.

Milker No. 3, Dec. 17, 1892, cows gave 304 lbs.; Feb. 28, 1893, 204 lbs.

During this time the cows of No. 1 shrank 98 lbs., No 2's cows shrank 54 lbs., and No. 3's cows 100 lbs. The per cent of shrinkage was: No. 1, 27 per cent; No. 2, 18 per cent; No. 3, 32 per cent. The shrinkage per cow from Dec. 17 to Feb. 28 was for No. 1, 7 lbs.; No. 2, 5 lbs., and No. $3,9 \frac{1}{2}$ lbs.

The milkers in the future will have their record and will secure employment on it. It will 
require time for this plan to work its way to the front, but it is sure to develop.

Milking for prizes.-After studying over this milking question for two years trying to devise some plan by which I could interest my milkers in their work, thereby securing better service, I decided to offer prizes to be competed for. I have five milkers and I offered three prizes to be awarded on the percentage of shrinkage for a term of months. The first prize was $\$ 10$, the second $\$ 5$ and the third \$2.50. My milkers were greatly interested in this work during the whole time of the contest and the results showed careful work.

One milker who milked 12 cows had a variation from highest to lowest daily weight of 7 lbs. during a week. Another milker who had 14 cows to milk had as low a variation as $7 \frac{1}{2}$ lbs. in the daily milk of his cows in a week. My total milk, which reached 1,850 lbs. daily, varied less than some of the patrons who had 250 to $300 \mathrm{lbs}$. daily. This was the result of careful, systematic work and work that pays. The young man who won the first prize had a shrinkage of $1.85 \mathrm{lbs}$. per cow in three months. The winner of the second prize made a shrinkage of 2 lbs. per cow, and the third prize winner made a shrinkage of 2.6 lbs. per cow for the three months. These shrinkages figured to percentages are as follows: First prize, .074; 
second prize, .089, and third prize, .095. This work, when compared with the work of the previous winter for the same months and under the same conditions as nearly as possible, is interesting to say the least. Some of the work of the previous winters was alarming, though it was doubtless as good as the average milking. I have the record of one milker for three months in 1892 and 1893, also in 1893 and 1894 . In the first winter his percentage of shrinkage for the three months was $27 \frac{1}{2}$ per cent, and the following winter when competing for a prize his shrinkage was $9 \frac{1}{2}$ per cent for the same months. When not competing for a prize his shrinkage was $7 \mathrm{lbs}$. per cow in three months; when competing it was $2.6 \mathrm{lbs}$.-a difference of $4.4 \mathrm{lbs}$.

The difference between the poorest work of the winters of 1892 and 1893 and the best work of 1893 and 1894 rolls up in a way to frighten me and make me doubt my own figures. The poorest work shows a shrinkage of $9 \frac{1}{2} \mathrm{lbs}$. per cow in three months, and the best work shows a shrinkage of $1.88 \mathrm{lbs}$. per cow for the same length of time. This difference is $7.62 \mathrm{lbs}$. per cow daily. I think it fair to suppose that the average difference of shrinkage for the three months would be one-half as much as it was at the end of the three months. This would be 3.81 lbs. per day for the 90 days, or 343 lbs. 
Now we will suppose the shrinkage after the three months is the same in both cases, and we have 200 days at $7.62 \mathrm{lbs}$., or $1,524 \mathrm{lbs}$. +343 $\mathrm{lbs} .=1,867 \mathrm{lbs}$. per cow, and for fifteen cows 28,005 lbs. of milk, which valued at $\$ 1$ per 100 lbs. would amount to $\$ 280.05$. I do not think this comparison is an exaggeration. I have supposed that the shrinkage in both cases was alike after the three months, which is not fair to the best milker, as it is more than probable that the shrinkage of the poor milker kept on increasing over the good milker and that his cows were dried a month earlier than were the cows of the good milker.

I had a plain talk with my milkers when the prize work commenced, telling them of the need of kindness, care and regularity of time in milking; also the necessity of securing all of the milk. I told them that if at any time the totals of milk at the barn and the creamery did not agree each milker would be furnished with separate cans and would be expected to make his milk at the barn and creamery compare, and that if at any time I learned of any man's unfair work to get an advantage I should exclude him from the competition. I am now pleased to be able to say that nothing of the kind was discovered.

How to milk.-The milkers should do their talking before they begin to milk and then at- 
tend strictly to their milking, doing the work as fast as they practically can, being careful not to hurt the cow in any way and particular to milk the cows clean. If the cow is not milked clean the richest part of the milk is left, and this kind of milking will cause the cow to shrink her milk. This point must be looked after carefully.

Ålways milk with dry hands. Do not dip your fingers in the milk or allow it to be done. A person can milk better with dry hands as soon as he becomes accustomed to doing so. I was taught to milk with wet hands but broke myself of the bad habit. Dipping the fingers in the milk or froth is an uncleanly habit. Don't do it.

The writer has milked fifteen to twenty cows regularly for months together, and once milked thirty-five cows for several days, the cause being a strike of milkers. The whole bunch of strikers got left and I got better ones as fast as I found them.

Experiment station work.-The Wisconsin Station (Report 1889, page 44) reported experiments on the effect of change of milker, rapidity of milking, manner of milking, milking tubes vs. hand-milking, and milking one teat at a time. Differences were noticed between good milkers which were attributed to the manner of milking, since the cows were all 
milked dry. The greatest effect was always noticed at the first milking after a change of milker, and with some cows this was more marked than with others.

In comparison of milking fast and slow, cows were milked in from three to four minutes and in double that time. The yield of milk seemed to be little affected, but in every case richer milk was given when the cows were milked fast, and this was most marked with cows giving the most milk. On an average from the whole lot of cows there was a gain of 11.73 per cent in the total yield of fat from fast milking. This difference in quality, however, seemed to decrease gradually, though not to disappear altogether.

When cows were milked one teat at a time there was a decided difference in the composition of the milk from the different teats. The milk richest in fat was invariably obtained from the teat milked second, that milked first coming next in richness, that milked third following, and that milked fourth the poorest. If the order in which the teats were milked was changed, the order of richness also ehanged so as to conform to the above rule, indicating that the richness of the milk from separate teats was due to the order of milking rather than to any characteristic differences in the parts of the udder. With this manner of milking the 
average percentage of fat in the milk from all four teats was considerably below that with ordinary milking.

Comparisons of milking by hand and with tubes were, as a rule, unfavorable to the milking tubes. On the whole the yield was slightly less with tubes than with hand milking and the quality of the milk was poorer, although there were individual exceptions to this rule. The average for the eight cows tested showed a total less with tubes of $6.5 \mathrm{lbs}$. of milk and 2.718 llos. of fat per day.

As to the frequency of milking, tests made at the New Hampshire Station of milking hourly and at the Vermont Station of milking two and three times a day, indicated that while there was a gain in some cases from frequent milking this was only temporary and was not apparent after two or three days. There was often a decrease in both yield and composition when frequent milking was continued. The Vermont Station found that in these fluctuations of quality the fat only was affected, the casein, sugar and ash remaining practically constant.

Quality of first and last milk drawn.-The "Handbook of Experiment Station Work," published by the United States Department of Agriculture, gives the results of many interesting and instructive experiments in milking 
made by the different experiment stations. It is stated that the milk from the first portion of any single milking is relatively poor and increases in richness to the strippings, which are relatively very rich. Thus the New York Station found that in the case of five cows the first pint of milk contained only .3 per cent of fat while the last pint contained 6.85 per cent and the mixed milk from the whole milking averaged 2.55 per cent. In every instance the first half contained only from one-third to onehalf as much fat as the last half. Similar results are reported in Connecticut, also in Indiana and New Hampshire.

Daily variation.-The milk of the same cow differs both in composition and in yield from day to day. Babcock states that yield may vary by 15 per cent and the amount of fat by as much as 50 per cent.

Four cows tested at the Wisconsin Station (Report 1889, page 42) showed an average daily variation of from 1.18 to 1.8 lbs. of milk, and the yield of fat per day fluctuated about 8 per cent. In connection with this work $\mathrm{Dr}^{\text {. Bab- }}$ cock says (Wisconsin Report 1889, page 43):

Our experimental work during the past year has directed attention especially to these variations and has served to indicate some causes for them which have not been given much prominence by writers upon dairy matters. It is generally considered when the farmer has supplied a sufficient amount of proper food and has provided good shelter and 
care for his cows, that he has done all that it is possible for him to do in order to secure an akundant yield of rich milk and the cow is usually held responsible for any failure.

All of these'conditions are of course essential for the best results, but the immediate conditions under which the milking is done appear to have almost as much influence upon the yield and quality of milk as any other factor. The manner of milking, the frequency with which it is done and the time occupied in doing it may, I believe, have more influence with many cows upon the yield and quality of milk than the kind of food, so long as sufficient food is supplied.

All of our experimental work indicates that temporary conditions existing only at the time of milking may very materially affect both the yield and quality of the milk produced. This can be most easily explained by assuming that the milk glands are most active at this time and that the quality of the secretion depends on this activity. It seems probable that the action of the milk glands is greatly modified by the nervous condition of the animal at the time of milking as well as by the stimulus derived from manipulation of the teats and udder.

This experiment also brought out the fact that the manner of milking also affects the composition of the milk. It was found that cows which ordinarily gave milk with 4 and 5 per cent of fat respectively, gave milk with only 2.7 and 3.92 per cent respectively when milked one teat at a time. The milk was richer in fat when milked rapidly (three to four minutes) than when milked slowly (double that time), though the yield seemed not to be affected, the fat being as a general rule more sensitive to such changes than the other ingredients or the total yield of milk.

Morning's and night's milk.-There is at times a marked difference in the per cent of fat contained in the morning's and night's milk. Some dairy writers have claimed that one was the richest in fat and some that the other was. My experience in testing my own herd, also in 
doing "detective" work at our creameries, has convinced me that the time between milkings is the greatest cause of this difference. I know that some farmers have been suspected of being dishonest with their milk when in fact they were the reverse of it. Being hard-working men and up at 4 o'clock in the morning to milk and making long days in the field caused the milking to be done as late as 8 o'clock in the evening, thus making the time from morning to night's milking sixteen hours, and the time from night's to morning's milking eight hours. When these conditions exist the morning's milk will contain the largest per cent of fat. In extreme cases the night's milk will be so much poorer in fat than the morning's that it is pretty strong circumstantial evidence that there is something wrong about the night's milk, or at least that was the fact before the introduction of the Babcock test. Now we have light on this subject and many others.

At the Mississippi Station ("Bulletin 13") it was found that when cows were milked at between 5:30 and 7 in the morning and between $3: 30$ and 5 in the afternoon it required on an average $18.1 \mathrm{lbs}$. of the morning's milk and 13.5 lbs. of the night's milk to make a pound of butter. In this case the hours of milking made the time from morning to night ten hours and the time from night to morning fourteen hours. 
Here the difference in time $(14-10=4 \div 10=.4)$ was .4 per cent and the difference in the pounds of milk $(18.1-13.5=4.6 \div 13.5=.34)$ required to make a pound of butter was .34 per cent.

The facts brought out by the work of our experiment stations on milking should cause dairymen who are not giving thought to this question to commence thinking seriously and immediately. Who can tell us how many cows that are now unprofitable could be made profitable by a change of milkers or by more intelligent work without a change? 


\section{CHAPTER V.}

\section{MILK FROM COW TO CREAM VAT.}

As soon as a cow is milked strain the milk through a wire strainer into a can which is to be used to convey the milk to the milk-house or the room where it is to be set to raise the cream or put through the separator to separate the cream. There

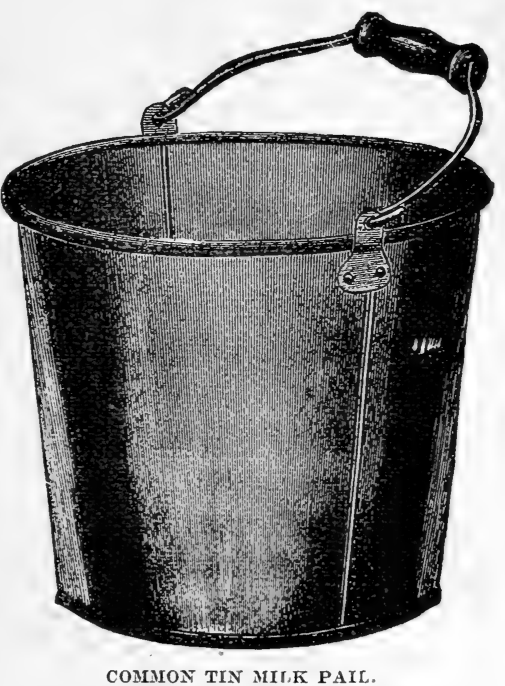
it should be strained through a cloth strainer.

Flannel strainers.-When I made butter at my farm I used woolen strainers for this purpose. They do thorough work, but require considerable care to prevent their thickening or fulling so the milk will not run through them. Cotton strainers will do more thorough work 
than a wire strainer, and I prefer them in the milk-room. When the shallow-pan system is

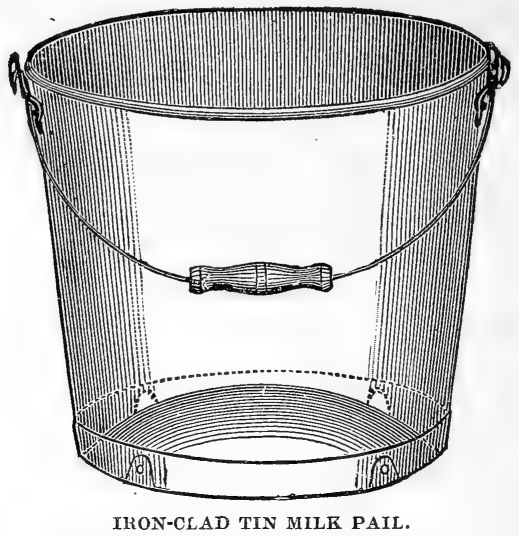

used the milk should be set as fast as is practicable after it is strained, as the cream rises the fastest while the milk is cooling and the

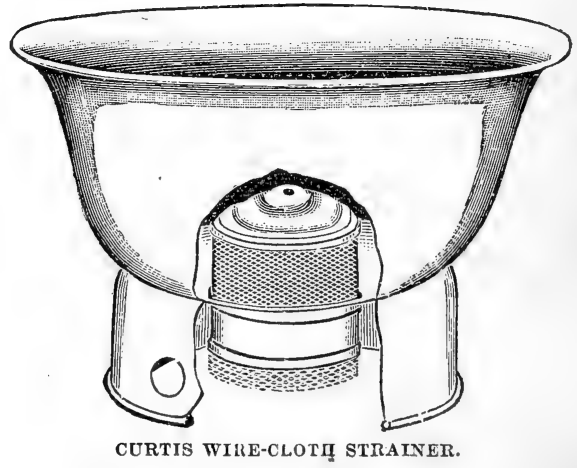

sooner set after milking the more benefit we get from the cooling provess. 
Temperature of room.-The temperature of the room in which the milk is set should be 60 to 65 deg., so that the milk shall be sour but not thickened, except at the bottom of the pans, when it is to be skimmed. I believe the most thorough creaming is secured when the milk sets 36 hours to reach this proper stage for skimming. I have sometimes in the winter time allowed it to set 48 hours, and warmed the milk at the end of 12 hours and warmed the second time at the end of 24 hours.

Repeated cooling gives thorough creaming. In this way we repeat the cooling process and secure very thorough creaming - the most perfect of any plan except the centrifugal separator. I used large shallow pans holding 500 lbs. of milk, and these pans were surrounded by a water pan for heating and cooling the milk. This plan of heating and cooling gave the richest cream I have ever seen. I practiced cutting the cream into squares with a knife and picked them up with a tin ladle, as pancakes would be taken up. I remember some instances when it would not pour out of a can 8 inches in diameter when I put it into the churn. Such cream cannot be churned until reduced with skim-milk or water.

The advantage that comes from such a quality of cream is the thorough creaming that is secured. I have not found it practicable to 
treat the milk in this way in the summer months. Such cream as this is ripe and ready to churn when taken from the milk, but it can be held two or three days with safety if kept at a low temperature. It contains but a small per cent of milk, and for that reason does not

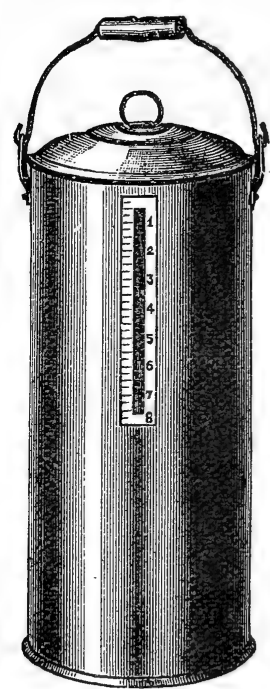
sour or ripen so fast as cream that has a larger per cent of milk in it.

When milk is set in small shallow pans it can be treated to this heating and cooling process by placing the pans into a vessel of hot water or over boiling water and heat with steam. When this is practiced the temperature of the milk-room must be held down as low as $40 \mathrm{deg}$. Fah., if possible, or the milk will sour too soon. My practice was to open the windows and get DeEp-setTing can. the temperature down near the freezing point until the milk was cooled.

Do not skim the milk until it is ready to be skimmed. Thin cream cannot be taken off from shallow pans without considerable loss. It should stand until the cream thickens and the temperature of the room should be such as to cause it to thicken before it is old enough to suffer in flavor. Observation and experience 
teach a person about these matters. It is also important that milk should be skimmed as soon as it is ready; if not, there is danger of loss in the flavor.

Submerged plan.-If the submerged or deep, cold system is used for cream-raising the milk should be set as soon as practicable after it is

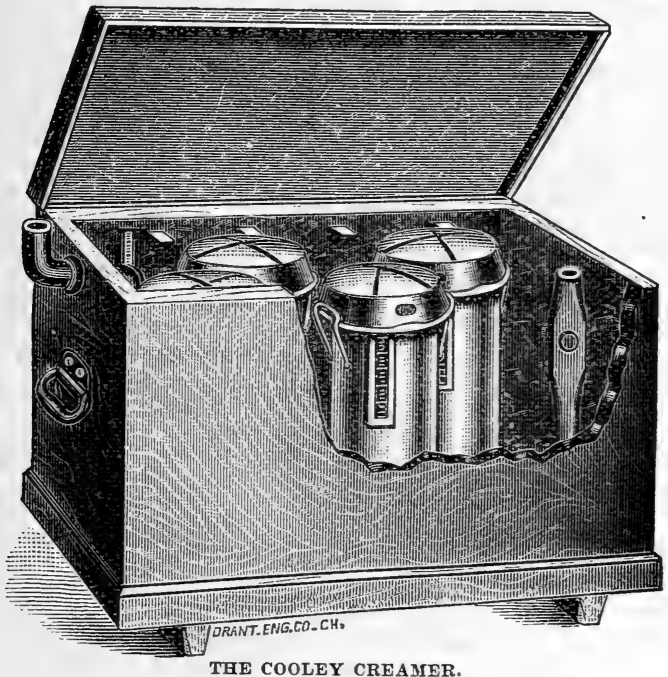

milked and strained. The sooner it is set and the colder the water it is set in the better the results. The warming and cooling process can be used to advantage with this system. Cream rises fastest while the milk is cooling, and if we can repeat the cooling process we accomplish more efficient work.

There is a variety of opinions as to the neces- 
sary time for milk to set to secure the best results by the deep, cold-setting system. My experience is that a larger yield of butter is secured when it is held 24 hours in ice water than when held 12 hours, and if held in water at $60 \mathrm{deg}$. Fah. it is best to let it set 36 hours, and in some cases 48 hours.

The breed and period of lactation have much influence on the cream raising. The cream

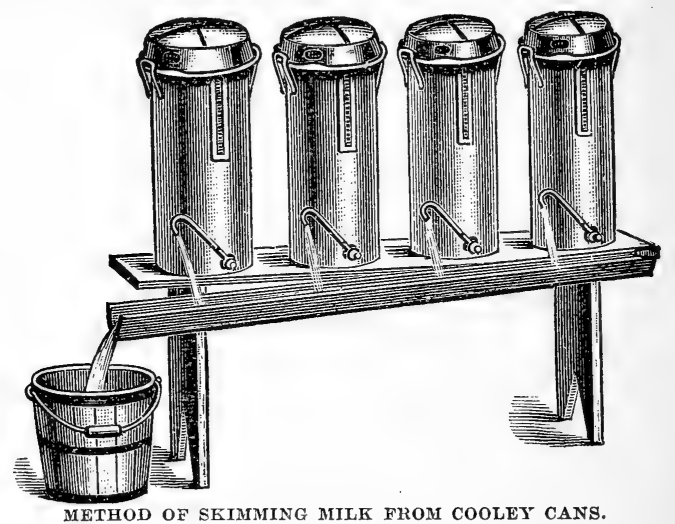

globules are larger in the milk of some breeds than others, and this fact must be taken into account in the gravity methods of cream-raising. The milk of all cows creains more readily when they are fresh than when they are advanced in the period of lactation. This will apply to all methods of creaming, whether the shallow pan, the deep, cold system, or the separator, although the separator will secure a 
larger increase of butter over the gravity methods when we have a hard-skimming milk than when we have a milk that creams readily. The conditions must be the most favorable to secure thorough creaming with the gravity methods, but the separator can be adjusted to get practically all the cream from any and all milk.

Care in skimming.-The skimming of the Cooley and "shot-gun" deep-setting cans is very different. In the Cooley can the skim-milk is drawn from the bottom and the cream is not disturbed except as it settles as the milk is drawn out of the can, but with the "shot-gun"

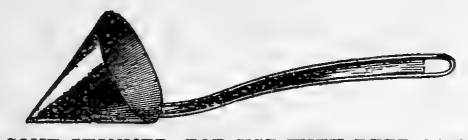

CONE SKIMMER, FOR USE WITH DEEP CAN

can the cream is taken off the top with a conical dipper and great care is necessary to avoid mixing the cream and milk during the process of skimming.

Experimental work in creaming.-The experiment stations of the United States have done much valuable work in this line. At the New York State Station a comparison of submerging milk in cans in spring water at 56 deg. Fah. and in ice water gave three-fourths of a pound more butter per 100 lbs. of milk from the use of ice.

The Wisconsin Station (Report 1884, page 17) 
found that the loss by setting in water at 55 deg. might be nearly a third larger than at 45 deg. and a tenth larger than at $50 \mathrm{deg}$.

Snyder (Minnesota "Bulletin 19") found that creaming was more rapid and nore complete in ice water than in water at $60 \mathrm{deg}$.

Jordan at the Maine Station found that the creaming was more complete at a temperature below 45 deg. than at a temperature higher.

At the New York State Station (Report 1889, page 210,) 12 hours setting in ice water was found insufficient and 24 hours adopted.

Centrifugal separators.-When a centrifugal separator is to be used I would recommend that some power be applied, either water, steam, or some animal power. Do not calculate on the hired man, the boy, or the proprietor doing this work. If you have cows enough so you can afford to have a separator you can afford to have some power to operate it. I have had just enough experience in this line to know that it is hard work. It is the kind of work that does not induce the boys to stay on the farm. If any person is to do this work it certainly should be the proprietor.

I do not wish to be understood as opposed to the separator as I know very well that it will secure for us the most effectual work possible. On this point the Delaware Station, in "Bulletin 17," calculates that with a herd 
averaging $100 \mathrm{lbs}$. of milk morning and night the year through the separator would save about

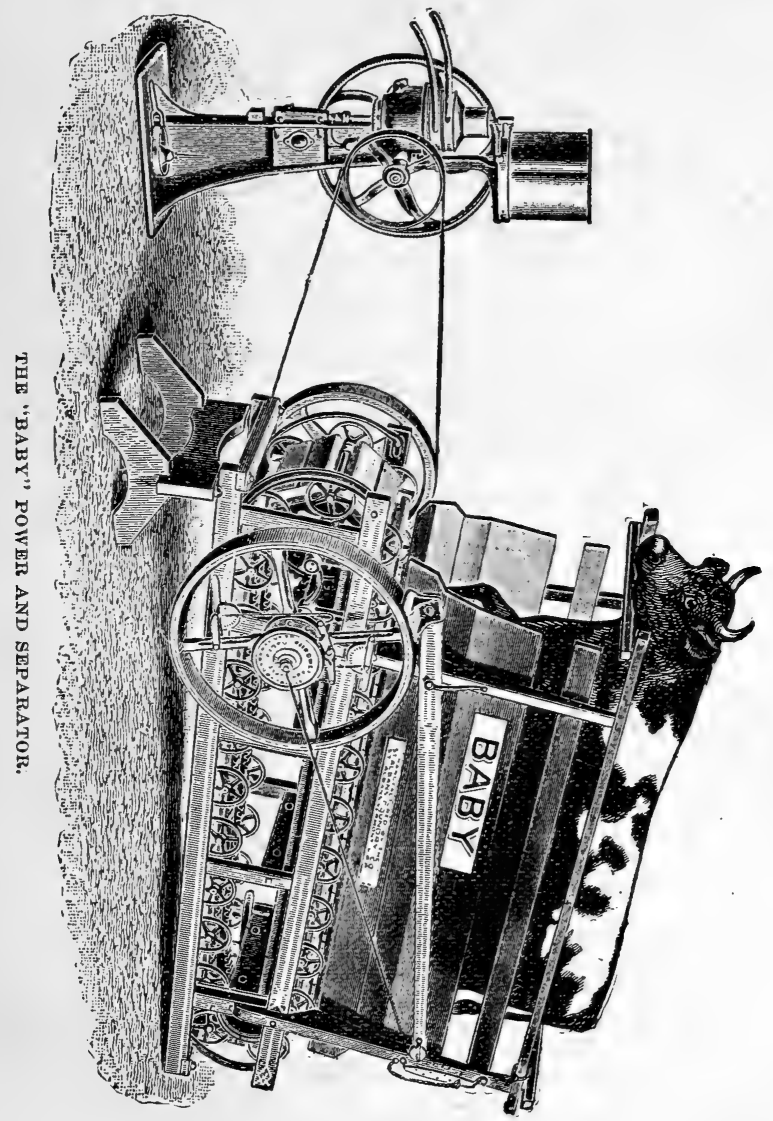

$280 \mathrm{lbs}$. of butter in the year, which at 25 cents per pound would be a gain of $\$ 70$ over cold 
setting; but if fair wages be counted for the hand-labor the profit would be much reduced, if not wiped out, and the station suggests that

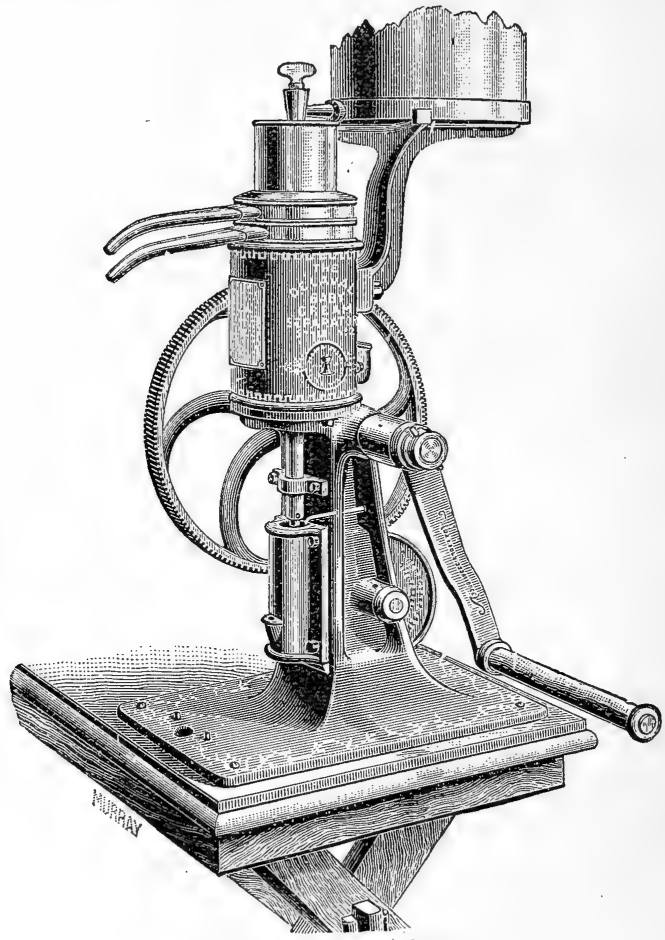

BABY DE LAVAL SEPARATOR.

horse or other power be used in place of hand power.

I believe that we can make butter with a more delicate flavor, or if you please a higher flavor, when the separator is used than with 
MILK FROM COW TO CREAM VAT.

the gravity methods of creaming. Especially will this be the case in the dairy, as the milk

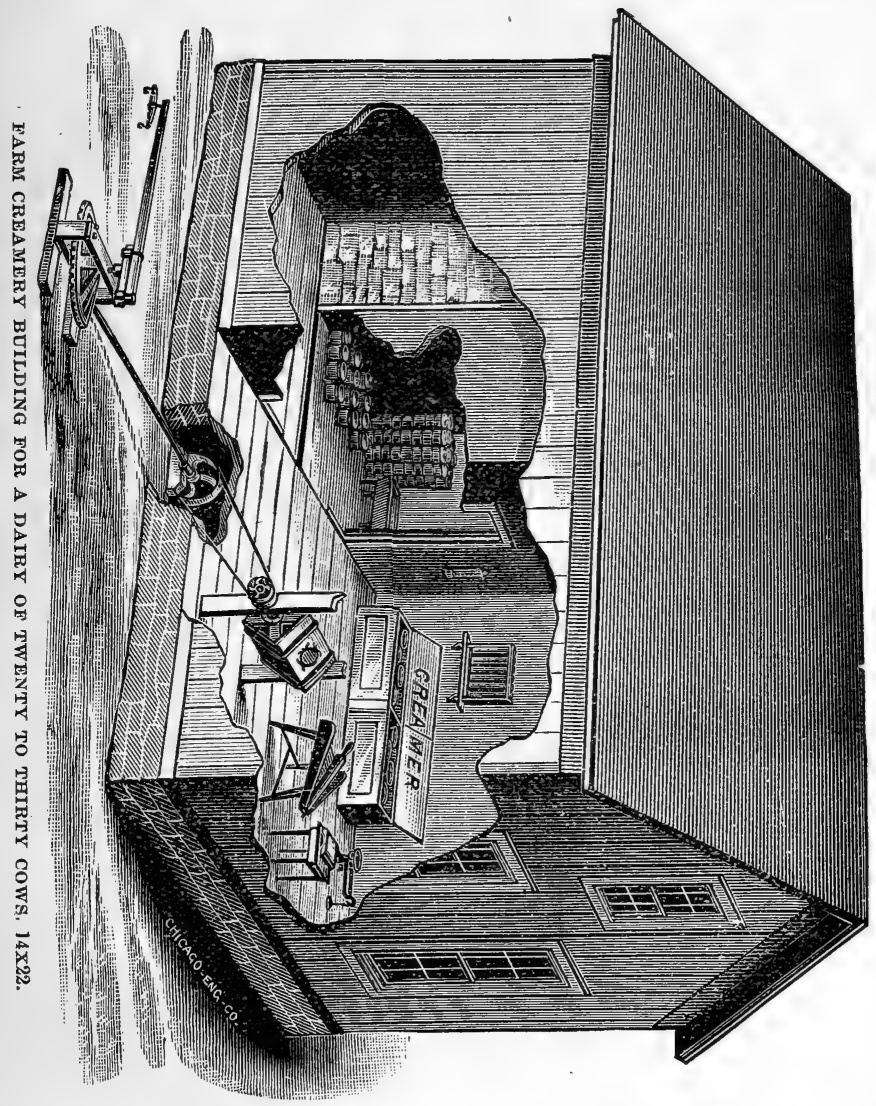

will be separated immediately after milking, and the quicker it is done the better. With the utmost cleanliness there is liable to be and 
at times will be elements in milk from contact with which it is best that the cream should be removed. Any person that has operated and cleaned separators for a few months can realize this point fully. In proof of this point it has been learned that milk for cheese-making is improved by running it through a separator without separating the cream. I think Dr. Babcock has practiced this in an experimental way.

When the separator is to be used it is best to separate as soon after milking as practicable. If power of some kind is used the separator can be put in operation soon after milking has commenced, or at least commence in time to have continuous work for the separator and get through separating as soon as practicable after the milking is done. The milk as it comes from the cow is in the best possible condition to separate.

Farm skim-milk.-There is a great variety in the quality of work done in the line of skimming by farmers. I have tested farmers' skimmilk from the gravity process that contained $1 \frac{1}{2}$ per cent of fat. They had recovered less than two-thirds of the fat in the milk. This quality of work makes an enormous loss. No business except farming could stand such losses. The dairyman of the future is not going to make such wastes. It is only quite 
MILK FROM COW TO CREAM VAT.

93

recently that we have had a practical method of knowing what losses were being made, and now we are stopping these leaks rapidly. 


\section{CHAPTER VI.}

\section{RIPENING AND CHURNING.}

We will now suppose we have the cream separated from the milk by some one of the processes. The cream from the shallow setting when the milk was sour at the time the skimming was done may be churned as soon as convenient after it is taken from the milk, as it has ripened on the milk and is in good condition to churn.

Holding cream. - It may also be put in a can and held two or three days if held at a low temperature-40 to 45 deg.-and cream may be added from each succeeding skimming and thoroughly mixed with the cream already in the cream can. The cream can should be large enough to hold a churning; then we are quite sure that the cream is all of a uniform ripeness. This is necessary to secure the most exhaustive churning.

When we mix cream of different degrees of ripeness in the churn there is sure to be a large loss in the buttermilk. If the churning is done at a low temperature the loss will be less than 
if done at 60 or 62 deg. This rule will hold good with all kinds of cream and all degrees of ripeness.

Some kind of a vessel about the same depth as the cream can and several inches larger in diameter is needed to put the cream can in and surround it with water, warm or cold, as needed to warm or cool the cream. A wooden vat may be used for this purpose.

Deep cold-setting cream.-The cream from the deep cold-setting will be, or should be, at a low temperature when taken from the milk. This may be put in the cream can or vat and held at a low temperatuie, as low as 40 deg. if practical, adding the cream from each succeeding skimming until a churning is secured, or two to four days, giving the cream a thorough stirring every time fresh cream is added. About eighteen to twenty hours before you wish to churn warm this cream up to 65 cieg. and hold it at this temperature until ripened, which will be about eighteen hours. Acidity of cream and an acid test for cream will be talked about in "Part II" of this book.

Separator cream.-The cream from the separator should be immediately cooled to a low temperature, the degree depending on when it is to be churned. If to be held two or three days cool it to 40 deg., or as near it as is practical. If ice is used 40 deg. can be reached. 
The cream from each successive skimming may be added to the can and thoroughly mixed at each addition of cream. This cream may be ripened the same as the cream from the deep cold system.

Different temperatures for churning.-We now have the cream from the shallow setting,

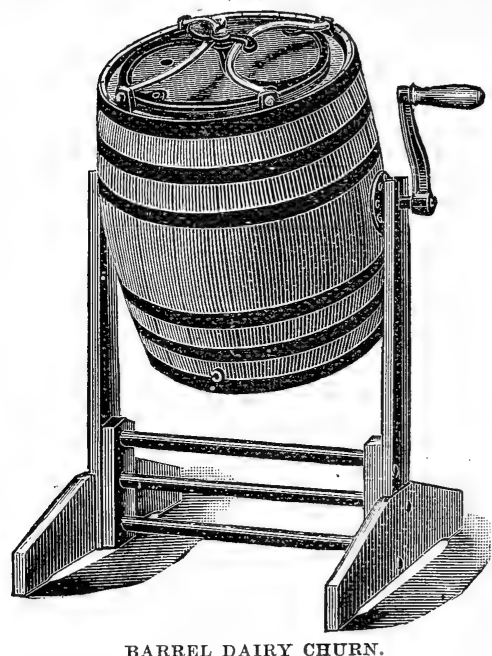

the deep setting, and from the separator ripened ready to churn. The next point is to secure the proper temperature before putting it in the churn. It is best to cool the cream from the shallow-setting system to 54 to 56 deg. before churning. This cream is rich in fat and can be churned at this temperature without any difficulty. Let the cream stand at low temperature before churning long enough for the fats to solidify or harden.

The cream from the deep cold system has a much larger per cent of milk in it, and consequently a smaller per cent of fat, and will need to be churned at a higher temperature. If we 
undertake to churn this cream below 55 deg. we will probably have trouble from its swelling and will find the churn full of frothy

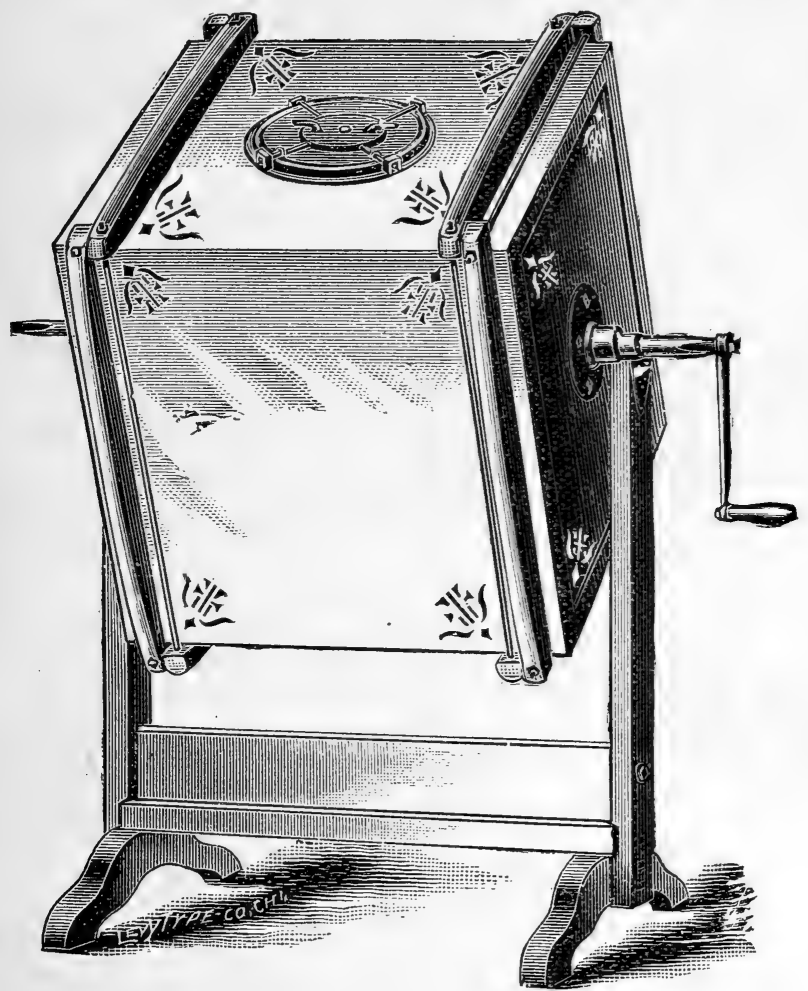

SQUARE BOX CHURN.

cream. The proper temperature for this cream is 60 to 62 deg. in winter and 58 to 60 deg. in summer.

The separator cream should be cooled to a 7 
temperature to correspond with the per cent of fat it contains. If the separator is adjusted to take from one-seventh to one-eighth of the whole milk as cream it will contain sufficient fat so we can churn it at a temperature below 55 deg., but if the separator is adjusted to take from one-fourth to one-fifth of the milk as cream we shall need to churn at the temperature of 58 to $60 \mathrm{deg}$. This kind of cream gives us more buttermilk and a buttermilk with more fat in it. Rich cream and low temperature give the most exhaustive churning.

When the cream is being cooled get the churn ready by first scalding with water that is above $180 \mathrm{deg}$, and if it boils, all the better, as it will then surely scald. After scalding cool thoroughly with cold water and ice if you have it. When cooled the churn is ready for the cream. Never fill the churn more than half full, as it will require more time and not do so thorough churning.

Strain the cream into the churn. A perforated tin strainer is good for this work. Straining breaks up any dried cream there may be, also the curd if there is any, and enables us to wash it out of the granular butter with less labor and care. There should be no curd in the cream, and if it has been agitated frequently and not allowed to become too sour there will be none. 
Butter color.-If the butter needs coloring to satisfy your trade put it into the cream before starting to churn. When purchasing butter color be sure that you get fresh goods, as it will sometimes become stale with age and injure the flavor of the butter. If you buy the small bottles at your grocery store you will

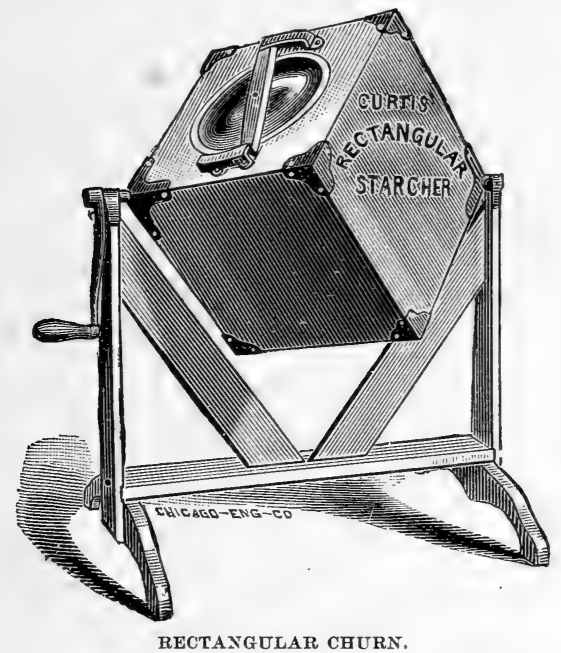

need to look well after this point. I have had butter color that would impart a flavor to the cream that could be detected before the churn was started.

Temperature of churn room.-Have the temperature of the room in which the churning is to be done as cold as the cream if possible, and if it is 10 to $15 \mathrm{deg}$. colder all the better, 
as the cream will then not warm during the churning process. But if the churn room is up to 75 to 80 deg. the cream will warm up very fast and the butter will not be in as good condition. It will need much more washing than when it gathers cold.

Washing the butter.-The churn should be stopped when the granules of butter are the

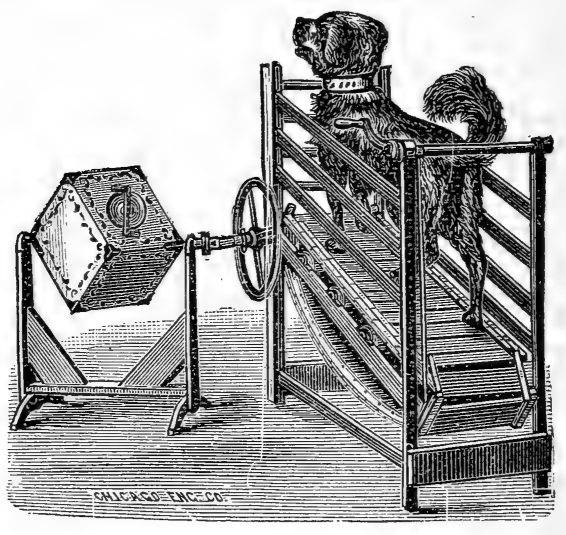

DOG POWER.

size of wheat, the buttermilk drawn through a fine sieve, and the butter then washed as little as practical to remove the buttermilk. Here is where the cold churning has the advantage, as the butter will not need so much washing. When the butter gathers at 62 to 64 deg. it will need three washings to remove the buttermilk. and it will then show milky when being worked. But if the butter gathers at 52 to 54 
deg. it will need but one washing, if any, and I am confident we will have a better flavor if not washed at all. When washing do not let the butter-remain in the water any longer than is absolutely necessary. Remove it as soon as it has done its work. Allowing butter to lie in water is a vital mistake.

Low temperature.-Churning at 50 to 52 deg. is a radical change from the general prac-

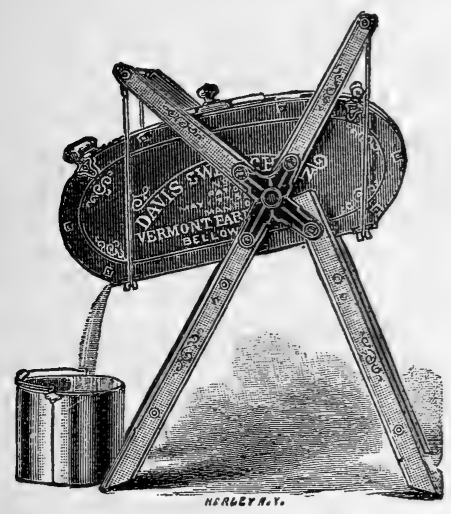

DAVIS SWING CHURN. tice and there are still many who do not believe it practical, but it is the daily practice in our creameries in cold weather. It is not unusual, but the rule, that our butter will stand as low as 54 deg. in winter when the buttermilk is removied. To avoid too much washing churn at as low temperature as possible. To secure the most exhaustive churning churn at low temperature. To churn at a low temperature it is necessary to have a rich cream. Do not attempt to churn poor or thin cream at a low temperature, as you will have trouble. I have many times in my early experience with cream from deep, cold setting that was too cold and 
swelled so as to fill the churn too full, therepy preventing churning, drawn out one-half of it and made two churnings. This will require less time and much less patience than it will to churn, or try to, when the churn is so full that there is no concussion.

Handle with ladle.-Keep the butter in the granular form until it is put onto the worker and the salt added. Keep your hands out of the butter and handle it with a wooden scoop and ladle. 


\section{CHAPTER VII.}

\section{SALTING, WORKING, PACKING AND PRINTING.}

The salting may be done in the churn or on the worker. If the box or barrel churn is used it can be salted very nicely in the churn. Use a sieve and put the salt through it into the granular butter; then revolve the churn very slowly and the salt can be thoroughly mixed with the butter before it is taken from the churn and while it is in the granular form. The main objection I have to salting granular butter in the churn is the uncertainty as to the amount or weight of the butter. When a small churn is used this can be overcome by weighing the churn with the butter in it. This was my practice until my dairy increased so as to require a churn of a size that could not be readily handled and weighed. The advantage of churning at a low temperature comes in here too, as butter at a low temperature does not pack so readily and the salt can be mixed with less working. 
Use sufficient salt to suit your trade. Our experience is with a trade that wants threequarters to one ounce per pound. Work the butter once or twice as you like.

Take the butter out of the churn with a wooden scoop. A small hand scoop can be secured for dairy work. Some style of a hand

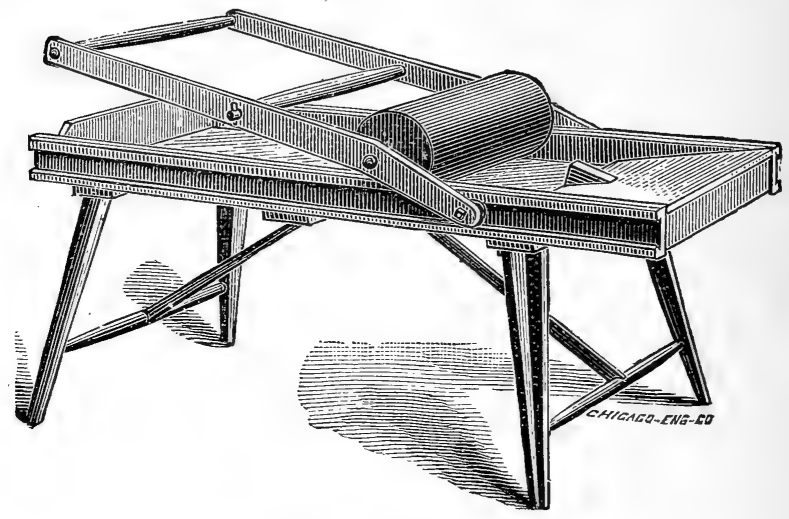

EUREKA BUTTER-WORKER.

butter-worker should be used. There are several styles or makes that are all right.

Once working. - The butter should be worked enough to thoroughly incorporate the salt so that when it has stood twenty-four hours it will not show mottled or streaked when bored or cut with a ladle. If at any time you find this appearance in your butter you may know it is not sufficiently worked, and it is best to rework butter that has much of this appearance. 
Twice working.--If twice working is practiced it should be worked sufficiently at the first working to get the salt well incorporated with the butter; then it should stand long enough

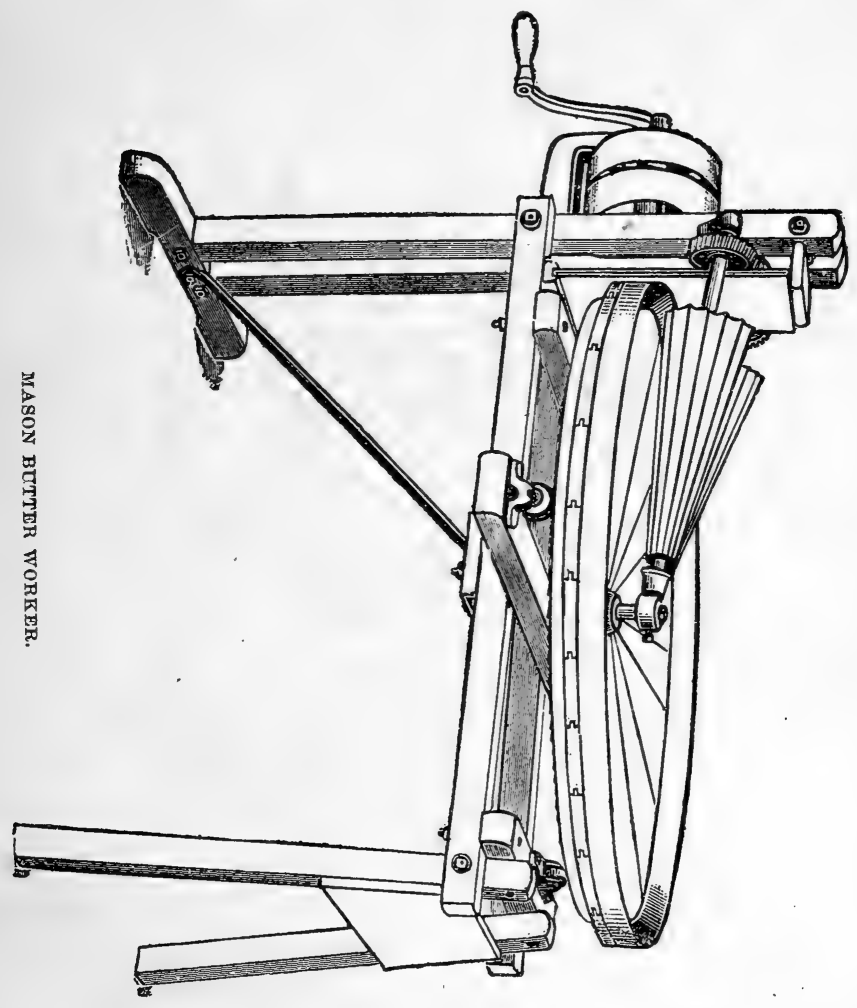

to allow the salt to dissolve, when it is ready for the final working At this working the butter is sufflciently treated when there are no 
streaks of white to be seen when cut with the ladle and held to the light.

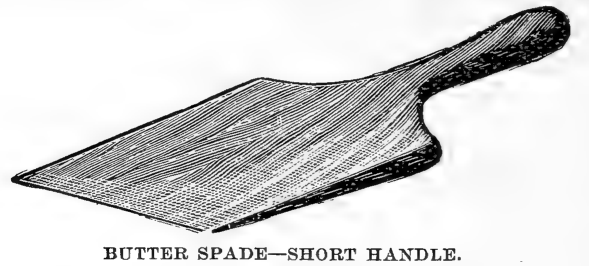

Do not confound this mottled or streaked appearance that comes from
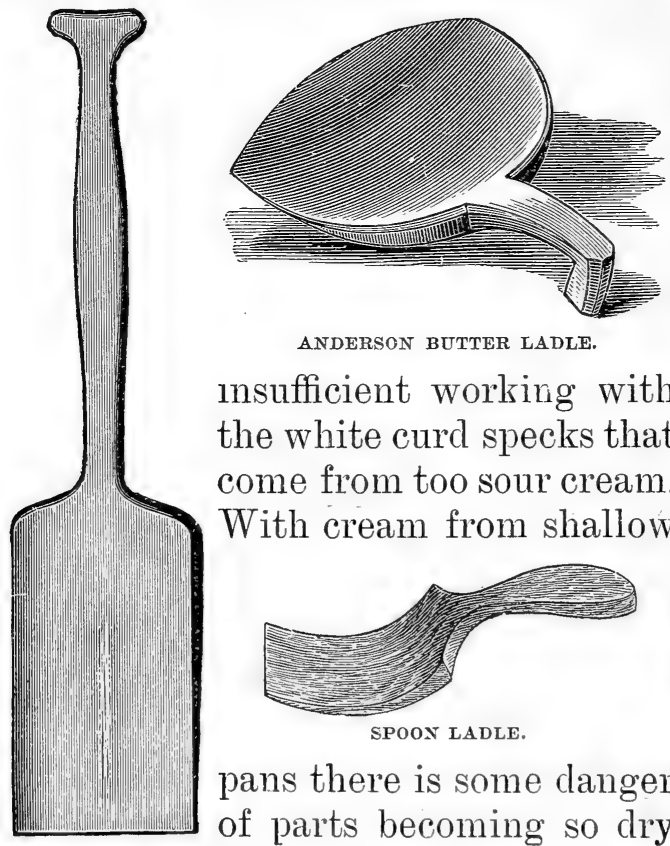

ANDERSON BUTTER LADLE.

insufficient working with the white curd specks that come from too sour cream. With cream from shallow

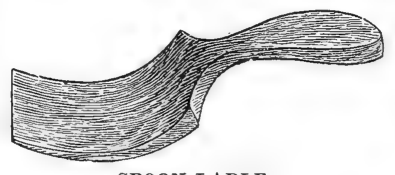

SPOON LADLE.

pans there is some danger of parts becoming so dry BUTTER SPADE-
LONG HANDLE.

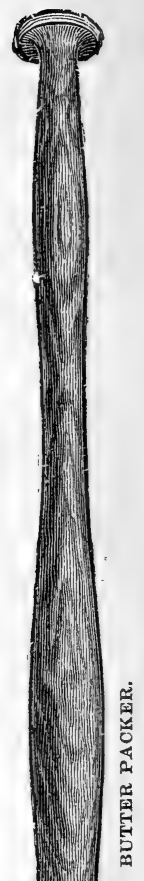


churning process and we find them in the butter as dried cream, and when color has been used they will show as light spots, though not white as the curd will. Straining the cream will remedy this trouble. You can readily tell the difference, as one is fat and will readily dissolve between the thumb and finger and the

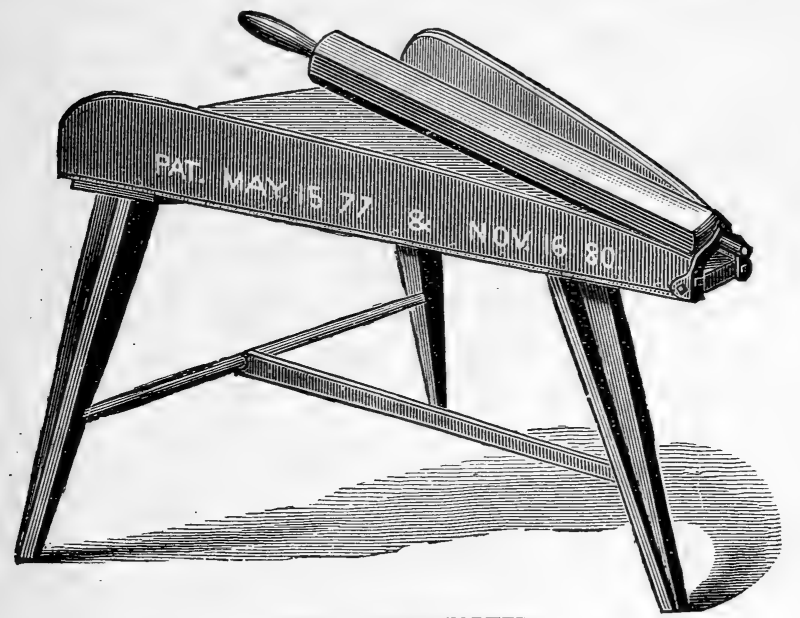

LEVER BUTTER-WORKER.

other is curd and will not dissolve either in the mouth or by heat.

Kind of packages.-Use a package to suit your trade, but whatever you use be sure that it is clean and sweet. Stone and earthen jars must be looked after very carefully, especially if they have been previously used, as they quickly get out of condition if not properly 
cared for. Wooden packages should not be used a second time for packed butter. Most of them are cheaply made and are intended to be used but once, and it is a very difficult matter to have them kept so that it is safe to use a second time.

The dairyman will have more of this to contend with than the creameryman will, and he must look sharply after it. I have had badsmelling packages come from the best families. The mistress - cannot see to everything, but must trust to someone, and she is sometimes deceived on this point.

A desirable way to put up butter for near-by markets is in prints.

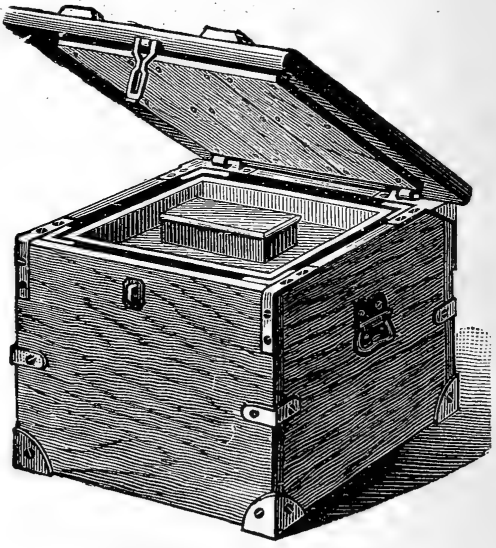

BUTTER SHIPPING BOX.

I find that the retailer prefers this form to the solid packed, as he can handle it like canned goods in filling orders. I have been told by grocerymen that when they sell small quantities from a large package three cents margin is necessary to get back the money they paid for the butter. Another point in favor of the print 
butter is its better appearance. When it is nicely printed and wrapped in parchment paper it looks very neat and attractive. It can also be more readily put in good shape for the table. In the Eastern and some of the Middle States a large percentage of butter goes to market in prints.

There are shipping-boxes for print butter for sale by dairy-implement dealers, some with icebox attachment and others without. 


\section{CHAPTER VIII.'}

\section{MARKETING DAIRY BUTTER.}

There are many ways of marketing dairy butter. At times it may be sold to good advantage at the country store, but this is the exception, not the rule. The country store does not usually pay for butter on its merits. The seller is often a customer and they do not want to offend, and so they pay more for poor butter than it is worth, and to balance up must pay less for the good butter than it is worth.

In many places a good market may be secured among the citizens of the village or city where you trade. Many are anxious to have a reliable source of supply, and are willing to pay well for butter that-satisfies them.

Poor butter makes a loss.-Poor butter makes a loss to the maker and usually to every one down the line that has anything to do with it, excepting the commission houses, and it makes them tired. The dealer makes his profit on the fine goods.

Fine butter makes a profit. - There is no trouble in selling fine butter. The trouble will (110) 
come from not peing able to supply the demand. When you have reached this condition you are

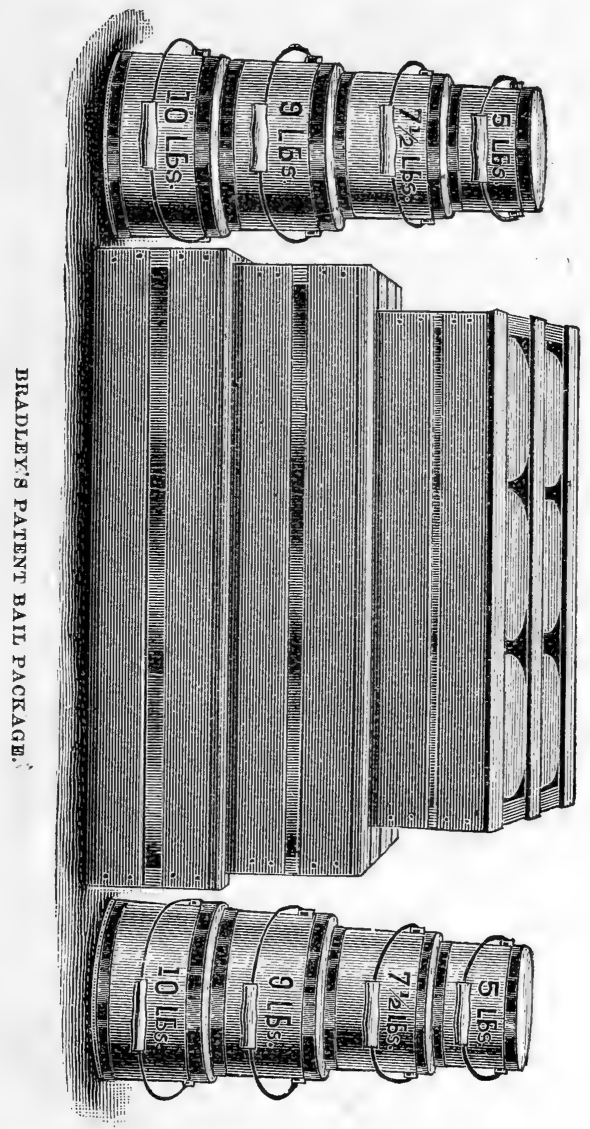

in position to secure an advance in price. This is what you have been working for. Now you 
have the move in the game and should try to keep it. This you can do only by continually trying to do better work. It will not answer to think you have reached the top and can stay there without an effort, as this feeling leads to defeat.

Commission houses.-A good way is to consign to a reliable commission house. Here your butter will sell on its merits, and if there is

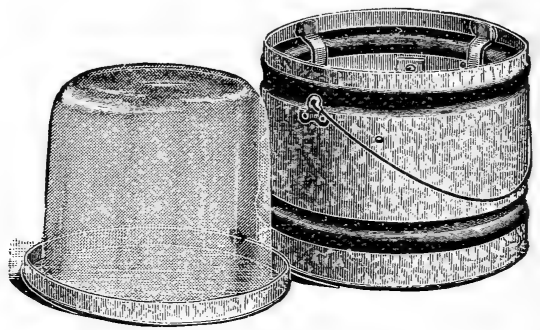

GLASS BUTTER PACKAGE.

anything wrong with it you can learn what the trouble is, and when you are told do not be offended about it, but go to work and remedy the trouble.

In selecting a commission firm to sell your butter be careful not to make a mistake. There are plenty of reliable firms that advertise in the dairy papers. Many dairy papers will not receive an advertisement from a firm that they do not know to be reliable. And this is right.

When you have decided to let a commission man handle your butter and have selected your 
man, remember that you and the commission man are both interested in having good sales made, and you can help him by shipping your butter on a regular day, as often as once per week. The commission man will soon have customers for your butter and they will depend on it.

Have a brand for your butter, anc be sure you keep the quality up to standard. If at any time you have butter that is not up to standard keep your brand off of it. Consign it to your regular man and tell him what the trouble is, if you know, and if you do not know ask him to help you over the difficulty and in many cases he will be able to do it. Treat him as a friend and nine times out of ten he will prove a friend.

In my early dairy experience I had private customers, but I somehow drifted away from them. Sometimes I had a surplus to consign and at other times I did not have enough to supply or fill my orders, and if I bought to meet the demand there was in many cases dissatisfaction.

Butter has individuality.-There is an individuality about butter as much as in persons, and when customers become familiar with a certain brand of butter they prefer it to some other make that is equally good. This individuality must be preserved. If at any time you 
think it best to make a change in any of the details of your work let the change be made gradually, so the customers will adapt themselves to the change and probably be pleased with it, when if you had made an abrupt change they would not have liked it. I recently had the pleasure of examining some butter made near one of our large cities. This butter was selling for seventy-five cents per pound. This caused me to examine it very carefully. The butter was very fine. It had a peculiar flavor, different from any flavor I had ever discovered in butter before. I was told that this peculiar flavor was virtually a trade-mark; that the consumers soon learned to like it and preferred it to any other flavor. I mention this in proof of the statement that customers prefer what they have become accustomed to rather than anything different that is equally good.

Care pays well.-Do not be afraid that extra time spent in fitting your butter for market will not pay. Remember that you are building a reputation that will enable you to secure a better price and cause your butter to sell readily at all times, and on a dull or declining market especially will it do you good, as your goods will move in time to escape a large part of the decline. Poor butter always gets caught when the market declines. This leaves it to go from bad to worse, and it will go at a terrible gait. 
This we are well aware of when the returns come.

Profits from a dairy farm.-Acting on the judgment of several of my friends that it is a proper thing to do I give here a short business account, showing in a condensed way the profit of $\mathrm{my}$ farm in 1893:

Sales.

Hogs........................... \$1,726.49

Fat cows........................... 480.90

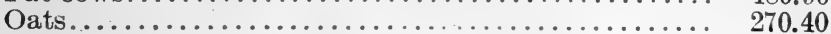

Butter and calves.................... 4,410.69

Expenses.

$\$ 6,888.48$

Ground feed and corn bought..........\$1,522.35

Five regular men................... 1,525.00

Taxes, insurance, blacksmithing, groceries,

hardware, extra labor. etc.......... 1,494.36

$\$ 4,541.71$

Profits...........................\$2,346.77

My stock I appraise at $\$ 3,760.00$, on which I figure 6 per cent interest, which amounts to $\$ 225.60$. This taken from the balance of $\$ 2,346.77$ leaves $\$ 2,121.17$ to be credited to the land. My farm contains 354 acres, valued at $\$ 60$ per acre, or $\$ 21,240$. This is practically 10 per cent interest on the land and 6 per cent on the stock, or $9 \frac{3}{8}$ per cent on the total invested in stock and tools. I do not live on my farm, but spend one day per week looking after it. I had more stock on the farm Jan. 1, 1894, than I did Jan. 1, 1893. This I did not take into account. 


\section{CHAPTER IX.}

\section{SKIM-MILK.}

There are comparatively few farmers that realize the value of skim-milk as a food for pigs and calves. My experience has taught me that when made the entire food of pigs weighing 50 to 75 lbs. it produced a pound's increase from 16 lbs. of skim-milk. With live hogs worth 4 cents per pound this would make the skimmilk worth 25 cents per 100 lbs.

Value fed alone.-I do not advise feeding pigs entirely on skim-milk. It is more profitable to feed some grain food in connection with it. The combination will give better results. The question arises, Where shall we credit the increased profit that comes from feeding the combination of skim-milk and grain food over feeding either one separate, or making either skim-milk or the grain the entire food? I formerly divided this increased profit and gave one-half to the skim-milk and one-half to the grain feed. I am now in doubt about the justice of this practice. I believe 
the skim-milk should have credit for all the increased profit there may be above what there would be in feeding the grain food alone.

Cost of growth with corn.-In June, 1874, a lot of 20 pigs weighing 51 lbs. each fed entirely on corn and the increase weight credited at 4 cents per pound, paid 34 cents per bushel for the corn.

In January, 1875, a lot of 32 pigs weighing $223 \mathrm{lbs}$. each fed entirely on corn made me $31 \frac{1}{3}$ cents per bushel for the corn fed, with pork at 4 cents per pound, live weight.

In February, 1875, a bunch of 30 pigs weighing $263 \mathrm{lbs}$. each fed on corn and the increase credited at 4 cents per pound brought me 34 cents per bushel for the corn.

In January, 1876, 54 pigs weighing 254 lbs. each were fed on corn and the increase figured at 4 cents per pound made me $39 \mathrm{~S}-10$ cents per bushel for the corn fed.

In October, 1877, 34 hogs weighing 302 lbs. each were fed new corn and made me 49 cents per bushel with live hogs worth 4 cents per pound.

The average of these four experiments gave me 37 cents per bushel for corn made into pork at 4 cents per pound, live weight; or, in other words, if the corn were figured at 35 cents per bushel the pork cost $\$ 3.78$ per 100 lbs., live weight. 
Wisconsin station work.-The Wisconsin Report of 1885 , pages 34,35 , and 36 , gives the results of some experiments showing the cost of producing pork with corn-meal at $\$ 16$ per ton to have been 4.3 cents per pound; with wheat shorts at $\$ 14$ per ton it cost 3.7 cents, and with a mixture of one-half each corn-meal and wheat shorts it cost 3.3 cents. With corn at 35 cents per bushel and wheat shorts at 70 cents per 100 lbs., the ration being two parts corn and one part shorts, the cost per pound of jncrease was 4.1 cents in one instance and with another lot with the same feed the cost was 4.4 cents. The same lots immediately following these experiments were fed on corn at 35 cents per bushel and made pork at a cost of 4.8 cents and 4.6 cents.

In the Wisconsin Report of 1888, page 109, it is recorded that the work with whole corn at 35 cents per bushel made the gain cost 4.9 cents per pound. On the same page the work shows wheat shorts at 70 cents per 100 lbs. to have made pork at a cost of 3.6 cents. Where two parts corn and one part shorts were fed, corn being 35 cents per bushel and shorts 70 cents per 100 lbs., the cost of gain was 3.85 cents per pound. When two parts shorts and one part corn was fed the cost was 3.25 cents per pound.

On page 111 of the same report the average of three experiments with whole corn is given 
as 35 cents per bushel. The pork cost 4.9 cents per pound live weight. In five experiments with corn-meal in summer at 80 cents per 100 lbs. the pork cost 4.29 cents, and in three experiments with corn-meal in winter it cost 4.14 cents per pound, live weight, to produce pork.

Illinois station work.-The Illinois Experiment Station, in "Bulletin No. 16," gives the results in tabulated form of sixteen experiments made in feeding corn alone to pigs. These experiments were made in nine different months of the year and show excellent work. The average of the sixteen lots showed $11 \frac{1}{2} \mathrm{lbs}$. live weight made from $56 \mathrm{lbs}$. of corn. With corn worth 35 cents per bushel this would make pork cost a trifle over 3 cents per pound. The poorest results were obtained from work done in January, which showed $6.93 \mathrm{lbs}$. from one bushel of corn fed to pigs weighing $108 \mathrm{lbs}$. each. The next poorest results were obtained in June, July and August, and showed 8.28 lbs. per bushel of corn fed to pigs weighing $208 \mathrm{lbs}$. each. The third poorest result was in July, and showed $8.66 \mathrm{lbs}$. per bushel fed to pigs of 223 lbs. weight. The best work was done in December, and showed $16.81 \mathrm{lbs}$. from one bushel of corn.

Virginia station work.--The Virginia Experiment Station, in "Bulletin .No. 10," found it to cost 5.3 cents per pound to produce pork 
with corn-meal at $\$ 20$ per ton. On this basis if the corn-meal had been $\$ 16$ per ton the pork would have cost $4 \frac{1}{4}$ cents per pound live weight.

Average farmer's work.-I am confident the average farmer feeding corn alone makes very little if any profit in producing pork on a basis of 35 cents per bushel for corn and $\$ 4$ per $100 \mathrm{lbs}$. live weight for hogs. There are short periods, for instance with hogs that have been at pasture or that have been having a part ration of skim-milk or when being fed new corn before it becomes hard, that there may be and is a good profit at the above-mentioned prices of corn and pork. On the other hand there are times when hogs have been fed an exclusive corn diet for several months that there is a severe loss at above-mentioned prices of corn and pork. We cannot expect the average farmer to do as good work feeding as the experiment stations, but we have farmers that can and do get equally good results.

Prof. Cooke's opinion.-In the 1892 report of the Vermont Experiment Station Prof. W. W. Cooke says: "It would be a proper method of accounting to take out from the amount received for the pork made the cost of the grain food and consider the balance as what was received for the skim-milk." $\mathrm{He}$ also says: "The only reason for keeping and feeding the 
pigs was to serve as a method of utilizing the skim-milk."

Credit skim-milk. - If I am right in my conclusions that there is little if any profit in producing 4-cent pork from 35-cent corn it will be just and fair to credit skim-milk with the profit that comes with feeding a combination of skim-milk and grain food when the growth is credited at 4 cents. When pork is worth more than 4 cents, as it frequently or generally is, we are on a new basis and both grain food and skim-milk will receive more credit.

Feeding sow with pigs.-In 1878 I made some experiments with feeding pigs, taking a litter of eight pigs and their dam when the pigs were twelve days old. The dam weighed 290 lbs. and the eight pigs 61 lbs., making a total of 351 lbs. Eighteen days later the dam weighed $295 \mathrm{lbs}$. and the eight pigs $112 \mathrm{lbs}$., a total weight of 407 lbs. This was a gain in eighteen days of 56 lbs. worth 4 cents per pound, or $\$ 2.24$. They were fed $141 \mathrm{lbs}$. of corn-meal and wheat bran worth $\$ 14$ per ton, or 98 cents. They were also fed $530 \mathrm{lbs}$. skimmilk. We will deduct from the value of the increase weight $(\$ 2.24)$ the cost of meal and bran ( 74 cents) and we have $\$ 1.26$ for the 530 lbs. skim-milk, or $234-5$ cents per $100 \mathrm{lbs}$. of skim-milk.

Same pigs at $40 \mathrm{lbs}$.- June 8 the eight pigs 
weighed 327 İbs. June 21 they weighed 423 lbs. - a gain of $96 \mathrm{lbs}$. in thirteen days which was worth 4 cents per pound, or $\$ 3.86$. They were fed $217 \mathrm{lbs}$. of corn which at 35 cents per bushel would be worth $\$ 1.36$, which deducted from $\$ 3.86$ would leave $\$ 2.48$ to the credit of the $439 \mathrm{lbs}$. of skim-milk, or $56 \frac{1}{2}$ cents per 100 lbs.

We will take this $\$ 3.84$ which we get for the 96 lbs. of growth at 4 cents per pound and charge up the corn fed at 50 cents per bushel: $3 \frac{7}{8}$ bushels at 50 cents would amount to $\$ 1.93$, which deducted from $\$ 3.84$ would leave $\$ 1.91$, or 43 cents per $100 \mathrm{lbs}$. for the $439 \mathrm{lbs}$. of skimmilk fed.

Let us figure this another way. We will suppose $200 \mathrm{lbs}$. of skim-milk equal to one bushel of corn, and we have 3.87 bushels of corn, and the $439 \mathrm{lbs}$. of skim-milk would equal 2.19 bushels, making 6.06 bushels, for which we received $\$ 3.84$, or 63 cents per bushel.

Now charge the pigs with the skim-milk at 25 cents per $100 \mathrm{lbs}$. and the corn at 35 cents per bushel and we have the following account:

439 lbs. skim-milk at 25 cents.................. \$1.10

$3 \frac{7}{8}$ bushels of corn at 35 cents....................... 1.35

Cost of the 96 lbs. growth................... $\$ 2.45$

Cost per pound of growth..................... $02 \frac{1}{2}$

Same pigs at 125 lbs. weight.-This bunch of pigs after reaching a weight of $125 \mathrm{lbs}$. made 
growth at a cost of 2.64 cents per pound with corn figured at 35 cents per bushel and skimmilk at 25 cents per 100 lbs.

I was a farmer when I did this work and am a farmer yet, but do not now milk the cows and feed the pigs and calves as I did when living on the farm.

Wisconsin experiments. - The Wisconsin report of 1888, page 92 , gives some interesting reports of work done in feeding corn-meal and skim-milk, also whole corn and skim-milk. A saving of about 10 per cent was found by grinding the corn into meal, which amount scarcely paid for the grinding. Taking the figures and charging up the corn-meal at 80 cents per 100 lbs. and crediting 4 cents per pound for the increase in weight made and giving the skimmilk credit for all the profit made, we have as follows: 183 lbs. sweet skim-milk and $366 \mathrm{lbs}$. corn-meal made 100 lbs. gain; 366 lbs. cornmeal at 80 cents per $100 \mathrm{lbs}$. equals $\$ 2.93$, to be deducted from $\$ 4$, the price of the 100 lbs. gain, and we have $\$ 1.07$ to the credit of the $183 \mathrm{lbs}$. of sweet skim-milk, which is 58 cents per 100 lbs. This lot of hogs averaged 288 lbs. Another lot averaging $204 \mathrm{lbs}$. each, fed at the same time and in exactly the same way, made 40 cents per $100 \mathrm{lbs}$. for the sweet skim-milk. Work done at the same time in feeding sweet skim-milk and whole corn, estimating the corn. 
at 40 cents per bushel and allowing 4 cents per pound for the increase and crediting the skimmilk with the whole profit, gives us 50 cents per $100 \mathrm{lbs}$. for it. The hogs were fed two pounds of grain food to each pound of skimmilk. The Wisconsin experimenters did not figure the trial in this way. I have taken the responsibility of putting their work in this shape. They may well feel proud of their work in this line.

On page 96 of the Wisconsin report of 1888 is a statement of the results of feeding different amounts of sweet skim-milk and corn-meal to pigs. In this work there were three lots of pigs of three each. Lot A was fed $350 \mathrm{lbs}$. of sweet skim-milk to $100 \mathrm{lbs}$. of corn-meal. Lot $B$ was fed $100 \mathrm{lbs}$. of sweet skim-milk to 110 lbs. of corn-meal. Lot $\mathrm{C}$ was fed $100 \mathrm{lbs}$. of sweet skim-milk to 300 lbs. of corn-meal. Figuring the corn-meal to be worth 80 cents per $100 \mathrm{lbs}$. and the skim-milk 25 cents per $100 \mathrm{lbs}$, the cost of the increase was as follows:

Lot A, fed 350 lbs. sweet skim-milk to $100 \mathrm{lbs}$. corn-meal, cost......................3 cts. per lb.

Lot B, fed $100 \mathrm{lbs}$. sweet skim-milk to $110 \mathrm{lbs}$.

corn-meal, cost....................

Lot C, fed 100 lbs. sweet skim-milk to $300 \mathrm{lbs}$.

corn-meal, cost.....................

Prof: Henry says: "This trial shows that to produce pork rapidly a large proportion of milk to corn-meal may be fed, but that such feeding 
is not the most economical when cost of product is considered, and that one pound to one pound and a half of milk to one pound of cornmeal is as much as can be profitably fed when milk is valued at 20 to 25 cents per $100 \mathrm{lbs}$. and corn-meal at 75 cents per $100 \mathrm{lbs} . "$

old and young animals.-The Wisconsin report of 1859 , page 24 , gives some results of work done to show the value of skim-milk fed to mature versus growing hogs.

With lot 1 , hogs weighing $400 \mathrm{lbs}$, it required 1,430 lbs. of skim-milk and 301 lbs. of corn-meal to produce $100 \mathrm{lbs}$. increase. Crediting the increase at 4 cents per pound and charging 80 cents per $100 \mathrm{lbs}$. for the corn-meal, we have 11 cents per $100 \mathrm{lbs}$. left for the skim-milk fed.

With lot 2, hogs weighing $144 \mathrm{lbs}$, it required $1,024 \mathrm{lbs}$. of skim-milk and 174 of corn-meal to produce $100 \mathrm{lbs}$. live weight. Figuring this on the same basis as lot 1 , we secure 25 cents per 100 lbs. for the skim-milk.

These figures illustrate the facts so often brought out, that to do profitable work we must have young and growing animals.

Before and after weaning.-In the 1889 Wisconsin report is recorded some very valuable work in feeding pigs before and after weaning. In these trials there were four lots of pigs. The experiment made before weaning continued from 55 to 64 days, the sows being 
weighed with the pigs. They were fed cornmeal and shorts and skim-milk. Figuring the corn-meal and shorts at $\$ 14$ per ton and the sweet skim-milk at 25 cents per 100 lbs., the growth cost as follows:

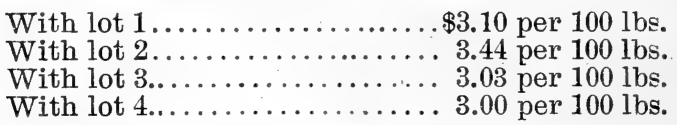

Figured on the same basis after weaning the growth cost as follows:

Lot $1 \ldots \ldots \ldots \ldots \ldots \ldots \ldots . . \ldots 3.23$ per $100 \mathrm{lbs}$.

Lot $2 \ldots \ldots \ldots \ldots \ldots \ldots \ldots \ldots . . .2 .95$ per $100 \mathrm{lbs}$.

Lot $3 \ldots \ldots \ldots \ldots \ldots \ldots \ldots \ldots 261$ per $100 \mathrm{lbs}$.

Lot $4 \ldots \ldots \ldots \ldots \ldots \ldots \ldots .2 .60$ per 100 lbs.

The trial after weaning covered from 30 to 46 days.

Figuring the gain made by these pigs at 4 cents per pound, and deducting therefrom the cost of the ground feed at $\$ 14$ per ton for cornmeal and shorts, half of each, thereby giving the skim-milk credit for all the profit, we find that in the work before weaning we receive 30 cents, 40 cents, 41 cents and 43 cents per 100 lbs. of sweet skim-milk, and after weaning on the same basis we receive 38 cents, 43 cents, 51 cents and 55 cents per 100 lbs. of skim-milk.

We have found in one instance that $400-1 b$. hogs paid us 11 cents per 100 lbs. for skim-milk, and in other cases we have found with pigs about three months old that we received as 
high as 50 cents per 100 lbs. of skim-milk. How much of this do we poor mortals need to get ourselves in the proper condition to receive good from such work? Let us not sit down and say we cannot accomplish any such work, for we can. Some of us have done it and more of us can when we go about it intelligently.

New Hampshire station work.-The New Hampshire Experiment Station, "Bulletin No. 11," gives some valuable work on pig-feeding. Every hog-raiser in the country should read it. It gives the results of feeding skim-milk and corn-meal versus corn-meal and middlings. The work commenced with pigs six weeks old and weighing $28 \mathrm{lbs}$. each. The experiment commenced Sept. 3 and ended Jan. 14, extending over four and one-third months' time and at a season of the year that gave a fair average of temperature. At the commencement of the experiment skim-milk is assumed to be worth 25 cents per $100 \mathrm{lbs}$; later in the work the results are figured so as to show the actual value of the skim-milk.

A valuable point.-The most noticeable point about the work is the marked superiority of the skim-milk and corn-meal ration over the corn-meal and middlings, notwithstanding the fact that the latter contained the most digestible matter. Another noticeable point is in- 
creased cost of producing pork as the pigs grew older.

Cost increases with age.-Lot 1, Sept. 3 to 24 , with skim-milk at 25 cents per 100 lbs. and corn-meal $\$ 20$ per ton, it cost .0258 to produce a pound's increase of live weight. With the same lot and same feed Oct. 15 to Nov. 5 it cost .035 per pound, and Dec. 10 to Jan. 24 it cost .0434. Lot 2 showed nearly the same results. The following is clipped from this bulletin:

With grain costing, as this did, $\$ 20$ per ton for corn-meal and $\$ 26$ for middlings such pigs as these were cannot be fed without loss when pork sells at 4 cents alive or 5 cents dressed.

With skim-milk, however, the case is different for two reasons: First, less "raw material," that is digestible matter, is required to produce a pound of growth, as shown below.

DIGESTIBLE MATTER PER 100 LBS. OF GROWTH.

Average digestible dry matter required to produce 100 lbs. gain:

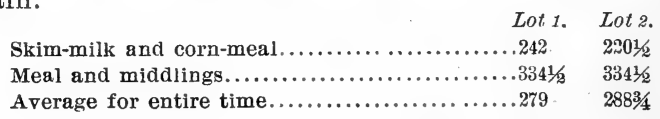

and secondly, because with skim-milk and corn-meal a greater quantity of food can be handled daily. Thus by both of these factors the time required for producing a 200-lb. pig is reduced very materially. This point is not sufficiently appreciated by many who feed pigs. With the present prices there is but one way in which pork can be produced at a profit and that is by producing a $200-1 b$. pig in the shortest possible time.

We see from Table II that the cost of growth and the amount of food required to produce $100 \mathrm{lbs}$. of growth increase as the pigs grow older, and it would have been much 
more profitable to have sold them when averaging $175 \mathrm{lbs}$. each than when averaging $240 \mathrm{lbs}$.

Thus far we have, for convenience, figured all results on the assumption that the skim-milk used was worth 25 cents per $100 \mathrm{lbs}$.

We will now see what its value actually was under the conditions of this experiment, the price of live hogs being 4 cents per pound and the cost of grain as previously mentioned.

For our present purpose we will neglect the first cost of the pigs and note the value of the gain of live weight for each period where skim-milk was used as a part of the ration:

TABLE IV.

\begin{tabular}{|c|c|c|c|c|c|c|c|c|c|c|}
\hline \multirow[b]{2}{*}{ 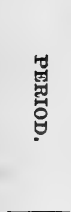 } & \multicolumn{5}{|c|}{ LOT ONE. } & \multicolumn{5}{|c|}{ LOT TWO. } \\
\hline & 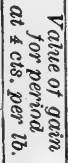 & 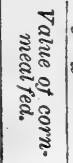 & 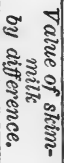 & 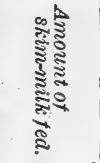 & 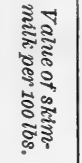 & 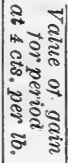 & 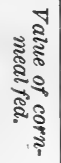 & 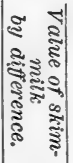 & 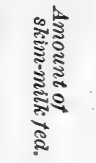 & 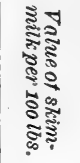 \\
\hline & $\begin{array}{r}\$ 2.32 \\
3.68 \\
9.68\end{array}$ & \begin{tabular}{r|}
$\$ 1.01$ \\
2.20 \\
7.28
\end{tabular} & \begin{tabular}{|r|}
$\$ 1.31$ \\
1.48 \\
2.40
\end{tabular} & $\begin{array}{r}196 \mathrm{lbs} . \\
406 \mathrm{lbs} . \\
1,295 \mathrm{lbs} .\end{array}$ & $\begin{array}{r}\$ 0.67 \\
361 / 2 \\
181 / 2\end{array}$ & $\begin{array}{r}\$ 3.58 \\
9.64\end{array}$ & $\begin{array}{r}\$ 1.68 \\
5.98\end{array}$ & $\begin{array}{r}\$ 1.90 \\
3.62\end{array}$ & $\begin{array}{r}294 \mathrm{lbs} . \\
1,116 \mathrm{lbs} .\end{array}$ & $\begin{array}{r}\$ 0.641 / 2 \\
.321 / 3\end{array}$ \\
\hline $\begin{array}{l}\text { Total. } \\
\text { Av'ge }\end{array}$ & $\$ 15.68$ & $\overline{\$ 10.49}$ & $\overline{\$ 5.19}$ & $1,897 \mathrm{lbs}$. & $\$ 0.271 / 3$ & $\overline{\$ 13.22}$ & $\$ 7.66$ & $\$ 5.56$ & $1,410 \mathrm{lbs}$. & \$ $\$ 0.391 / 2$ \\
\hline
\end{tabular}

This table is constructed by determining the value of the gain for each skim-milk period and subtracting therefrom the cost of the corn-meal which was fed with the skim-milk; the remainder represents the value of the skim-milk, which, divided by the amount, gives the value per $100 \mathrm{lbs}$. The showing is certainly a favorable one, and with thrifty pigs from 20 to 30 cents per $100 \mathrm{lbs}$. ought to be and can be realized for skim-milk when live hogs sell at 4 cents per pound. It must be constantly kept in mind, however, that they must be sold by the time they reach a live weight of from 200 to 230 lbs.

FEEDING WITH GRAIN ALONE.

Table $\mathrm{V}$ gives the results of feeding with corn-meal and midalings: 
TABLE V.

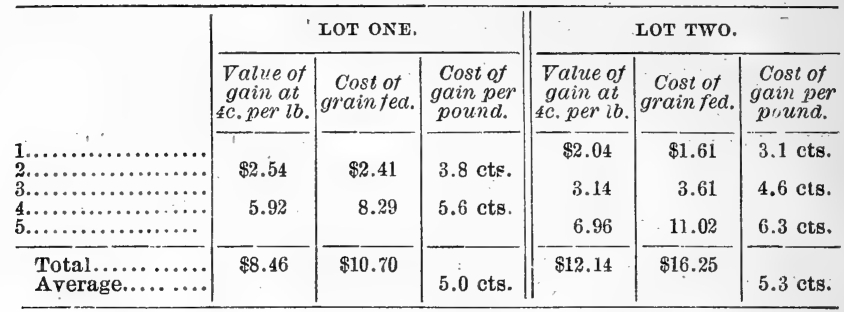

This table seems conclusive so far as these pigs were concerned, and we are obliged to say that on grain alone there was a loss of more than one cent for every pound of growth.

These results show us that we cannot blindly follow the teachings of feeding tables, for should we so do one of these rations would be as good as the other, but as a matter of fact, while chemically the skim-milk ration was not quite as rich in nutritive material as the grain ration, yet the former was, on an average, 30 per cent more efficient in actual results than the latter.

"Table IV" is a highly interesting and valuable one. Prof. Whitcher in the work here tabulated charges the corn-meal at cost and gives the skim-milk credit for the balance of the gain. This seems fair, as he shows in "Table V" that when corn-meal and middlings were fed the cost of producing was one cent per pound more than the increase made by the skim-milk was credited with.

In "Part II" of this bulletin F. W. Morse makes an interesting and instructive report of his work to determine the digestibility of rations. I wish again to call attention to the time this experiment covered-19 weeks. This 
makes it much more reliable and valuable than if it covered a short time. I use Prof. Whitcher's conclusions entire:

1. For each $100 \mathrm{lbs}$. of live weight eight pounds of skimmilk and four puunds of corn-meal make an ample and wellproportioned daily ration.

2. In the absence of skim-milk two and one-half pounds of corn-meal, two and one-half pounds of middlings, and eight pounds of water will give an equal amount of nutritive matter.

3. One hundred pounds of digestible matter in the skimmilk and corn-meal ration was equal to $146.9 \mathrm{lbs}$. in the cornmeal and middlings ration.

4. The superiority of the skim-milk ration is due in part, doubtless, to its greater digestibility; but still more, in my opinion, to the fact that there is less waste matter-that is indigestible matter-to be carried through the system, and to the noticeable aifference in the character of the dung, mentioned by Prof. Morse in "Part II" of this bulletin. The pigs on mixed grain invariably grew constipated, while those on skim-milk were not so affected.

5. The cost of a pound of gain on skim-milk and corn-meal was 3.6 cents, on mixed grain ration, 5.2 cents.

6. Digestible dry matter required to produce $100 \mathrm{lbs}$. of gain of live weight on skim-milk and corn-meal, $231 \mathrm{lbs}$, on mixed grain, $334 \frac{1}{2} \mathrm{lbs}$.

7. $\{$ Lot 1 when dressed shrunk 19.6 per cent.

7. $\{$ Lot 2 when dressed shrunk 18.4 per cent.

8. Calling skim-milk worth 25 cents per $100 \mathrm{lbs}$. and we get the following balance sheett, on the basis of the cost as given in "Conclusion No. 5":

30-lb. pig, first cost. ...................... $\$ 2.00$ $170 \mathrm{lbs}$. of growth on skim-milk and corn-meal, at $3.6 \mathrm{cts} .6 .12$

$\overline{200-1 b}$. pig cost $\ldots \ldots \ldots \ldots \ldots \ldots \ldots \ldots \ldots \ldots \ldots \ldots . . \ldots \ldots .12$ which equals 4.06 cents per pound.

30 -lb. pig, first cost...................... $\$ 2.00$ 170 lbs. growth on corn-meal and middings, at $5.2 \mathrm{cts} . .884$

$\overline{200-1 b .}$ pig cost...........................\$10.84 which equals 5.42 cents per pound. 
Massachusetts station work.-The Massachusetts Experiment Station has done a great deal of valuable work in the line of experimentation in pig-feeding. The following conclusions were drawn after closing its nineteenth experiment:

Briefly stated, from a practical standpoint, these two experiments and many others made at the station teach us the following lessons:

1. Skim-milk, together with corn-meal, gluten-meal, wheat bran, gluten feed, maize feed, etc., combined as above stated, have proved healthy and profitable foods for the production of pork for our markets.

2. With skim-milk reckoned at 1.8 cents per gallon, gluten feed from $\$ 21$ to $\$ 23$ per ton, and corn-meal at $\$ 23$ to $\$ 24$ per ton, we have been enabled in these experiments to produce dressed pork at from 4.6 to 5.3 cents per pound. The net cost of the dressed pork produced (obtained by deducting the value of the manure produced) was from 3.3 to 3.8 cents per pound.

3. Farmers having a quantity of skim-milk at their disposal can utilize it profitably by feeding it to growing pigs, as above described. If this milk can be sold, however, at 1 cent per quart, or more, it would undoubtedly be more profitable to sell it than to use it in the production of pork.

4. Experiments made at this station have proved that it is not profitable to feed pigs after they reach a weight of 180 to $190 \mathrm{lbs}$, excepting perhaps when pork commands an exceptionally high price. Fed beyond this weight the food consumed increases and the percentage of gain in live weight steadily decreases, so that the daily cost of food consumed is more than the value of the daily increase in weight. This fact has since been confirmed by other stations.

Ex-Gov. Hoard's work.-Several years ago ex-Gov. Hoard made an experiment in feeding skim-milk to pigs. The pigs weighed $100 \mathrm{lbs}$. 
each and cost $4 \frac{1}{2}$ cents per pound. They were fed 56 days on clear skim-milk which was weighed to them daily and fed sweet. At the end of 56 days they were sold and the growth figured at $4 \frac{1}{2}$ cents per pound paid $22 \frac{1}{2}$ cents per $100 \mathrm{lbs}$. of skim-milk fed. As Gov. Hoard says, this work was not done under the best conditions nor in the most economical way, as it would without doubt have paid better to feed some kind of grain food with the skim-milk.

C. P. Goodrich's work.-Mr. C. P. Goodrich of Fort Atkinson, Wis., kindly gave me the results of some experimenting he did in feeding pigs.

A bunch of six-months-old pigs weighing 125 lbs. each were divided into three lots as nearly equal as practicable.

Lot 1 was fed entirely on skim-milk and made 5 lbs. growth from 100 lbs. of skim-milk.

Lot 2.was fed entirely on cor'n and made 10 lbs. growth from one bushel of $70 \mathrm{lbs}$. of ear coln.

Lot 3 was fed skim-milk and corn in proportion of one bushel of corn to 100 lbs. of skimmilk. This combination produced $18 \mathrm{lbs}$. of growth. This illustrates very nicely the economy of feeding a combination ration. When the bushel of corn and the $100 \mathrm{lbs}$. of skim-rnilk were fed separate they made 15 lbs. of growth; when combined they made 18 lbs. of growth, 
Here is 20 per cent better results obtained from the combination of foods. And this is not all the meat in this nut by any means, as the farmer can feed three times as many pigs when he feeds one bushel of corn to 100 lbs. of skimmilk as he can when he feeds clear skimmilk, as the bushel of corn has in this case twice the feeding value of the $100 \mathrm{lbs}$. of skimmilk. I think it is fair to conclude from this work that there is twice the profit when the skim-milk is fed with the proper amount of grain food than when fed alone. This is in line with my own experience and also with much experiment station work. Mr. Goodrich is a farmer and did this work for his own information.

Salt, ashes, and copperas.-Keep a mixture of ashes, salt, and copperas by the pigs and hogs at all times. Mix one bushel of ashes, eight quarts of salt, and four quarts of copperas. Put in a trough where it is dry and accessible at all times. It will keep them clear of worms and lice and help promote thrift. My hogs consume a barrel of copperas annually.

Skim-milk for calves.-Skim-milk as a food for calves, and especially separator skim-milk, is underestimated very much by dairymen in general. I teach the calves to drink their mother's milk. The calf must have the first milk from its mother if not allowed to suck. 
The milk must be fed the calf when drawn. This is a law of Nature and must not be ignored. If it is there will be trouble and the calf injured or ruined. My calves are fed new milk for a few days; then we begin to mix some skimmilk and increase it until the new milk is dropped entirely.

Rules for calf-feeding.-There are a few simple rules to follow in growing calves on skim-milk and there will seldom be any trouble. The milk must be sweet; it must be as warm as the mother's milk, or 98 deg., and care must be exercised not to feed too much milk. Four quarts at a feed twice per day is sufficient for the average-sized calf for the first month. Add a spoonful of oil-meal to each feed of milk. Let them eat what oats or shorts and hay they will. Oats are an excellent feed for young calves. Never feed a young calf cold milk. Many times calves are injured by being fed too much milk, especially skim-milk. Many persons apparently think that because the cream is taken out they need to feed more of it. This is a mistake. Overfeeding causes the calf to scour. This is the greatest cause of scours.

Remedy for scours.-The calves must be watched and when there is a tendency to looseness of the bowels feed less milk. If this does not remedy the trouble heat some skim-milk to the boiling point, then cool it and feed the calf. 
If taken in time this will check it. I raise about thirty heifer calves every winter on separator skim-milk and have not had an unthrifty calf in two years. Linseed-meal is an excellent food to use with skim-milk. My practice is to add a spoonful to the milk at the time it is fed.

Keep calves dry.-Great care must be taken to keep the calves dry at all times. This requires a large amount of bedding. Calves will not thrive unless kept dry. I have had grade Short-horn calves gain two and one-half pounds each per day when four to five months old and were fed skim-milk, corn-meal and timothy hay. These were steer calves that were fed for veal. My heifer calves that I raise for cows I do not want to get fat, but keep them in a thrifty condition and growing all the time until they become mothers. A bunch of nice, thrifty calves is one of the prettiest sights on a farm.

Massachusetts station work.-The Massachusetts Experiment Station after a number of years' experiments (one object of which was to learn the value of skim-milk as a pig food) commenced some work to learn the value of skim-milk as a food for young calves. In this work there were seven calves, each kept, weighed, and fed independent of the others, so there were seven trials going on at the same 
time. A summary of results shows that when live weight sells for four and one-half cents per pound the average of the seven calves returned three-fourths of a cent per quart for the skimmilk fed. This would be the same as 35 cents per 100 lbs. These calves were fed ten weeks and gained an average of one and one-half pounds per day.

Dr. Groessman's comments on the results I use entire:

The experiments have shown that calves grown upon skim-milk alone or upon skim-milk and grains during the first eight weeks of their lives make good gains in live weight, namely, from 0.9 to 2.13 lbs. per day, with an average of $1.49 \mathrm{lbs}$. These animals, however, put on very little fat, either when fed on skim-milk alone or when fed on skimmilk and grains. They were not able to digest the necessary amount of corn-meal, Buffalo gluten feed, or wheat flour or middlings, when fed in connection with the nitrogenous milk, to promote the formation of fat.

The meat of the animals thus described was quite white in appearance, but not as tender as calves that were fed whole milk. The ribs and flanks of animals thus fed were thinner than those consuming whole milk, and the shrinkage in dressing is from 5 to 7 per cent more.

Butchers offered from 4 to $4 \frac{1}{2}$ cents per pound of live weight, whole-milk veal being worth at the time $5 \frac{1}{2}$ to 6 cents per pound. It is to be remarked, however, that at retail as much per pound was charged for the skim-milk as for the whole-milk veal. It will be noticed that when skimmilk veal, so called, brought 4 cents per pound of live weight, an average of 0.63 of a cent per quart, or 2.52 cents per gallon, was obtained for the skim-milk fed; while when live weight brought $4 \frac{1}{2}$ cents per pound the return for the skimmilk was 0.76 of a cent per quart, or 3 cents per gallon. When the skim-milk was fed to pigs, and dressed pork 
brought $5 \frac{1}{2}$ cents per pound, there was a return of 0.2 of a cent per quart for the milk; and when dressed pork brought 7 cents per pound, 0.6 of a cent was obtained per quart for the milk and 0.7 of a cent was obtained when dressed pork brought $7 \frac{1}{2}$ cents per pound.

These results are interesting and instructive, and worthy of the careful consideration of dairy farmers. It must be admitted that calves require rather more attention than pigs. The milk must not be sour and must be fed warm, and their condition must be carefully watched lest they be attacked with scours. A small quantity of lime water added to the milk at each feeding seems to act as a preventive.

No beneficial results were noticed when cod-liver oil was fed in small quantities to calf 7. Its smell and taste were obnoxious to the calf, and quite often he refused the milk containing it.

The experiment indicates that in order to secure the greatest profit it is not wise as a rule to feed calves as above described after they have reached $160 \mathrm{lbs}$. of live weight. The daily gain decreases and the food consumption steadily increases, so that the commercial value of a pound of live weight is about balanced by the cost of the food consumed to produce it.

This experiment is presented as the beginning of a series designed for the purpose of studying the most economical way in which to feed skim-milk to growing calves, especially to calves intended for veal. Whole milk forms a complete food for calves, and by its use they can be sold from five to seven weeks from birth in a fat condition. How to secure a food equal in its effect to whole milk by utilizing the skimmilk and substituting a cheaper fattening material in place of the cream removed, is the problem for future solution.

Indiana station work.-The Indiana Experiment Station "Bulletin No. 47," November, 1893, reports the results of four experiments made in feeding calves. In experiment No. 1 were two calves, one of which was fed skim- 
milk and one whole milk. They were fed 62 days. The one fed skim-milk consumed 19.3 lbs. per day and gained 78 lbs. in 62 days, a daily gain of $1 \frac{1}{4} \mathrm{lbs}$. The calf fed whole milk drank 11.9 lbs. per day and gained 73 lbs. in 62 days, a daily gain of 1.17 lbs.

Estimating the skim-milk at 25 cents per 100 lbs. the 78 lbs. of growth on this calf cost $\$ 3$; cost per pound, $3 . S 4$ cents. With the calf fed whole milk, estimating it to be worth $\$ 1$ per $100 \mathrm{lbs}$, the $73 \mathrm{lbs}$. of growth cost $\$ 7.42$, or over 10 cents per pound. These calves were both pure-bred Jerseys. There was but one day's difference in their ages. The one fed skim-milk was a male and the one fed whole milk a female.

In experiment No. 2 pure-bred HolsteinFriesian male calves were used. These calves were fed 61 days. The calf on skim-milk diet was fed 23.5 lbs. per day and gained $1.77 \mathrm{lbs}$. per day. The calf fed whole milk drank 17.6 lbs. daily and gained 1.67 lbs. per day. In this experiment with the calf fed skim-milk the growth cost $3 \frac{1}{3}$ cents per pound, estimating the skim-milk at 25 cents per 100 lbs., and the calf fed whole milk made growth at a cost of $10 \frac{1}{2}$ cents per pound, estimating the milk to be worth $\$ 1$ per 100 lbs.

Two other experiments were made in which skim-milk only was fed. Prof. Plumb says in closing: 
Taking the average result of the above six calves fed skim-milk, $15.6 \mathrm{lbs}$. skim-milk produced a gain of $1 \mathrm{lb}$. live weight.

Will it pay to feed calves simply skim-milk as has been done in the above examples? The six calves consumed 9,345 lbs. of skim-milk to make a gain of $598 \mathrm{lbs}$. This increased gain in this locality would sell for five cents a pound, or $\$ 29.90$. The milk drank, estimating its market value at 15 cents per $100 \mathrm{lbs}$., would cost $\$ 14.02$, showing a difference of $\$ 15.88$.

The writer believes that a still greater gain would have been made by these calves if the fat removed from the milk had been replaced by flaxseed or some other substitute.

Taking the growth of these six calves-598 lbs., worth 5 cents per pound-we have $\$ 29.90$ to be credited to the 9,345 lbs. of skim-milk, which is 32 cents per $100 \mathrm{lbs}$.

Mississippi station work.-The Mississippi Experiment Station (report of 1888, page 43) found that calves receiving $10 \mathrm{lbs}$. of skim-milk made nearly as large gains as those receiving 8 lbs. of whole milk.

Iowa station work.-The Iowa Experiment Station in "Bulletin No. 14" reports the cost of producing a pound of gain (estimating new milk at 87 cents per 100 lbs., skim-milk at 15 cents per 100 lbs., grain at 1 cent per pound, hay at $\$ 5$ per ton, and flaxseed-meal at $3 \frac{1}{2}$ cents per pound) was 7.6 cents for the fresh milk and 5 cents for the skim-milk ration.

Pennsylvania station work.-The annual report of the Pennsylvania State College for 1891 gives the results of work done with whole 
milk and skim-milk fed to calves. In the summary of results they say: "Counting whole milk at $\$ 1$ per 100 lbs. and skim-milk at 12 cents per 100 lbs., it cost 9.9 cents to make a pound of increase when whole milk was fed, and 3.4 cents to make a pound of increase when skim-milk was fed."

Separator milk good.-The Vermont Experiment Station Report of 1891 says: "There is a belief quite prevalent among certain classes that the separator has some mysterious influence on the skim-milk to make it of different quality from the skim-milk of ordinary setting. This difference is considered to extend not merely to the fat but to influence the other ingredients. To ascertain the truth of the matter three samples of milk were tested before and after being run through the separator." After concluding the work with the samples the station _says: "It is evident from these figures that the milk serum is not influenced by the separator and that the only difference between the whole milk and the skim-milk derived from it is in the amount of fat they contain."

Buttermilk.-There is probably very little difference in the feeding value of skim-milk and buttermilk. Some farmers prefer buttermilk to skim-milk. One reason for this is that it does not curdle and separate so quickly as 
skim-milk. Another reason is that previous to the introduction of the Babcock test the buttermilk contained considerable more fat than the separator skim-milk did. At the present time with skill at the cream vat and churn there is not much difference in the percentage of fat in the two. Some may ask what the Babcock test has to do with the churn? A great deal. With it we tested the buttermilk daily and commenced to investigate for the causes of the differences in different day's work until we are able to churn nearly as close as we can skim.

Buttermilk should be fed carefully to young pigs, as it is more apt to physic than skim-milk is. Especially is this the case with buttermilk from the shallow-setting system. I nearly ruined a bunch of fifty pigs before learning this. Since that time I have found old farmers who had known this for a long time. Buttermilk can be safely fed to calves by changing gradually from whole or skim-milk, but the change must be gradual or there will be trouble.

The figures on the following page from the Vermont Experiment Station report of 1891 show the analyses of skim-milk and buttermilk.

This work shows the skim-milk to have a larger percentage of total solids than the buttermilk, but the buttermilk has the largest per cent of fat. The skim-milk has a trifle the 


\section{SKIM-MILK.}

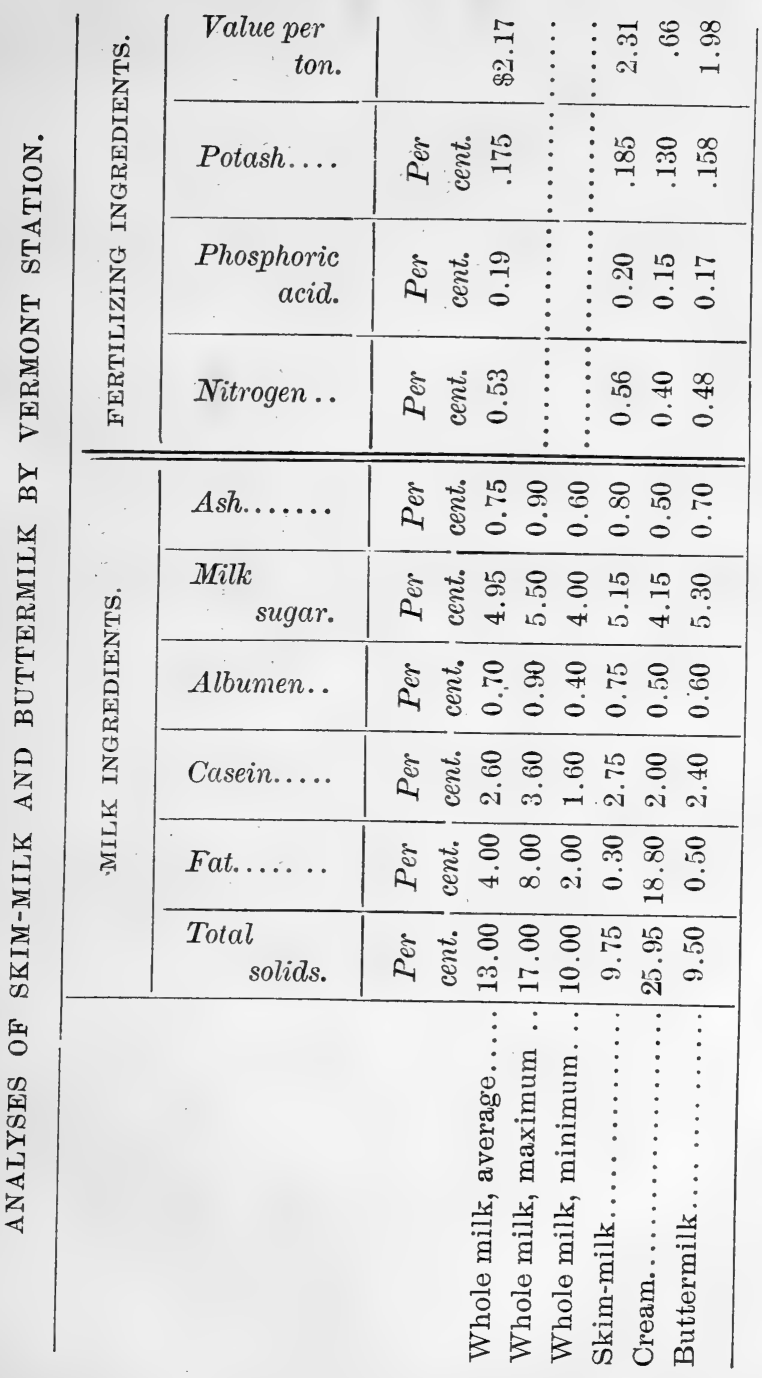


most casein, albumen, and ash, while the buttermilk has the most milk sugar.

Analyses made at the Massachusetts Experiment Station show the average total solids of skim-milk to be 9.48 per cent and of fat 0.39 per cent, and the average total solids of buttermilk were 8.33 per cent and of fat 0.27 per cent.

Experiment station work.-The work done by the experiment stations of the United States with the object of showing the feeding value of skim-milk and buttermilk as a food for calves and pigs would make a good-sized book and I should like to have this work all gathered into one book. The fact that the experiment stations have done so much work in this line is evidence to me that they believe as I do-that is, that the feeding value of skim-milk is not appreciated by the average dairyman.

I am anxious to have some work done to show the comparative value of sweet skim-milk and rotten sour milk, such as the patrons of a creamery get where the milk is allowed to run into an underground vat that is seldom empty and never cleaned. There are comparatively few creameries that handle their skim-milk in this way, but those that do ought to be court martialed. 


\section{PART II--CREAMERY WORK.}





\section{CHAPTER I.}

\section{CARE OF MILK BY PATRONS.}

Cooling.--As fast as dlawn the milk should be strained and some system of cooling and aerating applied to it. A cooler like the Star cooler is very efficient for this work. It can be

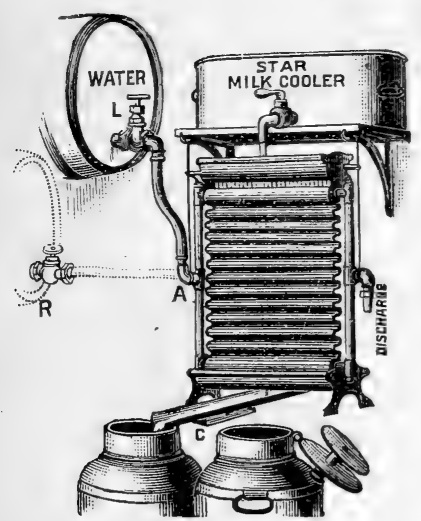

STAR COOLER AND AERATOR.

purchased of any dairy implement dealer. It will cool the milk within a few degrees of the temperature of the water used and aerate at the same time.

Aerating.-When the milk cannot be both cooled and aerated it can certainly be aerated, as that does not require water. When aerating be careful that it is done in a good atmosphere, as it is possible to do the milk more harm than good if the atmosphere is impure. The general practice in locations that I am familiar with is for patrons of creameries, con- 
densed-milk factories, and milk shippers to have the cans set in cold water (running water if it can be had) and the milk agitated while cooling.

Agitation. - A tin disc four inches in diameter, with a galvanized wire handle about thirty inches long and used like a churn dash, is an excellent device to agitate milk when cooling.

Vat for cans.Have a wooden vat a few inches wider than the cans and deep enough to have the water come as high as the milk in the can. With frequent agitations during the time of milking the milk

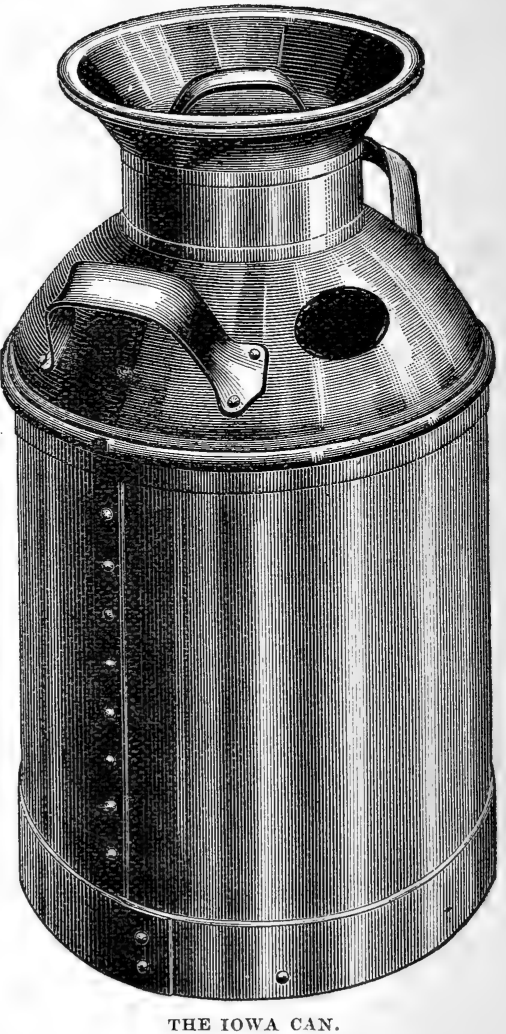

can be thoronghly cooled with but little time spent about it.

As the milker goes to the vat with milk he 
should agitate the milk that is already cooling, and in this way it is nearly all cooled when the milking is done.

Do not mix.-The night's and morning's milk should not be mixed; it should be kept in separ'ate cans. If from any cause it is necessary to mix the two milks they should be thoroughly cooled first. The Elgin condensed-milk factories require their milk to be cooled quickly to $55 \mathrm{deg}$. and to be delivered at the factory at a temperature of $60 \mathrm{deg}$. or below. This is an important part of the patron's work, as the creamery cannot make fine butter out of barl milk. It is a part of the work that patrons are inclined to neglect, and they apparently think that if their milk passes the weigh can they are all right. They are half right, as the man at the weigh can should not receive milk that is not all right.

Return bad milk.-It should be returned to the patron as often as is necessary to teach him that bad milk will not pass. The creamery man must do this to protect himself and the other patrons, as one patron's bad milk would act as a ferment for the whole vat of milk and there would be off-flavored butter, making a loss for some one and a loss of reputation to - the man operating the creamery, as poor butter will not pass on the good reputation of the maker. 
Unnecessary loss.-I have in my mind a creamery that lost over four hundred dollars in one month through poor butter. The cause I do not know, but it could have been prevented, no matter what the cause, for if none but good milk had been received and the work properly done the butter would have been all right and the loss would not have occurred. Now the party must establish confidence in his goods again after he has overcome the trouble, and his customers will be a long time in regaining full confidence, as they will think he stumbled once and may again. Perhaps this is not quite in place here, but I write it to show patrons that they have a responsibility in the matter beyond simply getting their milk into the weigh can.

Spring wagons necessary.-Milk should be drawn to the creamery or its destination in a spring wagon to prevent churning and to save the cans. I have seen milk that had been drawn a long distance without springs that had become churned and butter was floating on the top. This makes a loss, as the butter thus churned cannot be utilized. The saving in cans and on horses will pay well for the springs.

Canvas covers. - All milk delivery wagons should have a cover of some kind. A canvas or ducking cover will do good service and is quite generally used as a protection in summer 
from heat and in winter from cold. Be cleanly about your work and deliver your milk in prime condition, and then you have a right to demand good returns. Very few realize how susceptible milk is to absorbing any impurities there may be in the atmosphere.

Milk absorbing odors.-In one instance I found milk that was not just right and I could not tell positively what the trouble was until I took some of it and warmed to 110 deg., when I could detect the odor of the hog-pen. I sent word by the driver of the load for the man to come in, as I wanted to see him. When he came I learned from him that he put his night's milk in an open vat in a room a short distance from his hog-pen and left the windows open to cool the room. The result was that when the wind blew from the hog-pen toward the milkhouse the milk received the hog-pen odor and brought it to the creamery. A gentleman in Vermont told me of his experience with a skunk around the milk-house. When his butter arrived in Boston his commission man detected the skunk odor in the butter.

Bad conditions.-Milk will not only absorb impurities after being drawn from the cow, but it may be spoiled before by filthy surroundings of the cow. I have known of milk being spoiled by the carcass of a dead animal lying in the cow pasture. I once traced trouble with 
my butter to a row of calves that were tied in front of the cows of a patron and were not kept clean or dry. This impure atmosphere that the cows were breathing contaminated the milk. The butter was not very bad when new but it went to the bad at a very rapid rate, and in a few days was not fit to use.

After the milk is thoroughly cooled, if to be kept in a pure atmosphere leave the can covers off, but if the air is not good put the covers on the cans, or what is better, remove it to some place where the air is good. Very few dairymen realize how readily milk absorbs odors. To unbelievers I would say to convince you, take an open dish with milk in it and put it in some place exposed to bad odors for a few hours; then war'm the sample of milk to a temperature of 110 or $120 \mathrm{deg}$. and you will find that a person who is acquainted with the odor it has been exposed to can tell you where the milk has been. There are plenty of places where you can put this milk to make the test; for instance, in the vegetable cellar or by the cook stove when cooking vegetables, or you may set it away with the kerosene oil-can. I advise all that are skeptical on this point to try it. Do not say you do not believe it. That proves nothing. I once traced bad-flavored milk to hay from the bottom of a mow where it had lain on the ground and become moldy. 
I remember in my early experience of buying butter at my grocery store that I could taste mayweed in very distinctly. How that flavor got there I never learned but supposed the cows ate the weed.

An object lesson.-At a dairy school in 1892 we one day let a can of bloody milk go into the day's work to show the class the result. We found bloody matter on the wall of the separator and a very bad flavor to the cream the next morning. We also found the same flavor in the butter, and we immediately disposed of the butter on its merits.

I think I have given enough facts about the susceptibility of milk and cream to absorb odors from the surrounding atmosphere to convince any unbelievers. If not they must be convinced by some one else or go their own way until they get an experience that costs them enough to cause them to remember it. Many of us are so constructed that we cannot profit by others' experience; we do not appreciate information that costs us nothing. 


\section{CHAPTER II.}

\section{RECEIVING MILK AT CREAMERY.}

The person receiving milk at a creamery is filling an important position. A lack of care, good judgment, or decision may cause trouble with all the work in the creamery. It requires constant care to hold the patrons up to grade with their milk so far as condition goes. There are always a few negligent ones that must be watched, as they will not cool nor aerate unless compelled to; neither will they keep their cans clean unless looked after.

Need of tact.-It requires considerable tact to handle a lot of patrons without friction. Most any person can empty cans and weigh milk, but this is not the vital part of the work. We must refuse to receive milk that we cannot make fine butter from. I have done a little work in the line of pasteurizing-enough to satisfy me that there are great possibilities in the near future. Some of our experiment stations are at work in this line and we shall have valuable information from that source in the near future without doubt. Get your names (154) 
on the mailing list of your experiment station. Keep in touch with them; they will do you good if you will let them have an opportunity. We must not on any account lose our grip here. The idea of needing anything in this line to enable us to make fine butter creates a small rebellion in my mind, as I fear it would stimulate the negligent element.

The expert.-It is interesting to watch an expert at the weigh can. His nose becomes as sensitive to bad odors as a trained hunting dog's for game. He acts without thinking. If there is anything suspicious the can cover goes to his nose or his nose to the can and when the can is emptied his hand goes into the can and his thumb-nail is run around

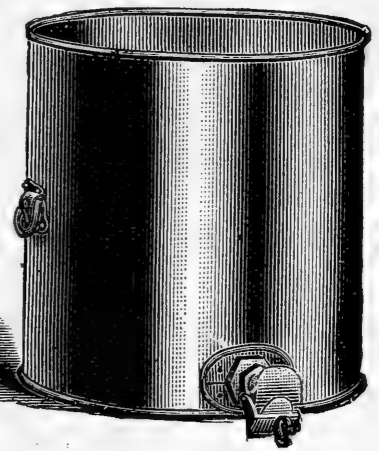
WEIGH CAN. the corners for indications of uncleanliness, which when found causes the patron to receive warning that more care is necessary, or perhaps the milk is too much off flavor and is returned to the patron.

Need of decision.-There must be no slipshod work here, no excusing of neglect on the part of the patrons. There is too much at stake, as one lot of poor milk might injure the 
whole day's goods. Any bad flavor develops fast and breeds trouble and loss. Do not receive bad milk from any one. If the patron gets angry and talks hatefully put the brake on your tongue and let him do all the talking. He will soon get tired and quit. If you cannot convince him that his milk is in bad condition warm a sample of it to 120 deg.; it will then give off its bad flavor so plainly that he must be convinced if he has any use of his nose.

Absorbing bad odors.-At a dairy school I once had a sample of milk set in a calf pen for a few hours, then warmed to $110 \mathrm{deg}$. Fah. and passed around the class, which knew nothing about where it had been exposed. It was interesting to watch the expressions of the different faces; some were surprised and some disgusted. At another time I had a sample put into the silo for a short time and when brought to the class at a temperature of $110 \mathrm{deg}$. Fah. they all found the flavor of silage in the milk, and all that were acquainted with silage recognized its flavor in the milk.

Taking composite samples.-Most of the creameries are now paying for milk on its butter value. This is the longest step in advance that has been taken in the dairy and creamery field. The man at the weigh can is the one that starts this part of the work on its way, as he takes the sample that is to be tested 
to show the comparative value of each patron's milk. This requires care. Nearly all creameries are now using the composite plan of testing, which need not be described. This requires a sample to be taken every day and put into the composite jars. These samples are taken in various ways; some dip out of the weigh can as soon as the milk is emptied, depending on the pouring of the milk into the can to do the mixing. Others take a sample with a tube or "milk thief," which takes a

"MILK THIEF."

column of milk out of the can, and some tap the conductor head and set a cup under it so as to to get a small stream as the can empties.

Scovell's sampling tube.-Prof. Scovell introduced in the work of the Columbian dairy test a novel and practical device-a tube with openings in the side at the bottom and a cap

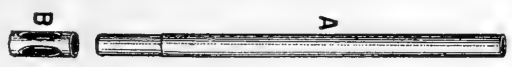

SCOVELL'S SAMPLING TUBE.

that when pulled out left the holes open for filling. This could be inserted in the milk, filling as it was lowered and when it touched bottom a slight pressure forced the cap up over the openings so as to prevent the escape of any of the milk until removed from the can. This 
device not only secures a correct sample of the milk but it also secures the same per cent or relative amount of milk, as it gets twice as much in the sample when the weigh can is full as it will when it is half full.

Preserving samples.-Bichromate of potash gives the best satisfaction as a preservative of anything I have used. It keeps the cream in a fluid condition and it does not adhere to the cans in which the composite samples are kept. With some of the preservatives the cream becomes so leathery that it requires much care to secure a correct sample out of the composite jar for testing.

Danger of too much heat.-I have found it necessary to heat such milk to near the point of melting the fat, and when the fat is melted it is very hard to get a correct sample, as the oil made by melting the fat will rise so rapidly that it requires quick work to catch a correct sample. Do not get the impression that there is any serious difficulty connected with doing accurate work all along this line; it simply needs care and good common sense with a determination not to be hurried.

Keep cool.-As a rule the person at the weigh can has several lines of the work to keep on his mind. In many cases he has the boiler and engine and the separators to look after as well as the weigh can. The machinery must 
have attention and the patron is often in a hurry and demands that his milk shall be emptied in about five seconds after he drives up to the receiving-room. Many men do not have a faculty of properly dividing their attention between the different lines of their work. Some will be hurried by the call of some loudmouthed patron and neglect the separator or some other machinery, and get caught with low water in the boiler or a hot bearing in the separator. Another man will go to the other extreme and become irritated by the overanxious patron and cause him to wait unnecessarily long just to get even with him or teach him he is not running that part of the work. I meet both these extremes in our creamery work, and they both show a weak point in the make-up of the person and it should be a study on his part to overcome it. It will pay him to do this. . 


\section{CHAPTER III.}

\section{THE BABCOCK MILK TEST.}

(BY E. H. FARRINGTON.)

One thing that surprised the writer during his six months of milk testing at the World's Fair was the ignorance displayed by so many agricultural visitors in regard to the Babcock test. Many had never heard of it.

Satisfactory to scientists.-When the inventor gave this method of milk testing to the public it was first tried by chemists of experiment stations or persons who were somewhat familiar with the chemical actions involved in the process. They found the results obtained by it were accurate as compared with those of the gravimetric methods they had previously used for getting the per cent of fat in milk; and to them the making of a test was wonderfully simple. The directions first sent out by Dr, Babcock with the test were sufficient instructions for that class of workers to get good results.

Not automatic.-As its field of usefulness broadened and the men who milked the cows (160) 
began to use the tester it was soon discovered that the Babcock milk test was not an automatic machine. Although very simple to a chemist, it was found not to be like a clock which only needed to be wound up and left to run itself for ten minutes to give accurate results, but the wheels must be watched, the milk properly mixed, and the strength of the acid correct.

Any milk can be tested.-It has generally been supposed to be easier to test a mixture of the milk of several cows than the milk of one cow, and that possibly there might be found a cow's milk which could not be successfully tested. The milk of each of 107 cows was tested at the World's Fair, and for four months there were made at least 150 tests of milk every day. This gave many tests of a great variety of milks. There was a great variation in the composition of these milks and in the characteristics and health of the cows. We were able to test successfully every one of these samples of milk and by proper manipulation to get a very clear separation of the fat.

Investigate.-Any one who uses a Babcock test may profit by our experience in two points at least. First, he can have perfect confidence in the process as described by Dr. Babcock, that it has given and can give satisfactory tests of milk; and second, that if any one has trouble 
with the test he can find out the difficulty himself. Investigate for yourselves. Find a reason for occasional poor separations of the fat, if you have them. You can find a remedy yourself just as well as by applying to Dr. Babcock.

A frequent difficulty.-The inquiries contained in some of the dairy papers seem to indicate that black or white stuff separating with the fat is the difficulty most frequently met with. This makes an obscure reading of the per cent of fat because of the indistinct separation of the liquids. The common remedy suggested for this difficulty has been a change of acid. If there is "black stuff" in the fat get a weaker acid; if a white curd separates in the fat column change to a stronger acid. That a too strong or a too weak acid may cause this trouble is undoubtedly correct in many cases, but not always. The manipulations of the test may also cause these defects.

Points to be watched.-My experience with the Babcock test has taught me to follow the directions given by the originator of the method, and in doing so to keep a watchful eye on the following points:

1. Mixing and temperature of the milk.

2. Strength, temperature, and quantity of the acid.

3. The way of pouring the acid into the milk in the test bottle. 
4. Mixing the milk and acid in the test bottle.

5. Adding the hot water, kind of water-hard or soft.

6. Measuring the fat.

7. The speed of the machine.

8. Keep the acid bottle corked when not in use.

These are not given in the order of their importance, neither are they supposed to cover every difficulty that may be met with in the use of the Babcock test. They represent some things that have had an influence on the proper working of the test and there is a reason for every one of them.

1. A thorough mixing of the milk, so that the fat is evenly distributed all through the sample to be tested, is sufficiently obvious and needs no explanation.

2. The intensity of the action of the acid on the milk is shown by the fat separation in the neck of the test bottle, either by the color of the fat or by the black or white stuff that sometimes separates at the bottom of the fat column. The black substance is probably charred fat and indicates too strong an action of the acid on the milk. The white adulteration of the fat shows too weak a reaction. The strength, temperature, and quantity of the acid used, as well as the temperature of the milk, all have an in- 
fluence on the action of the acid on the milk. Too strong acid and warm acid or milk may be the cause of the black stuff in the fat. Hence it may be advisable to use a little less acid, or cool either the milk or acid, or both, before mixing the two liquids in the test bottle. On the other hand if a white curdy substance separates with the fat this may be remedied by using a little more than the graduated full of acid or by warming the milk or acid 10 to 20 $\mathrm{deg}$. before making the test. None of these precautions will be necessary if the acid has a specific gravity of 1.82 and both milk and acid are at 60 to 70 deg. Fah. when used.

3. When measuring the acid into the test bottle hold it at an angle which will cause the acid to follow the inside walls to the bottom and not drop through the milk in the center of the bottle, because by the latter way of pouring the acid a portion of the milk may be acted on by the strong acid before it is diluted by the water of the milk. This makes a more intense action of the acid on a small part of the milk, and the fat it contains is somewhat decomposed and blackened. This black substance is then separated with the fat by the usual method of finishing the test. If properly poured into the test bottle there will be a distinct layer of milk and acid with little or no black color between them. 
4. Thorougly mix the milk and acid as soon as measurer into the test bottle. This is not always necessary, but for the same reason just mentioned a better separation of fat is sometimes obtained by mixing at once than by allowing the two liquids to stand partially mixed in the bottle, as often happens when the acid is poured into the test bottle.

5. Add the hot water in two portions and run the centrifuge after each addition of water. Use soft water for this purpose because many hard waters contain so much carbonate of lime that the carbonic acid set free by the sulphuric acid makes considerable foam at the top of the fat column. Some waters can be used to fill the test bottles without causing any foam if first boiled a short time or by adding a teaspoonful of acid to about one quart of the water used for filling the test bottles.

6. When the test bottles are taken from the machine it is a good plan to put them into water at 140 to $160 \mathrm{deg}$. Fah. The fat is kept liquid at this temperature. Each end of the fat column can be distinctly seen and its amount measured.

7. Too low results will be obtained if the centrifuge does not have sufficient speed. The machines have to be watched, as constant use wears some of them so that the speed designed by the manufacturer is not obtained. 
8. Keep the acid bottle corked when not in use, because sulphuric acid takes up water from the air and is thus diluted or weakened.

9. When testing skim-milks and buttermilks which have a very small per cent of fat (twotenths of one per cent or less) the reading of the per cent of fat should be made immediately on taking the test bottle from the centrifuge. If this is not done and the test bottle cools before taking the reading the contraction of the liquid in the bottle will leave the fat spread over the inside surface of the measuring tube so that it is not seen but has the appearance of being only a dirty tube. If read when taken from the machine the small fat globules can be seen and estimated.

The Babcock tested and proved.-The Babcock milk test was one of the things that made a "ten-strike" at the World's Fair. It went through a trial which gave it a very thorough test. An understanding of the daily records made by this test at the World's Fair ought to convince any fair-minded person that the Babcock milk test deserves the highest award. Some who had previously expressed doubts about its accuracy and practicability freely confessed their conversion. The awards given in the last or heifer test were based on the amount of butter-fat found in the different cows' milk by the Babcock milk tester. 
The milk given by each cow was tested daily through all the different tests from May to November. During the two butter tests the skim-milk, buttermilk and butter were also analyzed. 'The amount of fat in these three products should be equal to that found by the tests of the milk from which they came. During these butter tests three balance sheets of this kind were made daily, making a total of 360 accounts.

Each of these accounts included tests of twenty-five samples of milk on one side, and on the other tests of one sample each of skimmilk and buttermilk and an analysis of one sample of butter. The difference between these two records of the butter-fat was called mechanical loss. Sometimes it was gain.

Figures from the test.-The complete records are not yet available, but the writer has 312 of the total 360 comparisons which can be made. These include 120 Jersey, 90 Guernsey and 102 Short-horn records. They show the following results:

The number of times there was a mecnanical gain was-Jersey 42, Guernsey 22 and Shorthorn 19 per cent of the whole number of days. The greatest gain observed on any day was for the Jersey 1.22, Guernsey 1.31 and Short-horn $0.81 \mathrm{lb}$. fat. The greatest loss was Jersey 1.93, Guernsey 1.63 and Short-horn $1.26 \mathrm{lb}$. fat. The 
average weight of fat unaccounted for daily was Jersey 0.35, Guernsey 0.37 and Short-horn $0.38 \mathrm{lb}$. These weights of fat were for the Jersey 0.9, Guernsey 1.2 and Short-horn 1.4 per cent of the total weight of fat produced daily during the ninety-day test, or for the Jersey 0.043 , Guernsey 0.054 and Short-horn 0.052 per cent of the milk produced per day in the ninetyday test.

Considering the great difficulty of getting a fair sample of forty pounds or more of butter, the analysis of which must come into every one of these 360 accounts, and the fact that the fat is measured in the test bottles instead of weighed, these results show very close work, not only by all the men connected with the Columbian dairy test but also by the Babcock milk test. 


\section{CHAPTER IV.}

\section{TEMPERING AND SEPARATING.}

Temperıng milk for separating is apparently a very simple matter. At the same time there is a right, way and a wrong way of doing it.

Sudden heating. - Sudden heating is not advisable, as milk so heated separates harder than milk that has been gradually heated. This is no theory. It is a hard fact that I discovered in comparing the work of different creameries. The theoretical part comes in when I try to explain why this is a fact. This point developed as follows: In one of our creameries we heated the milk for the separator with a jet pump, which does its work very suddenly. In another creamery the milk was heated mostly in the receiving vat. By the use of the Babcock test I found the most thorough skimming was being done at the creamery where the milk was heated in the large vat to near the proper temperature and finished up in the channel vat. The jet pump was in use in our home creamery where I had the very best opportunity to watch the work, but I could not secure (169) 
as good skimming as I did at the other creamery.

The cause.-I studied for the cause of this for some time before the idea came to me that the manner of warming the milk might have something to do with the thoroughness of the separating. As soon as this thought came to me I commenced to warm the milk at the home creamery in the large vat and I found the separators doing as good work as at the othery creamery where the milk was warmed slowly. My theoretical explanation of the situation is that the sudden heating expands the water in the milk faster than it does the fat and consequently there is not the difference in gravity of the cream and other elements in the sudden heated milk that there is in the gradually heated milk where there has been time for the fats to become of the same temperature as the other elements in the milk.

Channel vat.-It is not practicable in warm weather to do much warming in the receiving vat. In fact it is not necessary as a rule to warm the milk in hot weather for separating. I believe the channel vat to be the best device for tempering milk for separating.

Be sure to secure this vat of a capacity that will not require forcing to get the milk to the proper temperature. If the tempering vat is too small the waters surrounding it will need 
to be so hot to secure the right temperature of the milk that it will cook the milk onto the vat. This is objectionable and unnecessary. Eighty to $85 \mathrm{deg}$. is a good temperature at which to separate.

Quick cooling.- - It may be done at a higher temperature when there is a way of cooling the cream immediately to a temperature of 55 deg. or below. This is a vital point in the work and one that many butter-makers stumble over.

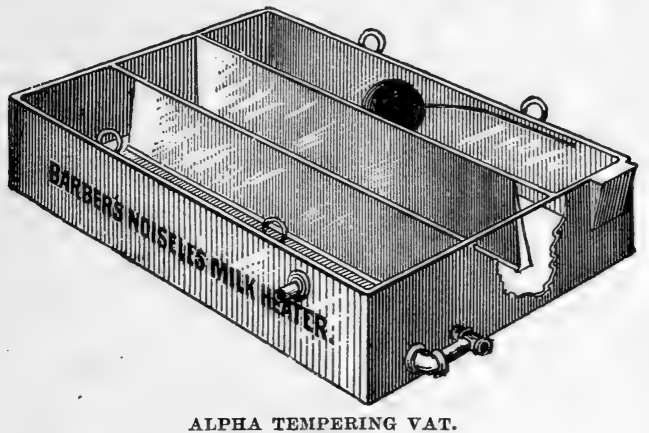

Care of separator.-When the milk has been tempered to the desired temperature it is ready to separate. The separator is run at a high velocity and needs good care. Be sure that the bearings are all well oiled before it is started, and especially is this necessary with a new machine as the parts are all new and they fit close. There is more danger of heating a new machine than after it has ran a time. Follow instructions sent with the separators. Do not be 
too ready to get an idea that you know more about operating the separator than the man

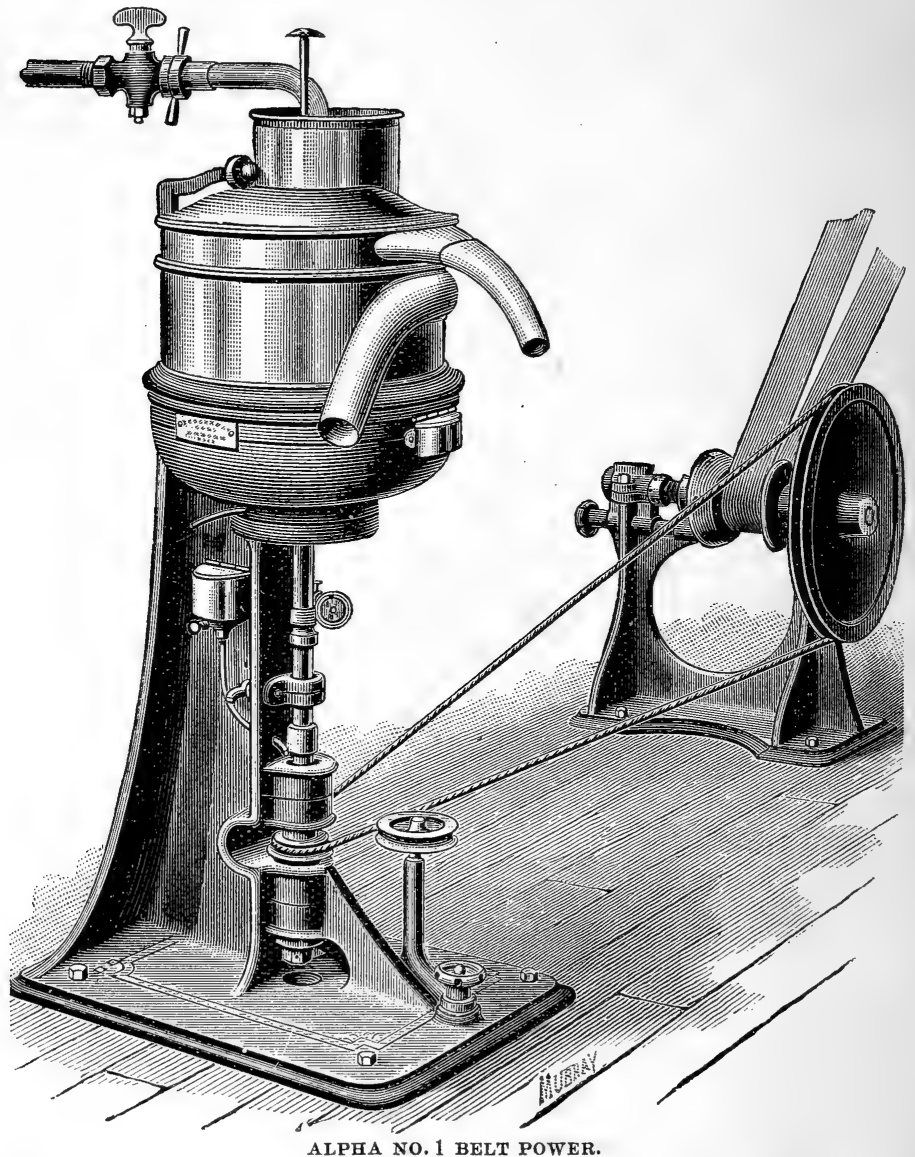

that invented it, for the probability is you do not and never will. 
TEMPERING ANU SEPARATING.

Smooth running necessary.-A separator must run smoothly to do its best work; when

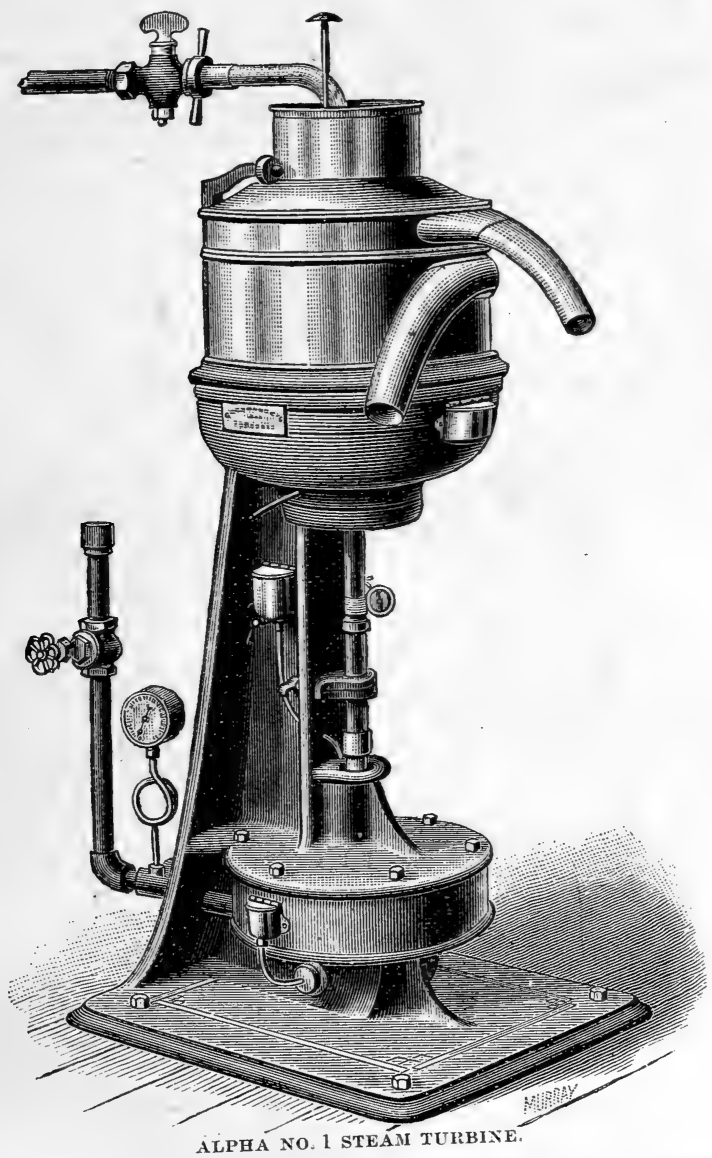

it trembles or shakes it is not doing its best work and it should be put in order immediately. 
You cannot afford to let .2 of 1 per cent of fat get away in the skim-milk. There should never be fat enough in separator skim-milk to cover the surface in the neck of the test bottle, and as an average of work done there should - be no more than two or three drops of fat the size of pin heads around the neck of the test bottle. I know it to be thoroughly practicable to do this kind of skimming as I see it done day after day and māny creameries are doing it.

\section{Babcock test. -} Look out for the motion of your Babcock tester: also the temperature. If the motion is too low it will not secure all of the fat and you will deceive yourself on your work. It is advisable to secure a rich

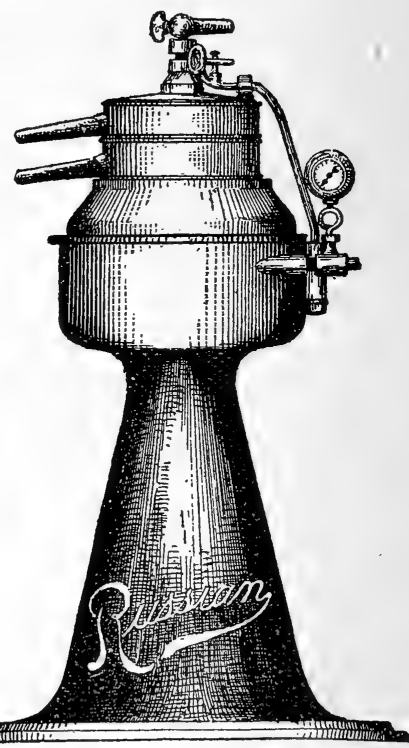

SHARPLES RUSSIAN SEPARATOR.

cream. Some of the reasons for this are explained in the next chapter.

Clean vs. close skimming.-There is a great difference in separators in this matter of close skimming and clean skimming. Some will 
take a smaller percentage of the milk as cream and still do more efficient work than others will. This is an important point, one reason of which is the fact that in hot weather there is danger of cream becoming too sour to make high-flavored butter, and cream rich in fat does not sour or ripen so fast as cream poor in fat.

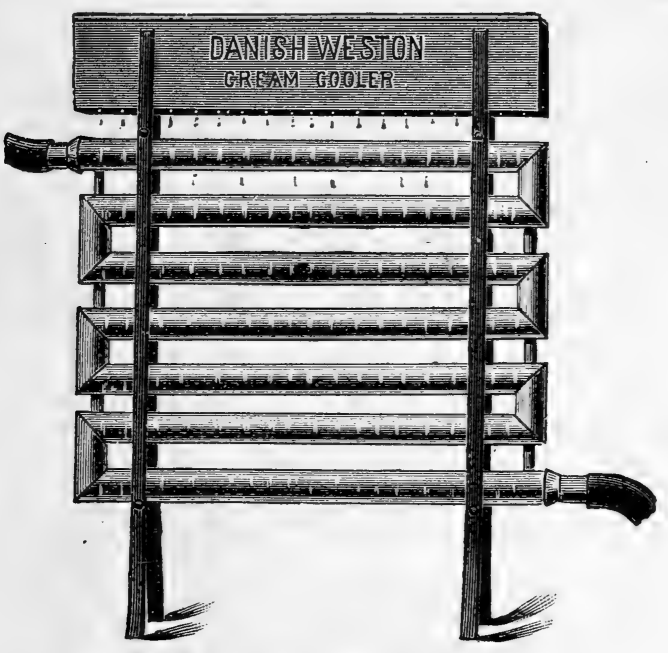

DANISH-WESTON CREAY COOLER

A cream with 35 per cent of fat in it might in extreme hot weather have the right degree of acid at churning time to produce the best results when if the separator had been adjusted to take a cream with 15 or 20 per cent of fat it would, under the same conditions as to temperature and time, have developed a degree of 
acidity that would have injured the flavor of the butter and probably caused a larger loss of fat in the buttermilk.

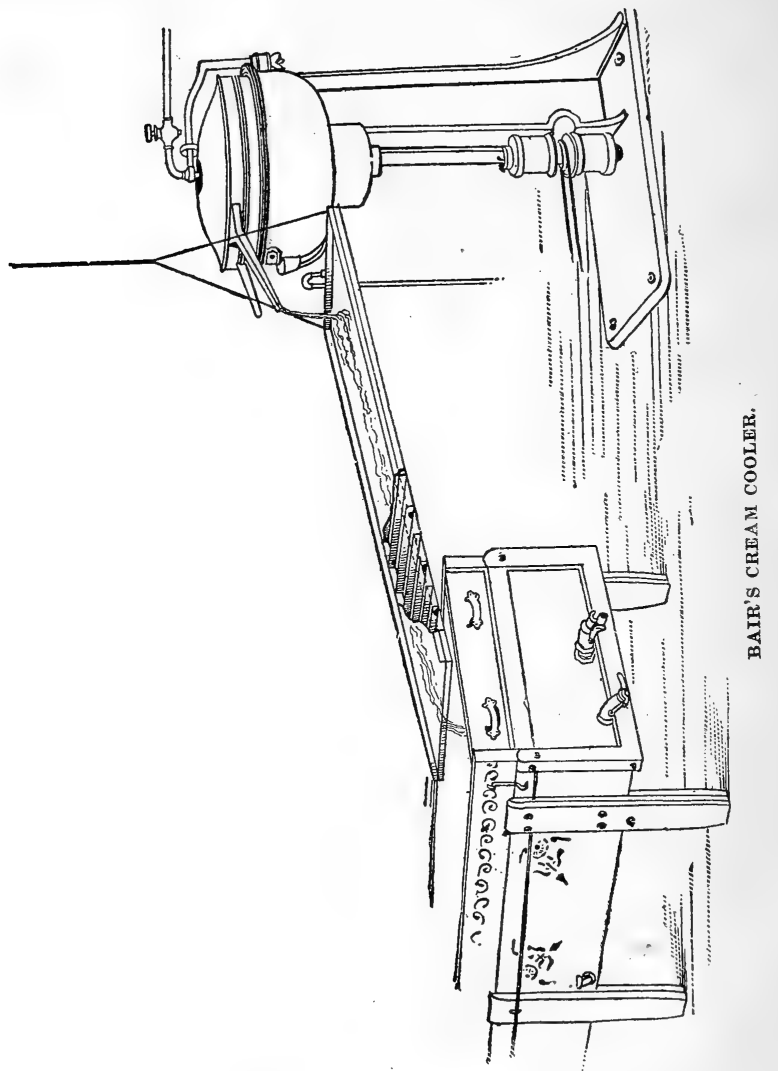

Cool quickly.-As fast as separated the cream should be run over a cooler of some 
style that will cool very quickly to the temperature of $55 \mathrm{deg}$. or below. This is a great help to the flavor of the butter. It helps very much to prevent the "summery" flavor or lack of flavor in extreme hot weather. I consider the immediate cooling of the cream from the separator one of the vital points in buttermaking.

Capacity of separator.-The quantity of milk a separator will skim per hour depends on the temperature of the milk, the time since the cows were fresh and on the breed of the cows. Other points being the same the milk will skim the easiest that has the largest globules of cream. This will hold good with gravity raising of cream as well as with the separator. I think it unnecessary to talk about gravity raising of cream in the creamery as I do not know of a milk creamery that does not use a separator for creaming the milk.

How to remove cream from bowl.-When the separator is stopped from any cause pour in water at temperature of milk to take the cream out that is in the bowl or it will become so thick from being retained in the bowl while in motion that it will stop the cream outlet and cause trouble when it is started again. If the stop is at the end of the day's work the cream certainly needs to be all removed.

The specific gravity of water is between that 
of cream and skim-milk and will for that reason take position between the skim-milk and cream and carry the cream or flush it out of the bowl. It is well to repeat this three or four times, leaving time enough between the acts for what cream there is to become separated and then flush it out. It is necessary to exercise care in getting the fat or cream all out of the separator bowl at the end of a run. I have seen separator bowls with more fat in them when taken out to be cleaned than there would be in 1,000 lhs. of the milk they had skimmed with this same machine. This was not the fault of the separator but of the operator. If the bowl is flushed out three or four times with tepid water, allowing a few seconds' time between the flushings, there will be no larger percentage of fat in the contents of the bowl than there was in the skim-milk.

Difference in separators.-There are many times large losses made in separating. I have operated separators that I could not skim closer than .2 of 1 per cent of fat with and I have operated others that I could get to skim to a trace, or not enough to cover one-tenth of the surface of the test-bottle neck.

Dairy school work.-Persons wishing information concerning work done by different separators under the same conditions can secure valuable facts from the work at our dairy 
schools. At the Penusylvania State College dairy school in 1894 there were several samples of skim-milk tested with the gravimetric and the Babcock. The average of twelve samples was as follows: Gravimetric, .095; Babcock, .063. Some of the gravimetric work showed as low as .01, .02 and .03 of 1 per cent in the skimmilk. The New York Experiment Station at Ithaca in "Bulletin No. 66 " gives the result of work done at its dairy school in 1894, where seven separators were in operation. The work by the different separator's showed great varialtions. The best average work by any separator was .1 of 1 per cent of fat and the poorest work showed .29 of 1 per cent of fat.

Tests of power required. - This bulletin also gives the results of tests made to show the horse power necessary to skim $1,000 \mathrm{lbs}$. of milk per hour. It will pay any creamery man to get this. "Bulletin No. 66." If creamery men all knew its value to them I am sure a new edition of it would be necessary. The Director of the Vermont Experiment Station (Prof. J. L. Hills) kindly lent me an abstract of their 1894 dairy school work. They had eleven separators in use during the term. The percentage of fat left in the skim-milk of the different machines averaged as low as .06 of 1 per cent and as high as .21 of 1 per cent. They also made porver tests of the separators. The Pennsyl- 
vania Experiment Station made power tests of separators at their dairy school in 1894.

Value of station work.-I consider the tests of separators at our dairy schools of great value. There is no more reliable source of information. It is right in the line of work that they were created to perform and they are doing us gool service that is sure to be appreciated more and more as the years go by and they develop as they are sure to do. I have just received "Bulletin No. 22" of the Iowa Station, in which Prof. Henry C. Wallace gives the results of work done with separators during the six months ending June 10, 1894. The work done by four separators is reported. The per cent of fat in the skim-milk was as follows:

One separator with 61 trials showed an average fat in skim-milk of :06.

One with 52 trials showed an average fat in skim-milk of .07 .

One with 22 trials showed an average fat in skim-milk of .22.

One with 54 trials showed an average fat in skim-milk of .08.

Prof. Wallace says: "It should be remembered that the tests were made by dairy students during the course of their instruction and consequently do not represent the best work that can be done with these machines, although perharps farity representing the work lone in 
the average creamery." In the above quotation Prof. Wallace is talking of the three machines doing the best work. It will pay parties interested in separators to secure "Bulletin No. 25."

Butter accumulator.-A comparatively new machine on the market is the butter accumu-

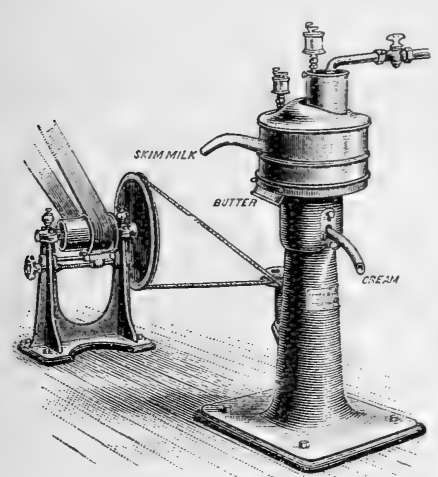

BUTTER ACCUMULATOR.

lator manufactured at Bainbridge, N. Y. It receives the milk the same as the separator except the temperature, which it is desirable to have at 65 deg. Fahr. The cream is first separated the same as in the common separator, after which the cream drops into another compartment of the machine, where the separation is continued until we have butter and buttermilk, which are then delivered from the machine. We had one of them at the Pennsylvania dairy school in January, 1s94, for a few days. It of course makes what we call sweet-cream butter, but it has more flavor than any other sweet-cream butter I have ever seen. 


\section{CHAPTER V.}

\section{RIPENING AND CHURNING CREAM.}

Having finished the separating and cooling the cream to 55 deg. Fah. in the morning we will in the afternoon prepare it for ripening. It should be frequently agitated with some kind of an implement to remove the froth there may be on top of the cream, as there is some fat in this froth, and if it is left on top of the cream it will not ripen with the cream and will not churn so thoroughly. It will cause a larger per cent of fat in the buttermilk than if it is stirred in, or untii it disappears. If the separator has partly churned some of the cream in the operation of separating, it cannot be stirred in, as the butter will float.

One cause of mottled butter.-This causes trouble in several ways. It will not take the color readily and will cause a mottled appearance in the butter, especially when new; but it will gradually disappear, or at least partially, when it is a few days old, probably taking color from the surrounding butter that has been colored. If there is much of it the flavor of the (182) 
butter will be affected by it, as it was churned at the temperature of the milk at separating, which is usually high enough to kill the flavor of the butter.

Temperature to ripen.-When the cream is in the desired condition it should be tempered, the temperature of setting depending upon when we wish to churn. If it is to be churned the following day it should be warmed up to 68 to 70 deg. This operation requires care. It must be done gradually and not have the water surrounding the cream reach a temperature that will cause the cream to melt if allowed to stand without agitation while being warmed, Agitation expedites the work and prevents the cream that is in contact with the vat from becoming overheated. I have known serious trouble with the flavor and grain of butter from careless work here.

Use a starter.-To hasten or help in ripening a starter may be uśed. Some use buttermilk for this purpose but it is not safe, as it carries from one day to the next, and if the flavor is once lost or gets bad the trouble is transmitted from day to day and so will go from bad to worse. Some use sour cream from the day's churning. There is the same objection to this as to the buttermilk. The best way is to make a starter from skim-milk, selecting the milk from a dairy of fresh cows 
(as it is the fresh cow's milk that imparts flavor) and skim it by itself and use it to make a starter. This should be made every day for the following day's use. For making the starter we use Boyd's starter vat. There are directions with it for its use.

Temperature at which to hold.-If the cream is to be churned the second day after separated it should be held at a temperature of 55 to 58 deg. This temperature will develop sufficient acid. The condition of the milk when received will have much influence on the development of acid, so much in fact that a rule cannot be made that will apply to all cases. Judgment must be used and experience is valuable in this work. If at any time there is trouble with the milk which causes a bad flavor to the cream it should not be ripened at a high temperature, as it will cause the bad element to develop rapidly and it will secure full possession of the cream vat, overcoming the starter entirely. Ripen off-flavored cream at a low temperature and agitate and aerate it as much as possible during the ripening process.

Cooling for the churn.-When ripened and before churning it must be cooled to the desired temperature. My early experience with cooling cream was with the common cream vat with a space for water surrounding the 
cream. This is a slow process and taxes a person's patience. Several years ago I devised a cooler consisting of a series of pipes like a single horizontal steam radiator. This is sus-
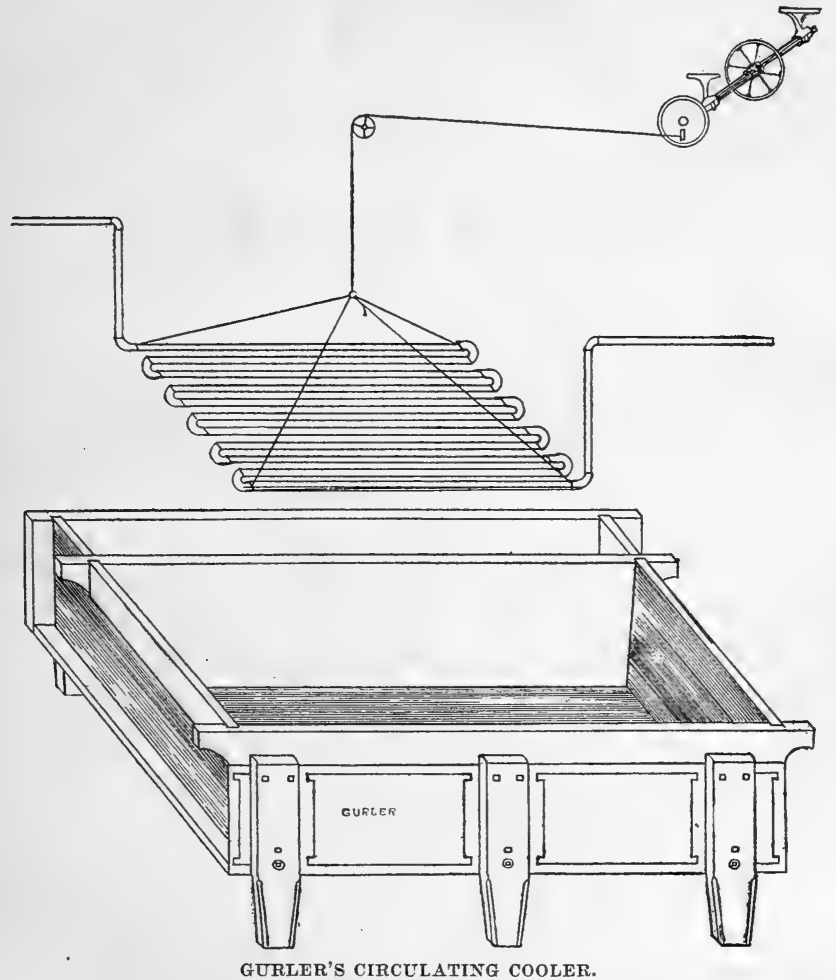

pended in the vat and worked mechanically up and down; at the same time cold water is running through it constantly. I believe this to be the first circulating cooler used and it is not 
patented. This does very efficient work; it will cool a vat of cream from $70 \mathrm{deg}$. down to within 3 deg. of the temperature of the water used in a short time, a full vat requiring not to exceed thirty-five minutes. Care must be used here, as this rapid cooling of the cream does not harden the fat with the same degree of rapidity that the thermometer indicates it has cooled the cream. It is best to cool a few degrees cooler than you wish to churn, or continue the cooling operation for a time to give the fat in the cream time to harden.

Temperature to churn.- The temperature to churn is the next question. The old practice was 58 to $62 \mathrm{deg}$. This is the temperature at which a large majority churn to-day. I have been studying over this churning question for several years. My early work was in the line of acidity, which work was done in connection with the Illinois Experiment Station and a bulletin issued which covered our work. But when the Babcock test was introduced I commenced to use it on the buttermilk and secured results that surprised me very much. The variations in the percentage of fat were astonishing, the range being from .1 of 1 per cent up to 2 per cent (tio per cent). At the end of the first year I had learned that the churning was much more exhaustive in winter than it was in summer. I had supposed the opposite would be 
the case, as I thought the cream from grass milk should be more churnable than that from dry food.

After a while I began to think that the temperature was the key to unlock the secret, and I very soon satisfied myself that it was, and that a temperature of 50 deg. gave much more ex-

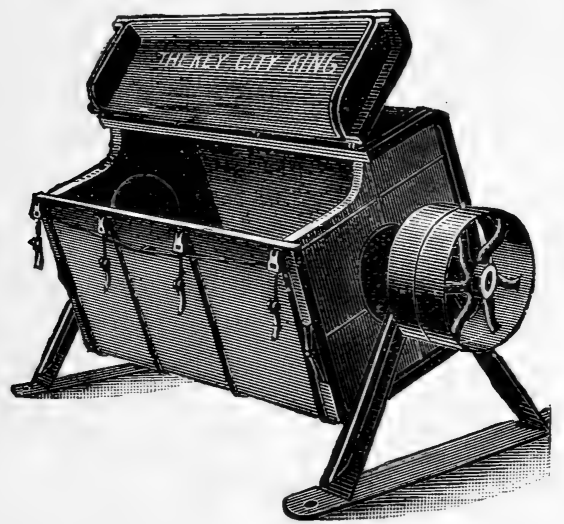

KEY CITY KING.

haustive churning than the old standard temperature of $60 \mathrm{deg}$.

The next question was how to be sure of churning ripened cream at this low temperature. We had known for a long time that sweet cream could be churned at a very low temperature; but my experience was like many others with ripened cream, i. e., it would not gather but would swell and froth and fill the churn full and cause an endless amount of 
trouble, which could be overcome best by removing a part of the cream from the churn and making two churnings of the one.

Low temperature requires rich cream.After a time I got an idea that the richness of the cream in fat had something to do with churning, and followed the idea which led me out of the trouble, as I found it to be a fact that ripened or acid cream with 35 per cent of fat could be readily churned and would gather at a temperature of 50 to $52 \mathrm{deg}$. I now mean that the buttermilk will be at 50 to 52 deg., and the butter after the buttermilk is drawn off will be at the same temperature. I have had men ridicule me when I told them it was practicable to churn at this low temperature, and have had men state before a public gathering that they did not believe me; but we are going right along doing it every day when the outside temperature is low enough so that the churn-rooms are cold enough to help us ont.

Temperature of churn-room.-The temperature of the churn-room has much to do with the change of temperature of the cream during the churning. When the churn-room is as cold as the cream in the churn the change of temperature of the cream during churning will be but a few degrees, depending upon the time required to churn. But if the temperature of the churn-room is $20 \mathrm{deg}$. higher than 
the cream in the churn the cream will warm up very fast. I have learned that with a box or barrel churn in a room 15 deg. colder than the cream in the churn one hour's churning would not change the temperature of the cream.

\section{Advantages of low temperature.-Churn-} ing at a low temperature not only gives more exhaustive churning but it gives better butter - butter with less foreign elements in it and with much better keeping qualities. Another point is that it requires less washing to remove the buttermilk. This I consider a great advantage, as it is a fact that washing removes some of the delicate flavor of butter. In this line I recently macie a test of a churning. The churning was stopped when the butter granules were the size of kernels of wheat, and the buttermilk, which was at a temperature

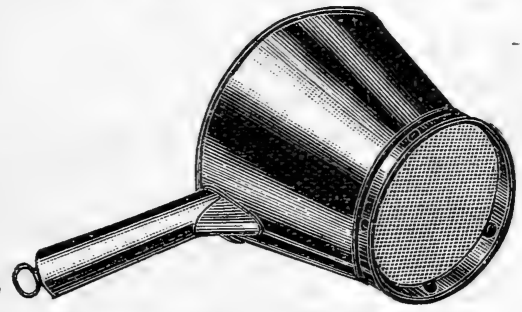

STRAINER DIPPER. of 53 deg., was then drawn out; then one-third of the butter was taken out and salted and worked. The remaining butter was washed once and then one-half of the contents taken out and salted and worked. The balance was then washed a second time and allowed to lie 
in the water about two hours, when it was taken from the churn and treated the same as the other two lots had been. From each of these lots was filled one tub and one ten-pound pail. The tubs were judged the following day by my brother, the butter-maker and myself, my brother and I not knowing anything about the butter except that we had a tub of each lot. We all agreed that the twice-washed had the least flavor, and two of us selected the butter that was not washed as the best in flavor of the three tubs and fully equal in every other way to the other butters:

I also sent the three pails, one being out of each lot, to Mr. A. H. Barber, who was chairman of the committee that judged the butter made in the breed contest at the Columbian Exposition. Mr. Barber also selected the package that had not been washed as the best in flavor and body. I also sent a sample of each lot to our experiment station to be analyzed, and received the following analysis from Prof. Farrington:

\begin{tabular}{|c|c|c|c|c|}
\hline & Fat. & Water. & Curd. & Salt. \\
\hline Not washed. & 83.41 & 12.86 & 1.65 & 2.14 \\
\hline Once washed......... & 83.83 & 12.32 & 1.13 & 2.72 \\
\hline Twice washed....... & 84.16 & 12.16 & 1.08 & 2.60 \\
\hline
\end{tabular}

Will unwashed butter keep?-Three months after this butter was made I was at the Illinois 
RIPENING AND CHURNING CREAM.

Experiment Station and found the samples I had sent Chemist Farrington for analysis still

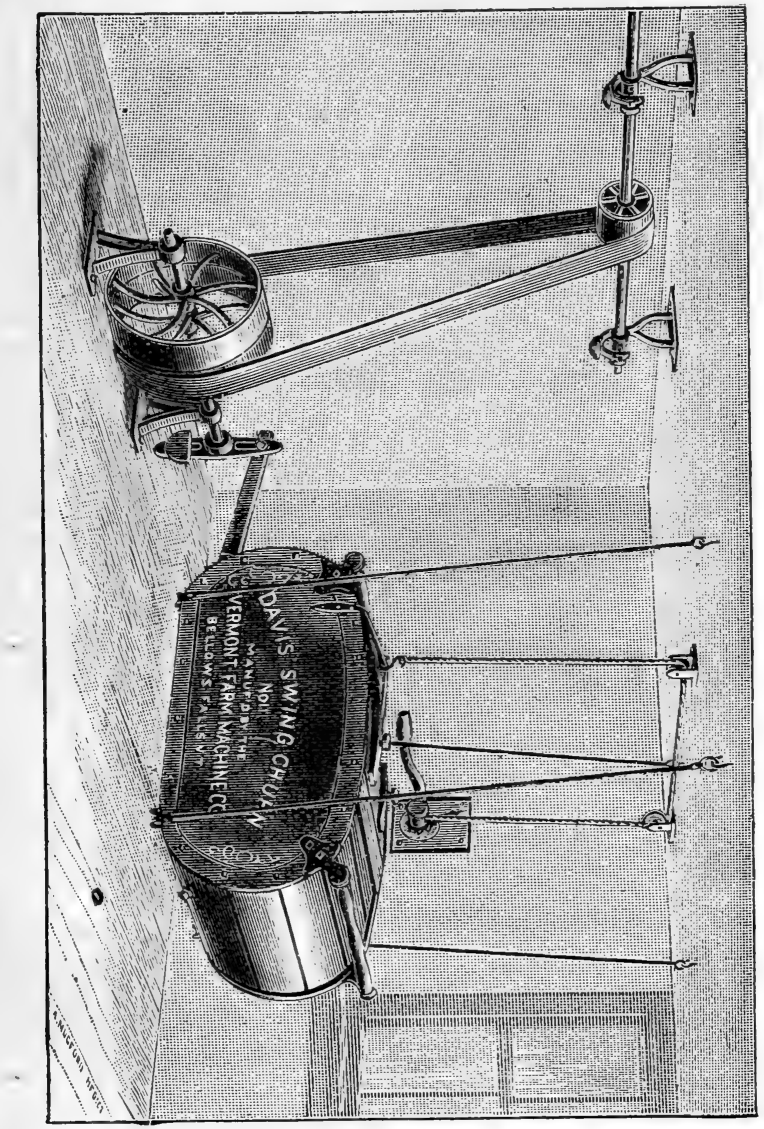

preserved except what had been taken for the analysis. The samples had not been cared for 
in the least except to keep the covers on the jars, there being no kind of a seal. I asked that the samples be set before me with private

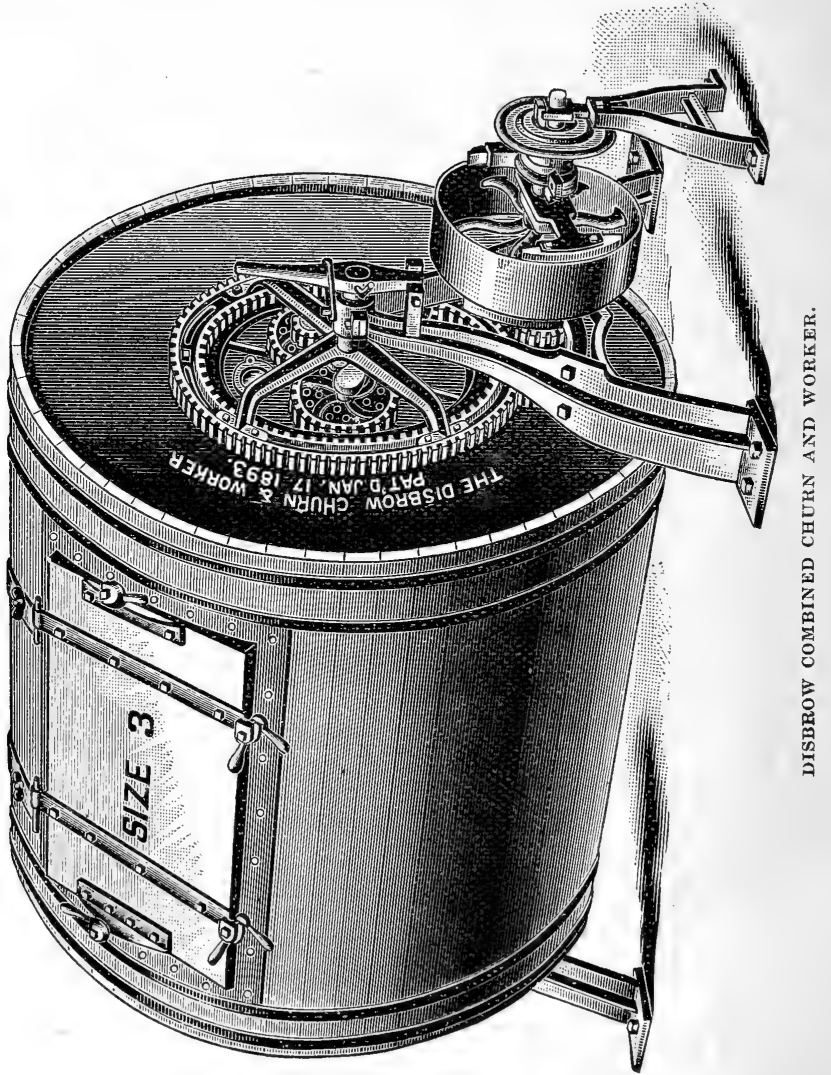

marks so that I could judge them without knowing which was which. I found no differ- 
ence in the flavor of the three. I expected to find that the samples that had been washed had kept the best but there was no difference.

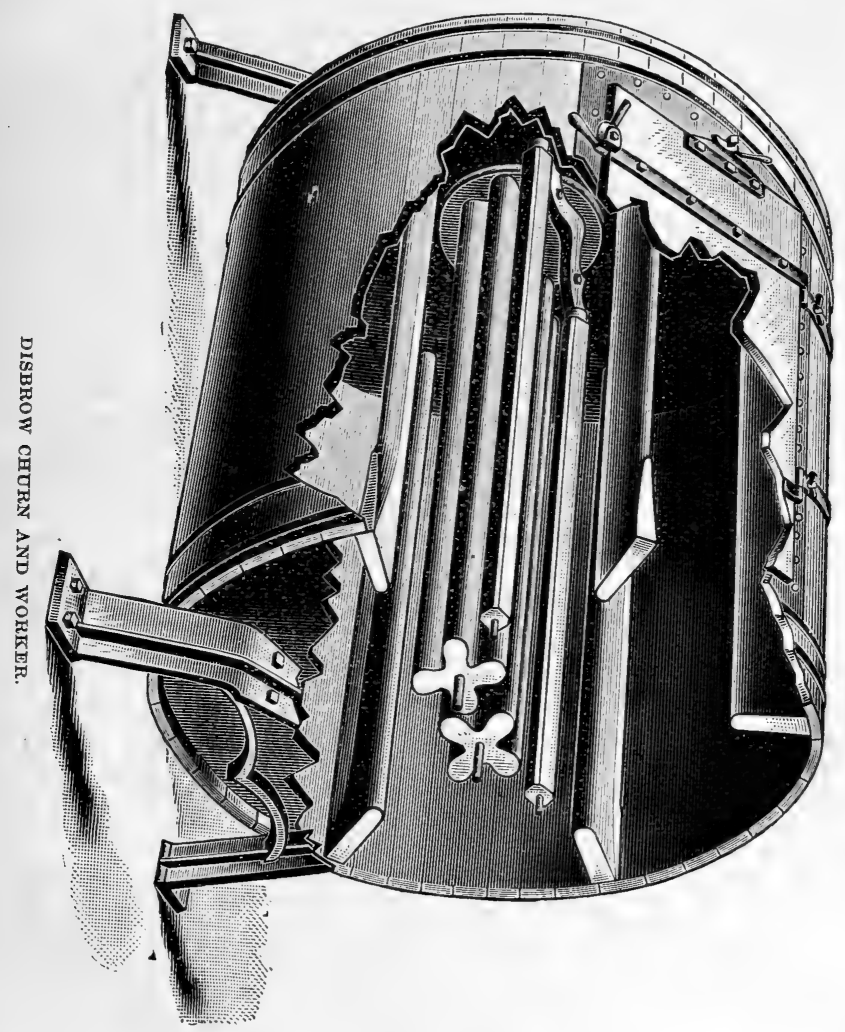

They had all kept well, there being no bad flavor; simply showing loss of freshness. I was surprised to find the flavor as good as it was. 
Look out for cream with small per cent of fat.-Ripened cream that has 15 per cent or less of fat in it cannot be churned at a very low temperature. Cream with a large amount of milk in it develops acid much faster than cream with a small amount of milk. This point must be looked after or there will be trouble from loss of flavor and also loss of fat in the buttermilk.

Look out for acidity.-The greatest loss of fat in buttermilk that I have ever found came from excessively sour cream. Before we had the Babcock test we learned that too much acidity caused a loss of butter, but we thought then that the acid destroyed the fat; now we know better; we know that it in some way gets the cream in a condition that it does not deliver all of its fat. There is much less danger of cream rich in fat becoming too sour than there is from cream that is poor in fat. I have tested buttermilk that I found 2 per cent of fat in, and I have tested hundreds of samples that I found less than .1 of 1 per cent in. I once tested a creamery daily for one week and found the first day less than .1 of 1 per cent; I read it .07 ; the other extreme was 1.2 per cent. This great difference was caused partly by the temperature and partly by difference in the acidity of the cream.

The record was as follows: 


\begin{tabular}{l|c|c|c|c}
\hline & $\begin{array}{c}\text { Tempera- } \\
\text { ture at } \\
\text { starting. }\end{array}$ & $\begin{array}{c}\text { Temper'ture } \\
\text { of but- } \\
\text { termillk. }\end{array}$ & $\begin{array}{c}\text { Time of } \\
\text { churn- } \\
\text { ing. }\end{array}$ & $\begin{array}{c}\text { Per cent of } \\
\text { fat in } \\
\text { buttermilk. }\end{array}$ \\
\hline First day...... & $50 \mathrm{deg}$. & $53 \mathrm{deg}$. & 45 min. & .07 \\
Second day... & 56 deg. & $58 \mathrm{deg}$. & 43 min. & .60 \\
Fifth day.... & 53 deg. & 55 deg. & 35 min. & .50 \\
Sixth day.... & 54 deg. & 56 deg. & 50 min. & .50 \\
Ninth day.... & 57 deg. & 59 deg. & 30 min. & 1.20 \\
\hline
\end{tabular}

The man in charge of this creamery had been in our employ but a short time and we had not got him up to our standard at the time. He was doing all right in cold weather, but when the warm days of spring came he was caught off his guard, and also caught the patrons off their guard with their milk. A portion of this great loss came from the milk not having been properly cared for at the farm, and it was off flavor when received at the creamery and caused the cream to become too sour before it was churned. If it had been cooled thoroughly and churned the afternoon after it was skimmed it would have given more exhaustive churning and a better quality of butter.

Washing butter. - When the cream is churned at a temperature of 62 to 66 deg. it will need several washings and the first washing should have salt added to it. This will help to separate the butter and buttermilk. It is well to use a brine wash in all cases, but there is not so much need of it when the butter gathers at a low temperature. I have seen the last that 
run from the churn when churned at $52 \mathrm{deg}$. and not washed look like whey, and our patrons would say that it was not buttermilk and ac-

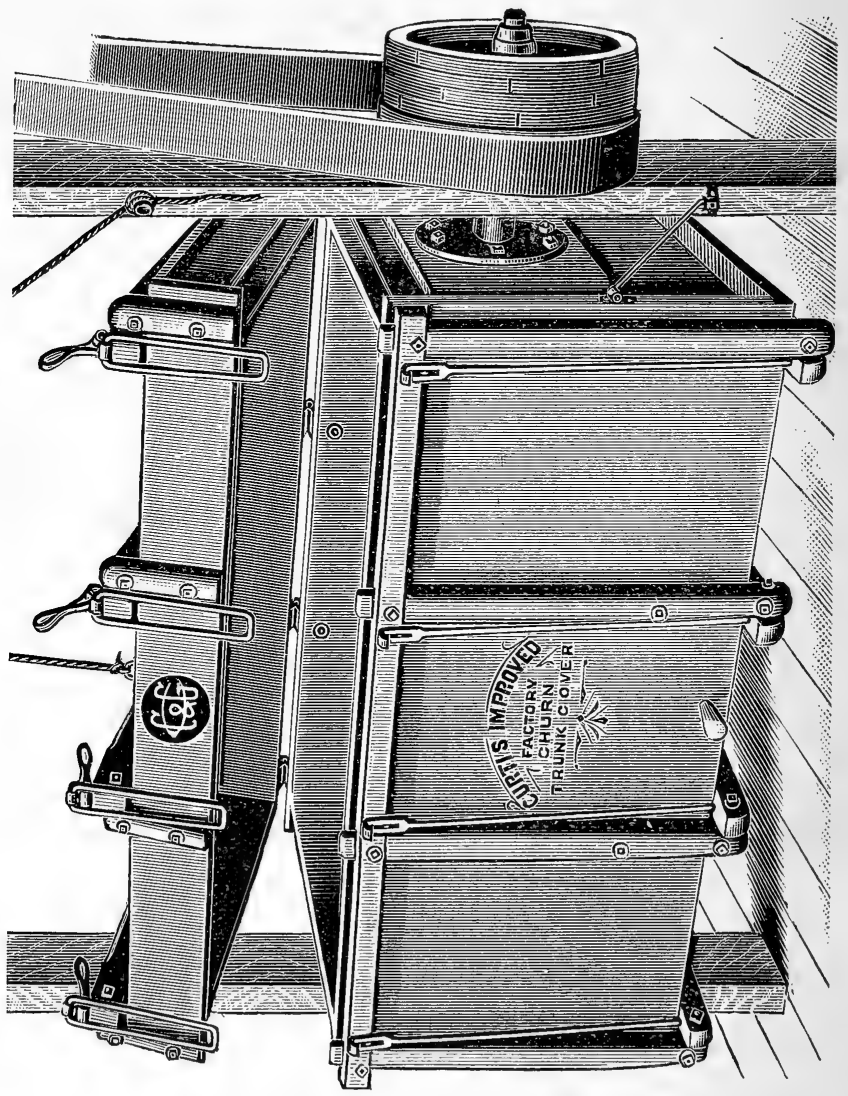

cuse us of watering it. A high temperature at churning gives us butter with less flavor, more 
foreign elements, less grain and solidity, and is therefore not to be recommended.

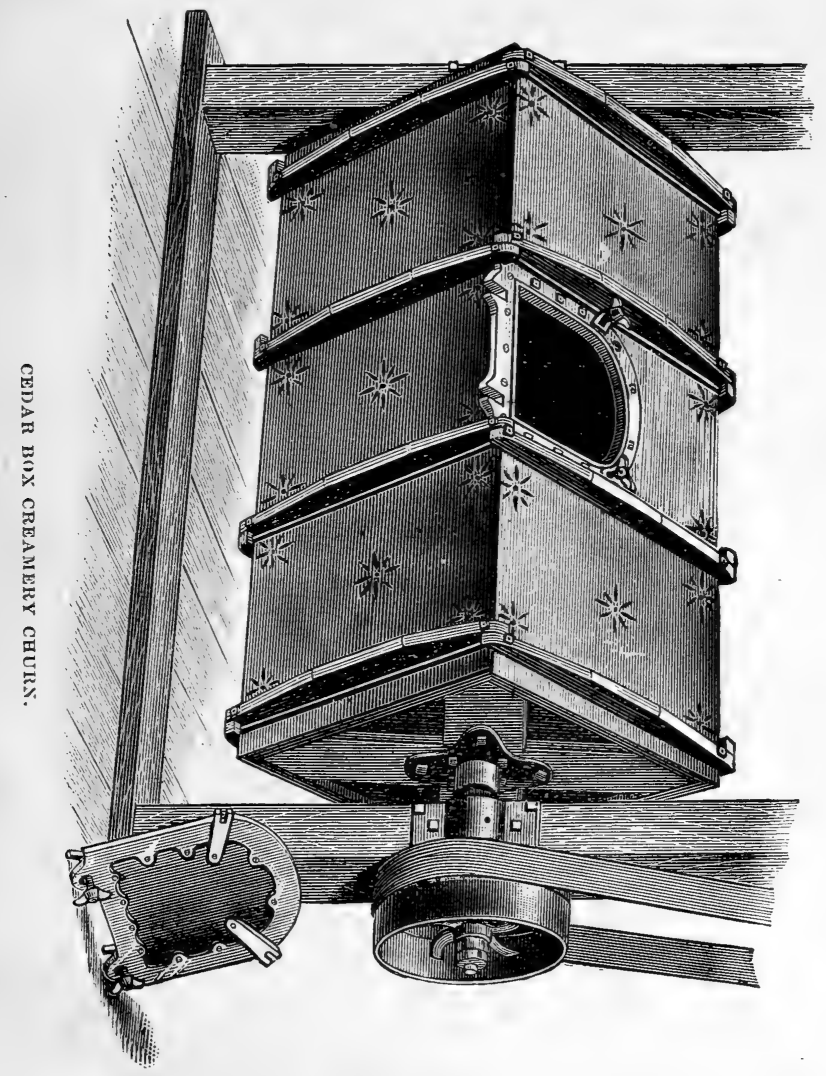

Advantages of low temperature.-When butter gathers at a low temperature it can be better handled, it will receive the salt with less 
working, will have a better grain, and more of the desirable waxy texture.

Churns.-I have used the box and barrel churn for twenty years. I will not make the claim that they are the best churns, but there are some good points about them. One is, that the cream has no place to adhere and not become equally churned. When cream can gather any place and not receive the necessary churning it causes an increased loss in the buttermilk; here is where we have an advantage over the dash churn and other kinds that allow cream to accumulate above the cream line in the churn. Another advantage of the box and barrel churn is that the temperature of the cream is less affected by the temperature of the room in which the churning is being done.

Watch temperature during churning.-I have known butter-makers who would pay no attention to the temperature of the cream in the churn after the churn was started. This way answers in cold weather, but in hot weather the temperature of the cream should be watched and if it gets too high put some ice, finely broken, into the churn. It is best to control the temperature without the use of ice or water in the cream, but it is better to use them and keep control of the temperature than it is to lose control of the temperature.

Color may be added to the salt.-Butter 
color, when used, should be added to the cream before the churn is started. When you do not know how much color to use be sure not to put in too much, and if the color is not high enough add more color to the salt before it is put into the butter. I have done this many times, When color is put into the salt it should be thoroughly mixed with the salt before it is put into the butter.

Test of buttermilk.-In April and May, 1893, we kept the record of three creameries, churning for ten days each, testing the buttermilk each day. In one creamery the average was .13 of 1 per cent for the ten days; the other two averaged less than 1 of 1 per cent of fat for the ten days. In one creamery there was not a test in the ten days in which there was 1 of 1 per cent of fat in the buttermilk. The following figures give the results of some of the work done at the Pennsylvania dairy school in January, 1893:

CHURNING.

\begin{tabular}{|c|c|c|c|c|c|}
\hline DATE. & 离 & 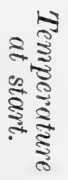 & 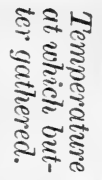 & 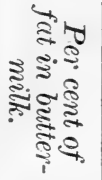 & 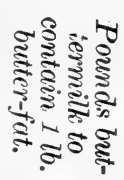 \\
\hline $\begin{array}{ll}\text { an. } & 9 . \\
\text { an. } & 10 . \\
\text { an. } & 11 . \\
\text { an. } & 12 . \\
\text { an. } 18 . \\
\text { an. } 19 .\end{array}$ & $\begin{array}{l}23 \\
25.2 \\
29.4 \\
20.5 \\
23.7\end{array}$ & $\begin{array}{l}40 \\
43 \\
44 \\
50 \\
50 \\
57\end{array}$ & $\begin{array}{l}52 \\
52 \\
5.5 \\
58 \\
60 \\
57\end{array}$ & $\begin{array}{l}.001 \\
.05 \\
.03 \\
.07 \\
.10 \\
.10\end{array}$ & $\begin{array}{c}100,000 \\
20,000 \\
3,333 \frac{1}{3} \\
1,429 \\
1,000 \\
1,000\end{array}$ \\
\hline
\end{tabular}


The per cent of fat in cream can be readily got at when you know the per cent of fat in the day's milk. If the milk has 4 per cent fat, and the separator takes one-sixth of the whole as cream the cream will contain 24 per cent of fat. If one-eighth of the whole milk is taken then the cream will have eight times as large a per cent of fat as the milk has, or 32 per cent.

How to remove curd from butter.-Cream should always be strained through a perforated

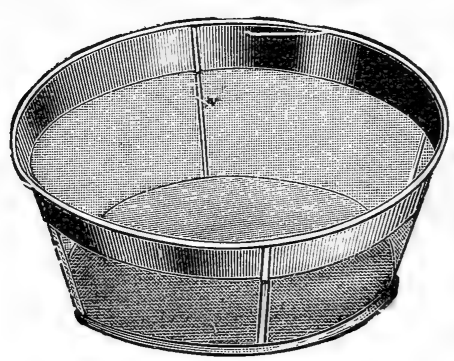
tin or a wire strainer into the churn. This breaks up any thick cream and helps to get it into good condition for the churn. When cream is being churned that has a perforated tin CREAM Strainer. large amount of milk in it the strainer is a help, especially if the milk is soured or curded, as it will break up the curd into small particles that can be removed by careful washing. In such cases when the butter has gathered in granules large enough to prevent a waste or loss through the strainer, stop the churn and draw off a part of the buttermilk and then put in water and agitate it gently, and draw off most of the water, leaving enough to float the butter, as the particles 
of curd are heavier than the butter or water and will sink to the bottom of the churn when liberated from the butter and can be drawn

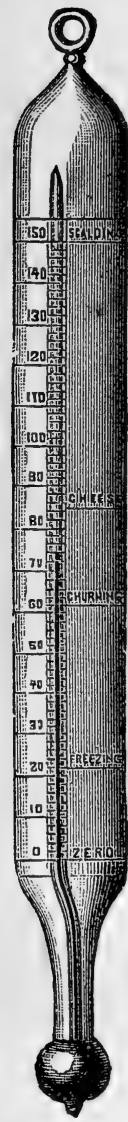
out with the wash water. But if the butter is allowed to settle down onto these particles of curd they adhere to the butter and it is impossible to get them out by washing. The cream should not be allowed to become sufficiently sour to cause this condition, but we sometimes get caught by a sudden change in the weather or some other cause and then should know how to make the best of the situation. Many churn too quick.-Do not let the desire to do quick churning lead you astray. Time is a minor point. Cream with a high per cent of fat and a temperature of 62 to $64 \mathrm{deg}$. may be churned in a few minutes, in some cases as short a time as ten minutes, but you will secure better butter when you reduce this temperature 10 deg. and churn one hour. You will also secure more exhaustive churning; there will be less fat in the buttermilk.

Have tested thermometer.-Every butter-maker should have a tested thermometer as a standard. Do not use it for any purpose 
except to test new ones by. There is a great variation in some makes.

Have a standard of color.-I also recommend that all butter-makers preserve a standard of color. This may be a sample of butter in a glass jar. This should be kept from the light as some butter color fades in the light. Some butter-makers will think this precaution unnecessary, but I know that it is necessary in many cases as I frequently find a butter-maker lost on this point; he is too high or too low and he does not know it.

Pasteurized cream.-I had expected to do some work in the line of butter-making from Pasteurized cream in time to report in this chapter, but I have not been able to find the time to do it. This is a live question and we should all be looking for information on it. I believe 1895 will bring us much reliable information on this subject. Here is a good field for our dairy schools to develop. I do not expect that Pasteurizing cream from milk that is practically perfect will improve the flavor, but milk or cream that has a bad flavor coming from food of any kind like garlicks or turnips, or that has absorbed bad odors, I believe will be improved by Pasteurizing. It is my belief that Pasteurized cream ripened with the right ferment will make butter with better keeping 
RIPENING AND CHURNING CREAM. 203

qualities than the same cream would make when not Pasteurized.

European work.-I know there has been some work done in this line in this country and much more in Europe. Denmark is probably leading in this field and we shall profit by following her work closely, not only in this line but in all other dairy and creamery work. 


\section{CHAPTER VI.}

\section{SALTING, WORKING, PACKING AND MARKETING.}

Test the salt.-Care should be used in selecting the salt. A good way to test it is to dissolve some in hot water, when if there is anything bad about the flavor it will be easily detected. At the same time notice whether or not there is any sediment in the bottom of the glass in which the salt has been dissolved. Also notice the color of the brine-whether clear or milky.

Salt absorbs odors.-I know from bitter experience that salt will absorb bad odors. I once left a small shipment of salt in the railroad freight house a few days where there was some barbed wire that was painted with some preparation that contained coal tar. The salt absorioed this odor and was spoiled for use in butter. My firm built a salt-room at one of our creameries, and adjoining it an open shed for hitching horses. The salt absorbed from the droppings in the horse shed and was spoiled, which would not have been a serious loss if 
we had discovered the trouble in time, but we did not until complaint came from New York that our butter was not fine and the trouble increased. We looked after the milk and cream and vats, churn and butter-worker, in fact everywhere we could think for the trouble. At last when about to give up the hunt we discovered it in the salt. We had taken, as we thought, the best of care of our salt and did not suspect any trouble from that source. We could not detect it in the butter when first made, but by the time it had reached New York it had developed sufficiently to cause serious trouble. We at first thought the butter had been exposed to something in transit, but at last found it in the salt, which was so badly impregnated that it was easily perceptible. Have a clean, dry room free from any impure surroundings for salt.

Butter injured by cheese.-The past summer my firm bought some butter for a New York house which was rejected on arrival in New York, and on investigation it was found the butter was shipped from Chicago in the car with some Limburger cheese. The railway company made the loss good without any delay. I mention this to show the necessity for care. There was a loss of $\$ 6,000,000$ on the butter that passed through the Chicago market in 1892 that was traceable to lack of care, in- 
telligent work, skill, or something that could and should have been remedied.

How much salt.- Use the quantity of salt in butter that suits your trade. Most of the United States markets wish three-fourths to one ounce per pound of butter.

Sift the salt.-Use a sieve to put the salt onto the butter. This will break all lumps and the butter will require less working to get it in proper condition. Keep the butter in the granular form until the salt is added, as the salt can be in this way thoroughly incorporated into the butter with less working than when the butter is allowed to pack before the salt is added.

Churn salting.--Salting in the churn is practiced by some of our best butter-makers. I think there is no better place to incorporate the salt with the granular butter than in the box or barrel churn when the butter is at the proper temperature so the granules do not pack. A slow motion of the churn mixes the salt with the granular butter very evenly and quickly. When doing this work it is best to revolve the churn by hand, as it is not practical to impart by power as slow a motion as is necessary. There are now on the market churns in which the butter is salted and worked before being taken out. The Disbrow and Owens churns are of this style. The Disbrow is in use by some of 
the most progressive creamery men in the Elgin district.

Estimating for salt.-When salting in the churn it is best to estimate the amount of but-

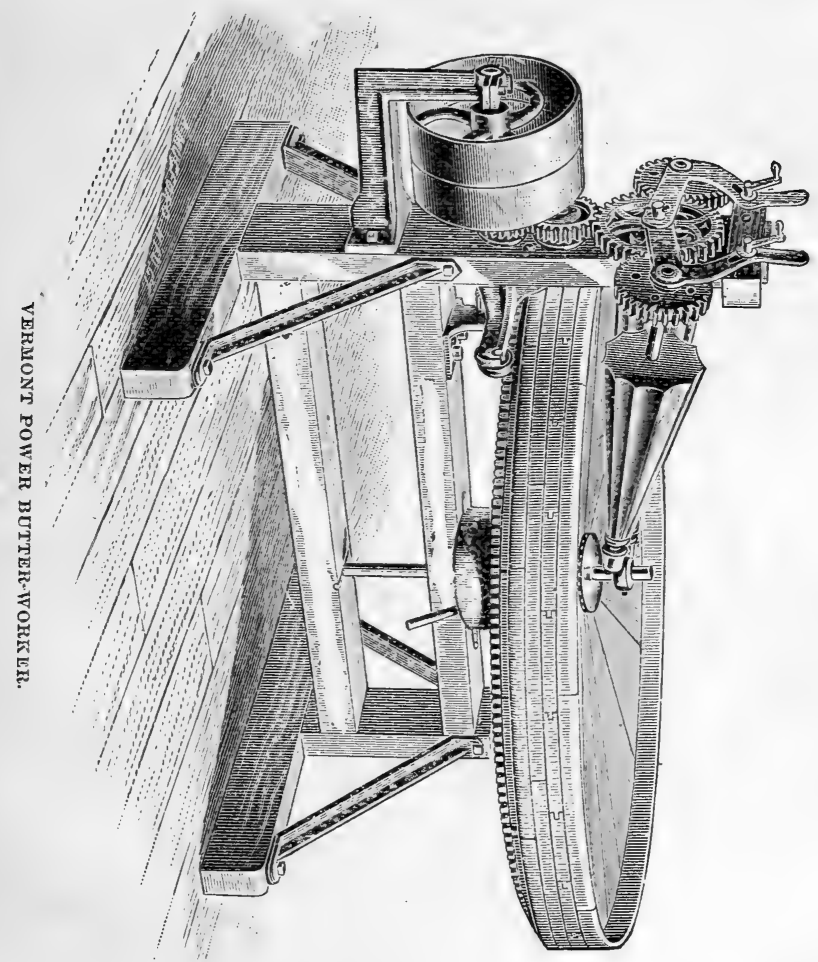

ter from the milk the cream was taken from. It is more reliable to figure from the milk than from the cream in the vat. 
One or two workings. - The majority of butter-makers now work their butter but once. One working has some advantages. The working is all done before the butter sets or becomes hardened from being exposed to a low temperature and can be worked more without injury to the grain than when allowed to harden before given the second working. I am now supposing it has been churned at a proper temperature. If it has been churned at 64 deg. Fahr. and is to be worked in a room with the temperature at 70 to $75 \mathrm{deg}$. I think it best to give it a second working after it has had time to cool and has come into condition to be worked. It requires more care and good judgment to finish butter at one working than it does when it is given two workings. When worked twice the appearance of the butter at second working is a sure guide as to when it is worked enough, as the time to stop is when the streaks caused by the salt are all removed. This rule cannot be applied when working once, as the salt is not all dissolved. I was one of the first in the Northern Illinois dairy district to put in practice one working, and I shall never forget how doubtful I was at first of its practicability. I took a sample of every day's make to my table for three weeks before I convinced myself that it was a safe way to do. This was fifteen years ago. I practiced it for 
three years when working the butter myself, but never reached the point that I dared depend on the appearance of the butter to tell when it was worked enough. I always timed myself or counted the revolutions of the worker table. I have met butter-makers and have had some in my employ who claimed they could tell by the appearance of the butter at the first working when it was worked enough, but I am still an unbeliever on that point. I admit that the work can be carried so far beyond the danger line that we are sure we will not have mottled or streaked butter, but I do not believe it is practicable to tell just when the danger point is passed. I have frequently caught a wise butter-maker-one that knew when he had worked the butter enough-with butter that showed mottled on the trier. I say be on the safe side and work by time or count the revolutions of the table. Twenty-five revolutions of most workers will carry over the danger line, but every butter-maker must make his own rule by timing the working and examining the butter the following day. Twice-worked butter has the best appearance. If I wished to do very fine work I should work it twice, and I recommend new beginners to practice twice working if they have a room at the proper temperature to hold the butter in while the salt is dissolving. This temperature should be $55 \mathrm{deg}$. 
or below. Either too warm or too cold makes it bad for the butter. Butter may have the second working the day it is churned; all the time necessary is for the salt to dissolve; four hours is sufficient with most makes of salt. Some very coarse-grained salt will require more time to dissolve.

Butter tubs.-Butter tubs should be first placed over a steam jet for two minutes and then soaked for twenty-four hours by being filled with water. Before using rinse out and rub the inside all over with salt, using no more than will adhere to the damp tub. This helps preserve the butter, prevents its adhering to the tub and causes it to show a tidy appearance when stripped. The various sized ash tubs are more generally used than any other package. Some markets prefer the spruce tub, and some use the tin-lined packages. The practice of lining butter tubs with paraffine paper is increasing. Some claim that it is a good plan to coat the inside of the butter tubs with paraffine. A safe rule is to use a package that pleases the parties who buy your butter. Do not run away with the idea that you know best and undertake to dictate to them, as you will probably create friction and may lose a good customer by such a course.

Care of packages.-Be sure that all packages are clean and sweet before you put butter in 
them. If you put butter in a package that is not sweet the butter will be injured before it is all consumed, you will be blamed for it, and you are not in a position to defend yourself.

Care in packing.--In packing butter be sure and get it solid in the package. Do not put in too much at one time. If not solidly packed it will not keep as well and will not appear well when stripped (as it is in many markets) before being retailed. Finish the top of the package to suit the purchaser if he has any choice. Some want it cut with a string or wire even with the top of the tub. Others want a straight-edge used with notches in it to cut down from one-eighth to one-quarter of an inch and a paste of salt put over the cloth circle. This salt paste will set and exclude the air, and is a good way to finish butter in tubs that are to be held for future use. A very fine salt is best to make this paste of. Make it thick enough so that it will just run, and then by striking the sides of the tub with the hand it will spread evenly over the whole surface of the tub and give it a very smooth and neat appearance.

Neat packages.-Use care in keeping the packages clean and neat. An untidy package creates a suspicion of the contents and is not complimentary to the butter-maker, neither is it to his employer. 
Marketing.-In marketing you must work your own way out. There are so many different conditions and different demands that it is impossible to make rules that will fit everyone. For near-by markets prints wrapped in paraffine paper afford a very satisfactory way to market butter. For shipping a long distance some kind of a tub is best. There is comparatively little print butter handled in the Central and Western States yet, but I believe this method of handling butter will increase. Whatever way you handle your butter do it well and make yourself a reputation. This is stock in trade to you. Every make of butter has an individuality and when a customer becomes acquainted with a certain brand he prefers it to some other brand or make that is equally good and would score just as high by an expert. This point the maker should take advantage of and profit by. If at any time you have butter. that is not up to your standard do not try to slip it through and "guess" it will pass. This does not pay in the end, as it may in many cases go to a particular customer and cause you trouble. Always mark such packages so you can describe them to the purchaser or consignee if you allow them to go with the rest of the butter. It is a much better way to not let them go with the fine goods, hut put them simewhere else on their merits. In this way 
you will hold your goods up to standard and. the reputation of your butter will grow and enable you to secure a larger price for your goods. Do not try to get something for nothing. It does not pay. 


\section{CHAPTER VII.}

\section{CARE OF SKIM-MILK AT CREAMERY.}

Skim-milk is of sufficient value to warrant its being well cared for at the creamery; but I am sorry to be compelled to say that in many creameries it is not properly cared for, though I believe the majority do as well as they know how.

Clean vats.-The skim-milk should be kept in vats that can be and are thoroughly cleansed every day. If the vat is allowed to become sour or there is some sour milk left over daily and the sweet milk is run into it the sour milk or sour vat acts as a ferment and the result is that the milk becomes too sour before the farmer gets it home and fed to the pigs. Some of the skim-milk needs to be kept until the following morning where it has to be drawn so far to the creamery that it will not be returned in time for the morning feed.

Sweet and sour.-The Vermont Experiment Station has done some work showing the comparative feeding value of sour and sweet skimmilk for pigs in which the sour milk gave the best results. I have been trying for two years 
to get the Illinois Experiment Station to do some work to show the comparative value of sweet and excessively sour milk fed to pigs, such as is returned from some creameries. An underground vat should never be used for skimmilk as it is not possible to properly clean it and keep it in good condition.

For calves.-For young calves it is necessary to have the milk sweet, and the creamery should provide some convenient way for the patrons to get it sweet and clean from the separator.

Scalding.-By scalding the skim-milk as soon as it leaves the separator it will keep much longer before souring. There was a device described in the dairy and creamery papers two or three years ago, I think by some man in Iowa, that is a successful contrivance and very inexpensive. It consists of a pail or tub to set into the skim-milk vat for the milk to run into from the separators and a wooden cover that drops inside not quite filling the tub or pail. This cover has a hole in it through which the exhaust steam-pipe from the engine is carried, reaching one or two inches through the wooden cover into the milk. The float cover prevents the slop from the boiling milk and aliows the milk to overflow around the outside of it. The exhaust pipe must not extend too far into the milk as it will create a back pressure on the 
engine. We have used this device in the summer months and know that it does efficient work, and it costs nothing but to conduct the steam to the vat. It comes nearer to getting something for nothing than we often reach. I am sorry that I do not know the name of the inventor, as I should be pleased to give him credit for it as a good thing. The creamery proprietor or manager should do all he can to insure the patrons getting their skim-milk in the best possible condition without too much expense.

Mutual interests should be regarded.-This is policy; as every little thing helps to make up the business. The patrons feel much better when the proprietor takes an interest in them and their work. In fact the interests are largely mutual. I know of some creameries where the skim-milk is run into underground vats and the proprietors will not comply with the wishes of their patrons and provide better means of keeping the skim-milk in good condition. Such creamery men are not deserving of patronage and they usually do not retain it a great length of time. If they could have the patron's experience in feeding the rotten milk for a time they would begin to think in the right direction. I am happy to be able to say there are not many of this breed of creamery men left and the earlier they are wiped out or reformed the better. 


\section{CHAPTER VIII.}

\section{CARE OF BUILDINGS AND UTENSILS.}

The work-rooms, utensils, and the drainage are vital points in the creamery work. In some cases they are sadly neglected.

A weak point.-I sometimes think that here is the weakest part of our creamery work. Many of our creamery employés have not had the proper training in this line. We have many men that are neat and orderly about their work and an honor to their business. It does me good to meet such. I feel that I want to shake with them.

Tinware.-All tinware in the creamery should be cared for the same as in the dairy so far as possible. The vats, churns, and butter-worker of course cannot be put out in the sun to be aired and sweetened. Tinware should be wiped dry after scalding unless it becomes hot enough by scalding to dry itself.

The churn.-The churn is the most neglected impiement in our creameries. They are a hard thing to keep clean and sweet, especially the box-churns, as they are so hard to get into, but 
they can be kept perfectly clean and sweet by the use of hot water and scrub brush and steam for scalding. A person can make use of his

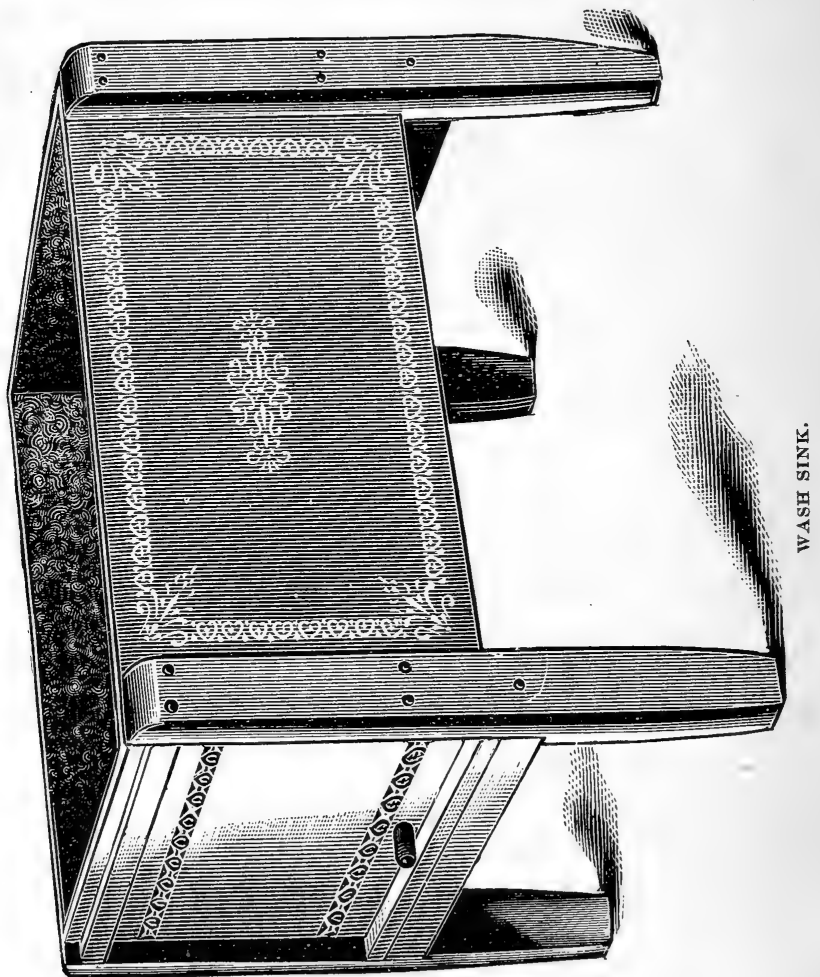

hands and nose in this work. A dirty churn can be detected by a blind man, even if he has lost the sense of smell, as the sense of feeling will tell whether it is clean or not. 
How to scald a churn.-To scald a churn use a hose to conduct the steam into the churn, having the churn nearly closed, giving an opportunity for the steam to escape sufficiently so that it will not burst the churn. We once had a churn confined steam. steam shrinks the joints, espeoak or ash, but taken as the without being exposed long enough to injure it. Care is needed here as in every other place.

Use care with a new churn. Often a new churn is injured by not loosening the nuts on the stay rods as the churn swells from the water used in cleaning it. This should be closely watched for a few weeks. I have seen hardwood churns ruined in this ruined by pressure of Too long exposure to the churn so as to open cially if the churn is this risk need not be churn can be sweetened

way. They are usually made of thinner lumber than is used in soft-wood churns, and it will spring out of shape more easily. Neglect to keep the churn clean is the cause of much poor butter. The butter may not show any serious 
defect when fresh, but the germ is planted and will develop rapidly.

A case in point.-A Boston butter dealer once told me of traveling from Boston to Iowa, 1,200 miles, to find out what was the trouble with the butter from a creamery in which he was interested and found it in the churn, which had not been properly cleaned and cared for.

The butter-worker.-The table butter-worker is easily got at to clean: It should be thoroughly washed with hot water and a brush and then scalded with boiling water. The churn and butter-worker should be scalded and then cooled with cold water before using. All wooden utensils should have the same treatment. Also the woodwork of the vats.

The creamery drain should have a trap to prevent any foul air returning to the interior. Many creameries are faulty in this way, the managers apparently not seeming to realize the necessity of pure air and thorough cleanliness. Cream and milk will absorb odors that the nose cannot detect. I have several times traced trouble with butter to causes that my nose could not detect without close contact.

Constant care necessary.-Constant care is necessary to success and in no business does this show more plainly than in the creamery. The drainage should be carried from the building in underground sewer pipes. If there is 
CARE OF BUILDINGS AND UTENSILS.
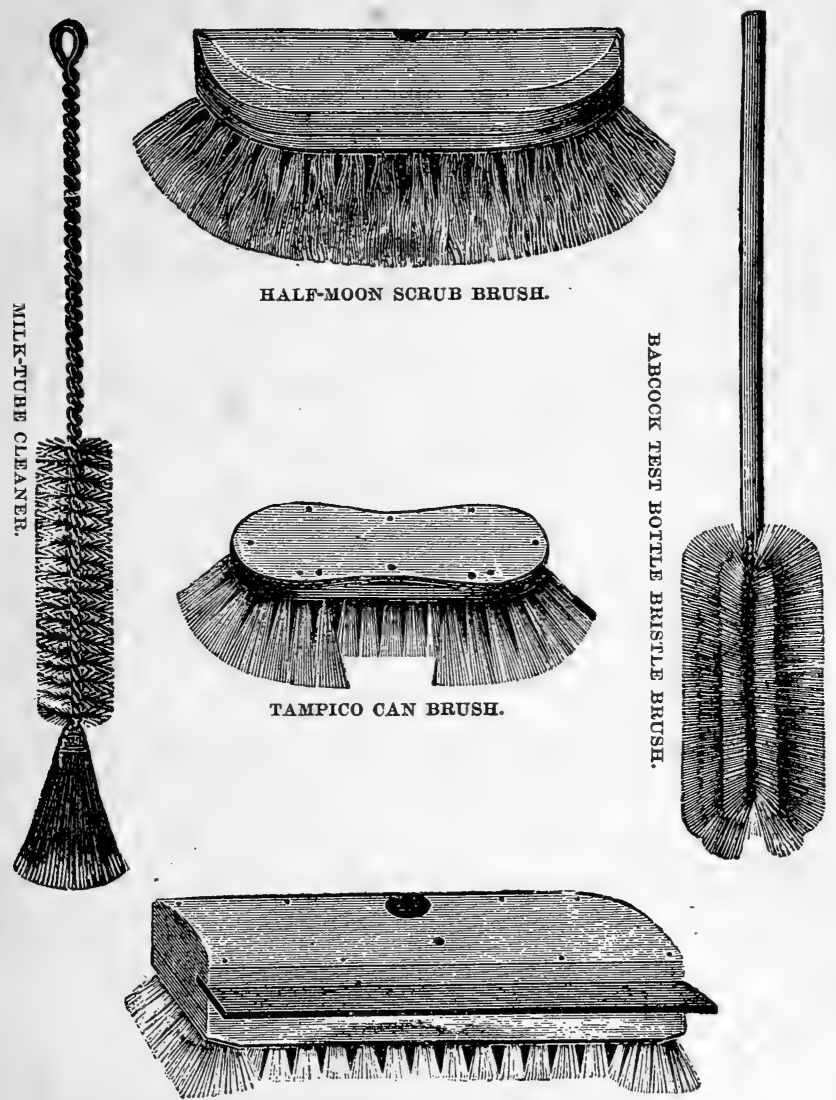

COMBINED MOP AND SCRUB BRUSH.

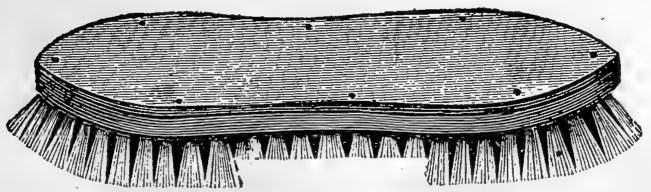

COMHON FLOOR SCRUE BRUSH. 
any necessary slop in delivering the skim-milk or other by-product from the creamery keep it sweet by the use of boiling water and disinfectants. There should not and need not be any bad smell about the creamery outside or inside. All pumps should be so constructed as to be taken apart to be cleaned. Insist on this point.

Leaky vats.-Leaky vats are often the cause of trouble as a very small quantity of milk when mixed with the water surrounding the vat or allowed to remain in the water space surrounding the tin vat, will. soon make a stench that will go all through the creamery and breed any amount of trouble. The tin vat should be removed from the wood part of the vat frequently and the wood part thoroughly cleaned. The gutter that conducts the waste water and washings to the sewer is also a source of trouble if not closely looked after. It should be treated to boiling water after the floor is cleaned. Too much care cannot be taken in this part of the work. If any offensive smell meets you on entering the creamery it should be hunted out and removed as soon as possible.

The boiler.-The boiler should be blown off and cleaned out as often as necessary to keep it clean. Have a certain day or days of the month for this work and do not postpone it, as delays are dangerous. Draw the fire and let the mason work cool partially before blowing 
off; when it can be had use a hose with a pressure of water to wash the boiler out. With some water a boiler can be kept clean without using any kind of boiler compound, but with

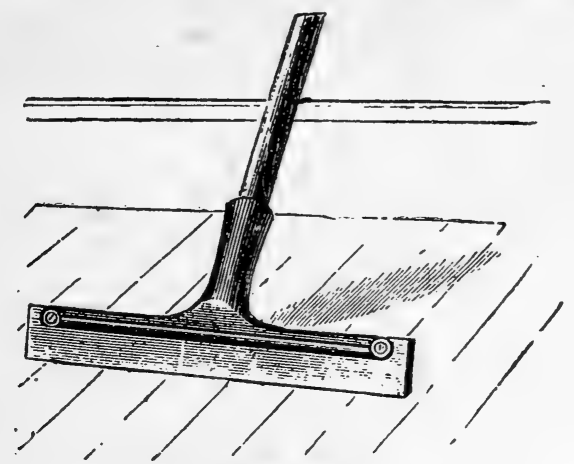

IRON MIOP HEAD.

other water something of this kind is needed. When anything of this kind is required be careful that you secure something that will not injure the boiler. Do not use anything that

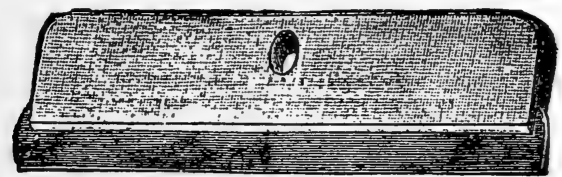

WOOD MOP HEAD.

you know nothing about. If burning soft coal the flues should be cleaned daily, the best time being in the morning before starting the fire; and if it is a slow-steaming boiler or there is a poor draft it may be necessary to clean in the 
middle of the day. If you ever get caught with low water in a boiler draw the fire and allow the steam to go down before filling it.

Results of neglect.-I recently saw a case where the flues of a boiler began to leak and had to be repaired, and an investigation of the case developed the fact that the fire had been banked to hold over night and the water had become so low from the lost steam in some way that the flues were exposed without water covering them and a leak was the result. I also saw a locomotive style of boiler leaking from a crack in the crown sheet caused from carelessly letting the water get too low.

Look to safety-valve daily.--Try the safetyvalve every morning to see that it is not stuck fast, as they will occasionally stick. Keep the valves all packed so they will not leak. Keep all steam and water joints tight. Leaky valves and joints are a poor advertisement for the creamery manager.

The engine.-The engine needs care as well as the boiler, though there is not so much danger resulting from carelessness. Keep all bearings oiled and the boxes tight enough to prevent pounding. If you have not had experience that has fitted you to do this work get some one to teach you. The trouble with some men is that they do not appear to realize the difference between an engine key and a forty- 
penny spike. Either one gets a full blow of the hammer. We have had men in our employ that could not keep their engine in order, while their successors would have it in the best of order in a very few days. This comes largely from a lack of perseverance about details.

Look to the belts.-Keep the belts in order; do not wait for them to break before repairing them. They should be examined at the end of the day's work and if out of order repair them before you call the day's work done, so as to be sure of making the next day's run. It is a terrible annoyance to have a belt break when there are several patrons waiting. This, if repeated many times, destroys the confidence of the patrons in the manager. Ten men with their teams waiting one hour means a day's work, or $\$ 2.50$ to $\$ 3$, lost. 


\section{CHAPTER IX.}

\section{SUGGESTIONS TO THOSE ABOUT TO BUILD A CREAMERY.}

Location.-When about to build a creamery one of the first points to settle is the location. Here we should be influenced by the chance for good drainage and the general lay of the ground. Some prefer to have a creamery built with different levels, so that the milk and cream have a down grade from the weigh-can through to the churn. When such a location can be secured it is nice in many ways, but it makes a hard place to work, as there is so much going up and down.

Which is preferable.-I prefer a creamery built all-except the receiving-room-on the same level and pumps used to elevate the milk and cream. The receiving-room should be enough higher than the main floor so that the milk will run from the weigh-can into the receiving vat and then be pumped into the tempering vat. The cream also to be pumped high enough to run over a cooler placed over the cream vat so that the cream drops from the cooler into the cream vat. 
Can elevate cream vat.-The cream vat may have its legs extended so that it is high enough to flow into the churn. All pumps in a creamery that are used to pump whole milk and cream should be so made that they can be taken apart to be cleaned, and it is best that the skim-milk pump be made in the same way. This removes the objection to a pump in a creamery, or at least it removes the vital objection of uncleanliness, as a pump made so as to be taken to pieces can be kept as clean as any other utensil in the creamery.

Creamery floor.-The floor should be put on the ground, and if made of wood should be laid in cinders, as it will then not decay as fast as if laid on the dirt. I have had twelve years' experience with both wood and cement floors, and my opinion of the merits of the two is but little changed from what it was eight or ten years ago. I think a little more favorably of the cement floor than I formerly did, and think I should now use it if I could be sure of securing a man to put it in that I knew understood the business; otherwise I would use twoinch flooring, filling up between the joists with cinders so the flooring would rest on the cinders. A cement floor will wear out in time and is difficult to repair. All creamery floors should pitch to the gutter.

A trap necessary.-Do not fail to put a trap 
in the sewer. This may be of sewer pipe or of wood. A wooden trap put inside the building

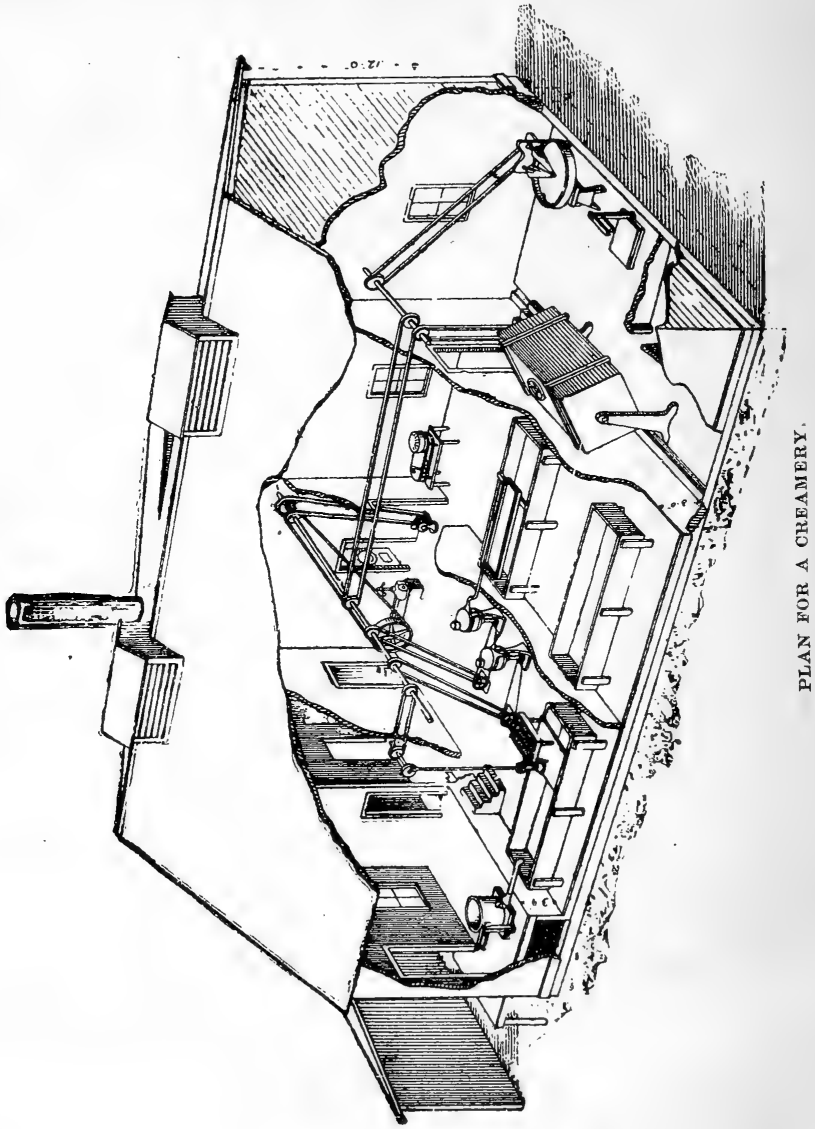

is the most convenient to clean and keep in good order. It is simply a box which the gutter flows through, the ontiet being at least 
one inch lower than the inlet, with a partition in it which reaches within two inches of the bottom of the box and below the outlet. This

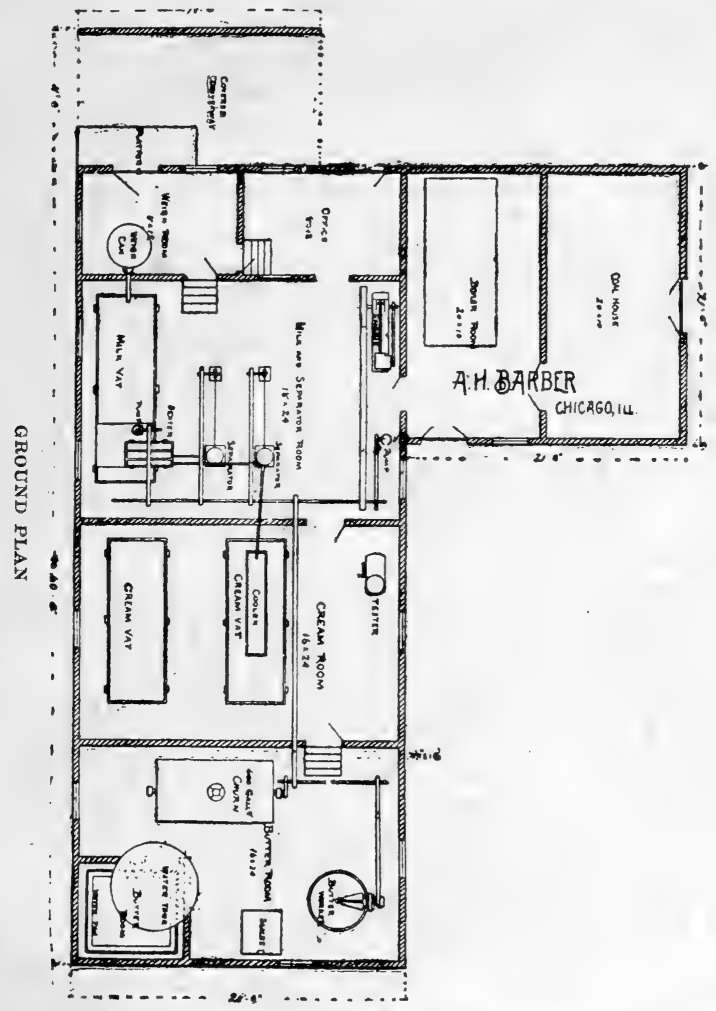

box is built or placed under the floor in such a position that the cover forms a part of the floor and can be removed readily to clean the dirt out of the trap. 
Importance of drainage. - The drainage should be conducted at least forty rods away from the building and a greater distance is better. Creamery drainage is very offensive in hot weather.

Criticisms of plan.-The accompanying plan shows a very well arranged creamery. The driveway and receiving platform should be two feet higher, which would make it much easier emptying the cans into the weigh-can. The engine is in the room with the separators. This is as it should be. The engine should not be in the room with the boiler. There is too much dust from the coal and ashes and it is more convenient to get at in the room with the separators. The cream vats are in a room separate from the separator-room and churn-room. The churn and butter-worker are in one room. This is a good arrangement. This room should be so arranged that the temperature can be controlled during the time of churning and working the butter. The temperature of the cream must be held down during the churning process to secure the best results in quality and quantity of butter. A high temperature vill not secure the desired object. The temperature may be controlled from the refrigerator or by having an ice-box in the room built so as to obtain a circulation of air about the ice. It is desirable to control the temperature of the cream-room 
also, and it may be done in the same way that the churn-room is controlled. I do not like the plan of having the separators, cream vats, churn, and butter-worker all in one room. It is impractical to control the temperature of such a room in hot weather so as to secure the best results. An ice-cooler in a cream or churnroom helps to secure a pure atmosphere, as the air deposits impurities when coming in contact with ice which are carried off with the water. This can be demonstrated by tasting water from melting ice that has impure air circulating about it.

Tempering vat.-Have an overflow in the tempering vat and conduct the overflow back to the vat from which the milk is pumped. Or when the tempering vat is lower than the receiving vat the milk can be allowed to flow into the tempering vat and be controlled by a valve to which a float is attached. It is best to keep a uniform depth of milk in the tempering vat. This is not a necessity when a float is used in connection with the separator faucet, as is the case with most separators. The object is to secure a uniform feed of milk to the separators. This must be accomplished in some way.

Act with caution.-The cost of a creamery is a matter for careful consideration. Every dairy implement dealer will furnish plans and 
most of them estimates of the cost both of building and equipments. Go slow and be careful in this part of the work. Do not make con-

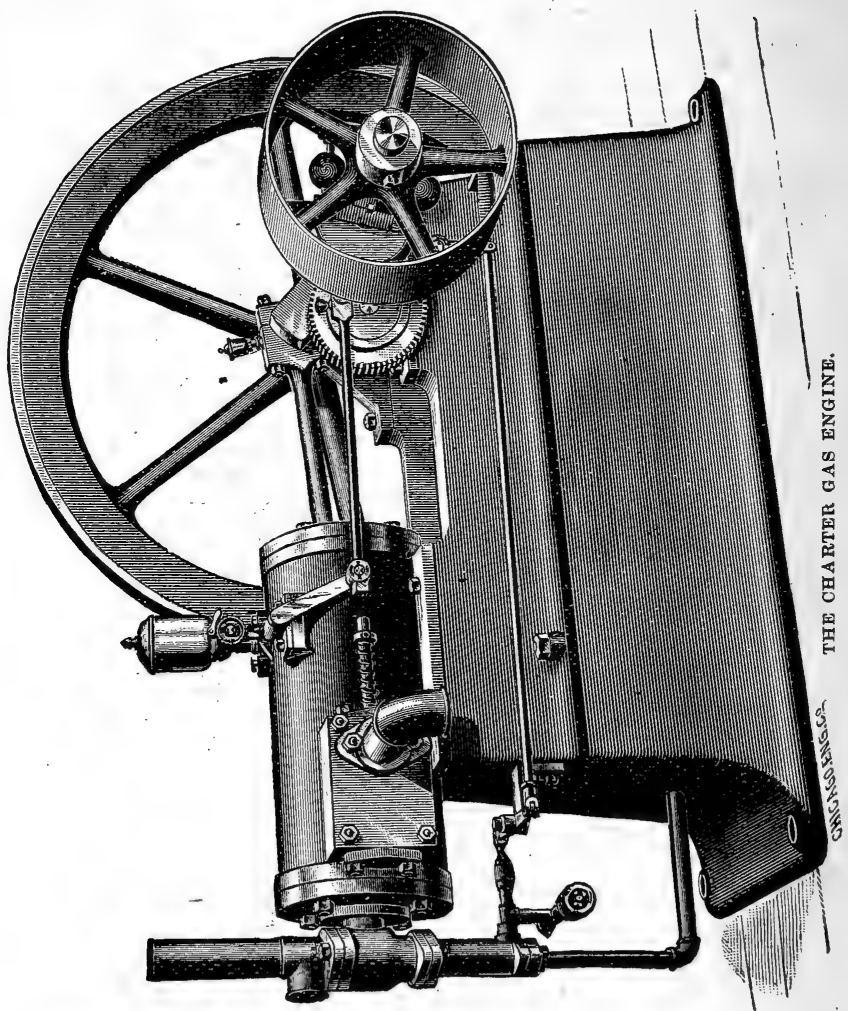

tracts with parties until you have informed yourself of their responsibility (as there are a plenty of reliable firms) and have learned what such a plant as you wish to build should cost. 
If there is doubt about the amount of business that will be done keep on the safe side and do not build too large. If the business outgrows

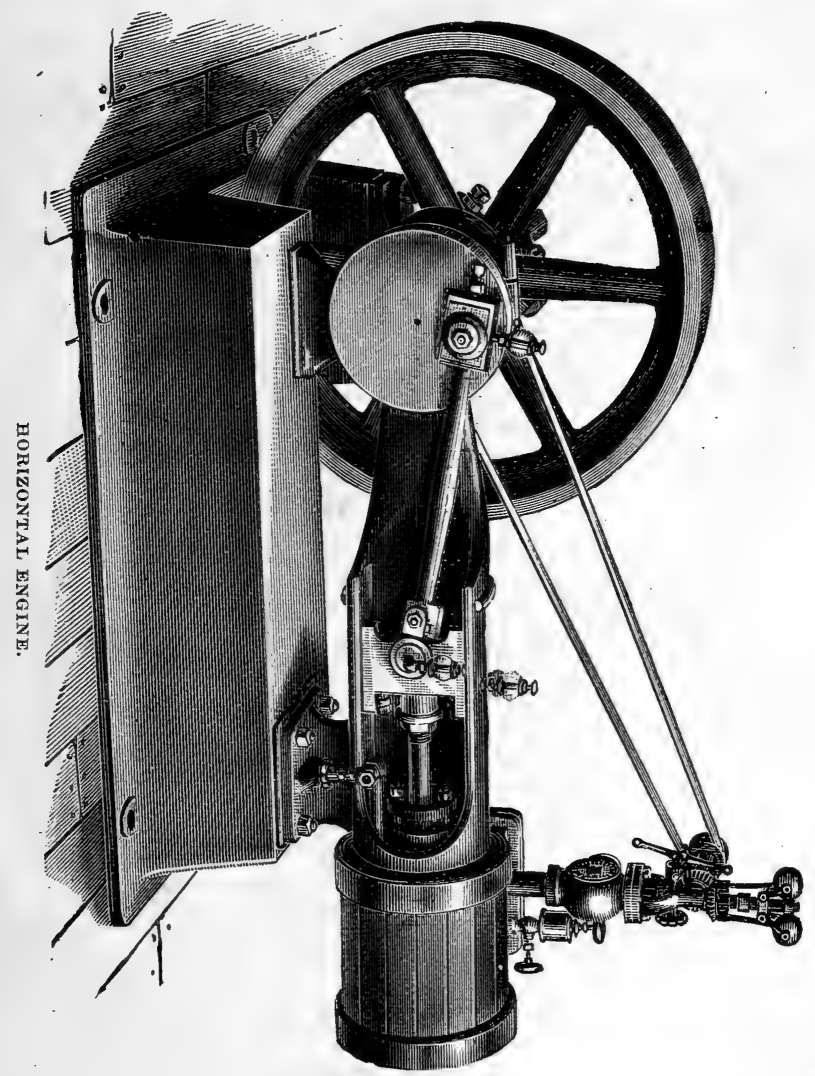

the plant you can afford to enlarge it. Keep this in view when building and arrange so it 
can be enlarged if needed and still be in convenient shape.

Necessary investment.-The amount to be invested in a creamery plant depends on the amount of business that is expected to be done. $\$ 2,500$ to $\$ 3,500$ is sufficient to build and equip a creamery to handle 10,000 to 15,000 lbs. of milk per day. The cost will vary with the cost of material in different localities.

Boiler and engine.-When purchasing boiler and engine have the boiler of 50 per cent greater capacity than the engine. There are two reasons for this. One is the amount of steam required for purposes about the creamery and the other is that the larger boiler does not need as much time spent in firing. This is quite an item in a creamery as a person cannot be employed for this work alone.

Look out for a good draft.-Have as direct a draft as possible to the smoke-stack. Every turn checks the draft. A good draft is economical of fuel, also of time and patience. A person that can have patience with a poor-draft boiler will probably have sufficient to get along with the patrons. As annoying work as I ever did was firing a boiler with a poor draft. The fact that this is an unnecessary evil makes it more aggravating. Too low a smoke-stack or too many turns is usually the cause. In closing this chapter I would ad- 
vise anyone about to build a creamery to get what information they can at home, then visit some modern-built creameries and get the latest ideas. The time and money necessary for this will be well spent and probably saved several times over before the creamery is completed. Do not go it blind in building a creamery. Do

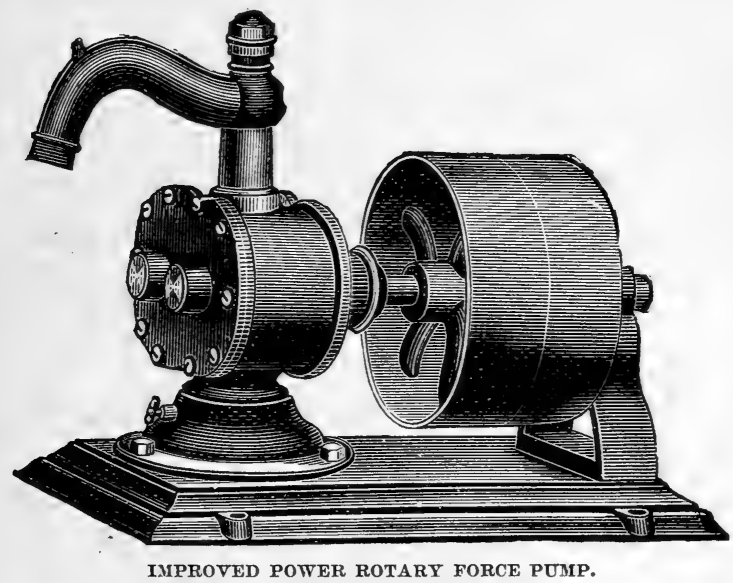

not rely too much on some interested party. See your way clear before starting out. There is some money in the business when managed with skill, and if not money can be lost and is lost very fast.

Skim stations.-I have had some experience with these, having had an interest in two, one of which has been in operation three years and the other one two years. This was a live ques- 
tion in the Pennsylvania State College dairy school in 1893, the class becoming so much interested in it that leaders were selected and an evening spent in discussing the question pro and con. I am now in the position in which I do not like to see another person; i. e., on the fence. I am satisfied that there are localities and conditions where it is advisable to operate skim stations in connection with a central creamery. But I do not believe it is desirable under all conditions. It is necessary where a skim station is built new to be operated summer and winter to invest about two-thirds as much as would be necessary to make it a complete plant. Power must be had, also water and a separator. This, with vats, shafting, pumps, etc., added to the cost of the building makes more of an investment than is at first thought to be necessary. A good supply of cold water is necessary to cool the cream, in lieu of which ice must be used, as the cream must be thoroughly cooled as fast as skimmed and kept cool until delivered to the central creamery. A cooler like the Star or the Danish Weston are very efficient for this work. If this cream is not thoroughly cooled from the separator or is allowed to become warm on the road it will churn and also become too sour and there will be trouble with the butter. I know these difficulties can be overcome, as I 
see them overcome day after day with the temperature up in the nineties. Sometimes room can be rented for this purpose at a price to make it more economical than to build. Power may also be rented to advantage at times.

I do not feel like advising for or against the skim station. I believe every one must study and figure his own way out in such matters. My firm is operating one skim station at my farm, where I had a farm creamery building in which I made butter when I lived there. I also had a well and a steam boiler, so the main investment necessary was in the separator. In this line there are scarcely two cases alike, so it is impractical to give intelligent advice. Experience is valuable, but we often secure it at too great a cost. 


\section{CHAPTER X.}

\section{GATHERED-CREAM WORK.}

My experience in the gathered-cream business began in the early days of the work when all the cream was bought by the gauge, or 113 cubic inches, which was supposed to make a pound of butter, no matter whether it was winter or summer, nor whether it was raised in ice water or in water at 60 deg. Fah.

Surplus and shortage.-We always had a surplus in the summer and a shortage in winter that more than balanced the surplus of the summer. The shortage always came when the butter was at the highest price of the year and one pound shortage would be equal to two pounds surplus in money value. I learned several things in this work and it cost me something to learn. I learned some things that I did not care to learn as it caused me to have less faith in the honesty of some persons, and I also learned that a patron could secure pay for more than he sold without being dishonest. In fact if he handled his milk in a way to secure all of the cream possible he would secure a quality that when sold on the gauge plan would beat the creamery eight months out of twelve. 
The cream gauge.-The gauge of 113 cubic inches was made to fit arerage work, but average work does not secure all of the cream; it allows the profit to go to the calves and pigs in the skim-milk.

Comparative profit of whole milk and gathered-cream work.-In 1882 I made some comparisons of our gathered-cream and wholemilk work to learn what our patrons received for their milk by the two systems. In making

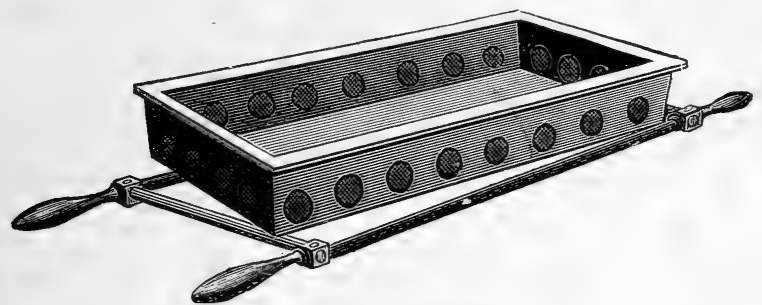

CREAM VAT STRAINER.

this comparison I allowed 10 cents per $100 \mathrm{lbs}$. for delivering the milk to the creamery or cheese factory and 15 cents per $100 \mathrm{lbs}$. for the difference between the feeding value of skimmilk and whey, and deducted this 25 cents from the price received by the patron who delivered his milk at the creamery before comparing it with the price received by the patron who sold cream. At that time we kept a record of the cans skimmed for the patrons, and knowing what the cans held it could be got at as closely as necessary. Figured on this basis the result 
was as follows for the several months from May to November:

\begin{tabular}{l|c|c|c|c|c}
\hline & $\begin{array}{c}\text { Cream- } \\
\text { ery divi- } \\
\text { dend. }\end{array}$ & $\begin{array}{c}\text { Less } \\
\text { twen- } \\
\text { ty-five } \\
\text { cents. }\end{array}$ & $\begin{array}{c}\text { To compare } \\
\text { with gath- } \\
\text { ered cream } \\
\text { dividend. }\end{array}$ & $\begin{array}{c}\text { Gathered } \\
\text { cream div- } \\
\text { idend- } \\
\text { cents. }\end{array}$ & $\begin{array}{c}\text { Differ- } \\
\text { ence- } \\
\text { cents. }\end{array}$ \\
\cline { 1 - 5 } May ........ & $\$ 0.89$ & 25 & $\$ 0.64$ & 58 & 6 \\
June........ & .83 & 25 & .58 & 49 & 9 \\
July......... & .81 & 25 & .56 & 47 & 9 \\
August..... & 1.02 & 25 & .77 & 49 & 28 \\
September... & 1.25 & 25 & 1.00 & $61 \frac{1}{2}$ & $38 \frac{1}{2}$ \\
October..... & 1.43 & 25 & 1.18 & $74 \frac{1}{2}$ & $33 \frac{1}{2}$ \\
November... & 1.49 & 25 & 1.24 & 89 & 35 \\
\hline
\end{tabular}

My firm formerly did gathered-cream work at all of our creameries, but it gradually changed to the plan of delivering of the milk to the creameries, so that we have not for several years done anything in the gathered-cream work. When in that work I tried as hard to make a success of it as I have of any part of mybusiness. These comparisons were made when we were making butter and cheese, setting our milk in pools to

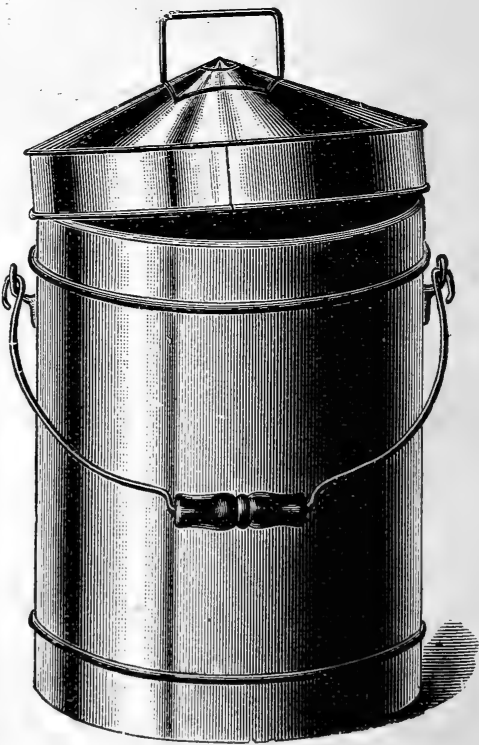

DRIVER'S MEASURING PAII. 
raise the cream and making the skim-milk into cheese. With the advent of the separator the comparison would be more in favor of the whole-milk work.

Test plan in gathered-cream work.-After a few years' work with the gauge plan of paying for cream we adopted the test plan, using the oil-test churn to decide the butter value of the cream. This proved to be quite reliable

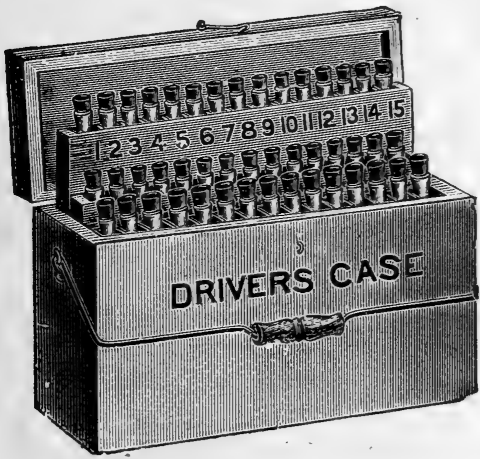
and accurate. The greatest trouble we encountered was to make the cream gatherers realize the necessity of care in securing the sample of cream to be tested. With careful work we found the test and churn to agree so closely as to surprise us. This plan of paying also did justice between the different patrons.

Pioneer work.-I look upon gathering cream as pioneer work. There are many sections where it can be made a success and the wholemilk work could not. The gathered-cream work can cover so much more territory that it can secure a business where there cannot be milk enough secured to make a paying business. 
Gathering cans and tanks.-In my early experience I used the common eight-gallon milk can to transport the cream; later on we

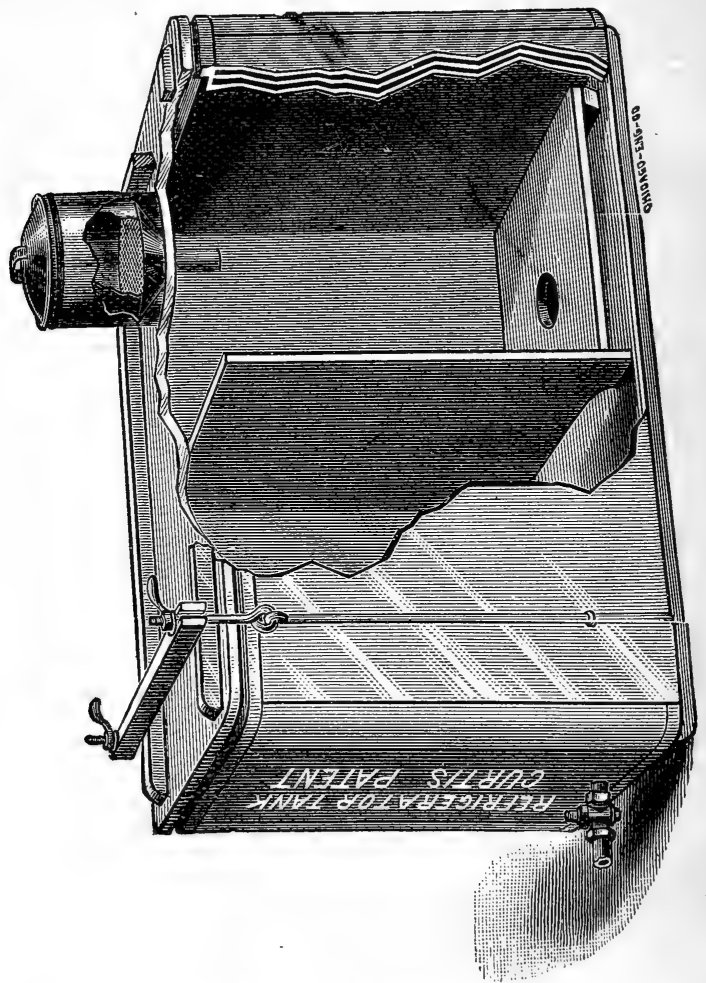

used the jacketed can, which had a space outside the cream can for air. It also had a floating cover that rested on the cream to prevent churning by agitation of the cream. Later still the tank or vat came into use, and this 
was a great improvement over the can. There was less-churning and the temperature was much less affected by the weather both in winter and in summer.

Use of ice.-In extreme hot weather we used ice in the vat, putting it in at the creamery

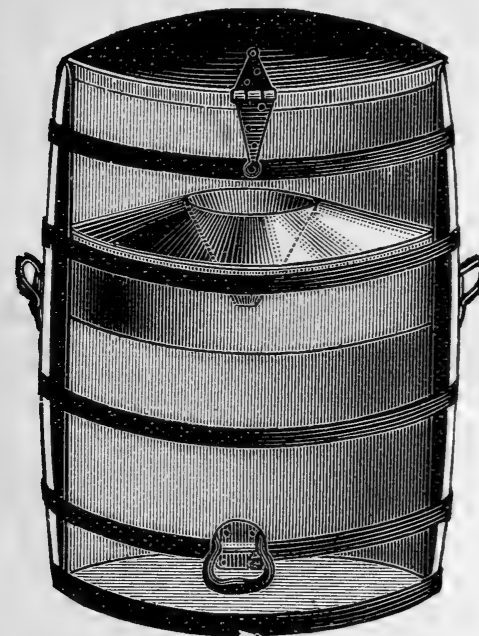

HANEY'S JACKETED CREAJ'CARRIER. when the wagon started on its daily route. I do not like to use ice in contact with cream or butter, but it is better to use it than to allow the cream to become too sour, as it is sure to in extreme hot weather without some precaution. It is desirable to get the cream to the creamery sweet and then ripen it to suit your ideas of what brings the best results.

Churned the day gathered.-I have in some cases cooled and churned the cream the afternoon after it was brought in, knowing that it would be too sour the next morning to make a good quality of butter.

Gathered-cream and whole-milk butter.It is possible to make as fine butter from 
gathered cream as is made by the whole-milk creameries, but it is not done as a rule. Where it is done all the conditions are favorable. If all the patrons would use a submerged can and ice-water to cool the milk, which should be skimmed at twenty-four hours and the cream delivered at the creamery sweet, there is no reason why first-class butter cannot be made, but if the patrons are allowed to use all sorts of vessels to set their milk in and set it in all sorts of places, where it will be exposed to impure air such as may be found in a vegetable cellar or in the kitchen, or various places that might be mentioned, it cannot be expected to make fine butter. I have seen gathered cream that when heated to $110 \mathrm{deg}$. and exposed to the nose was a revelation to the possessor of the nose. It revealed where it had been beyond question. Such cream cannot be made into fine butter. If I was about to start a gathered-cream business I should use and compel the use of some submerged cans, even if I had to furnish them and rent them to the patrons.

Submerged can.-The submerged can is a protection from heat and cold as well as foul odors. This system can be used in any cheap room or house, or even out under the trees where it is convenient to the water.

Pioneer work.-We had much to contend 
with in the West in the pioneer work with gathered cream, as many did not have water and were compelled to use pans and crocks to set

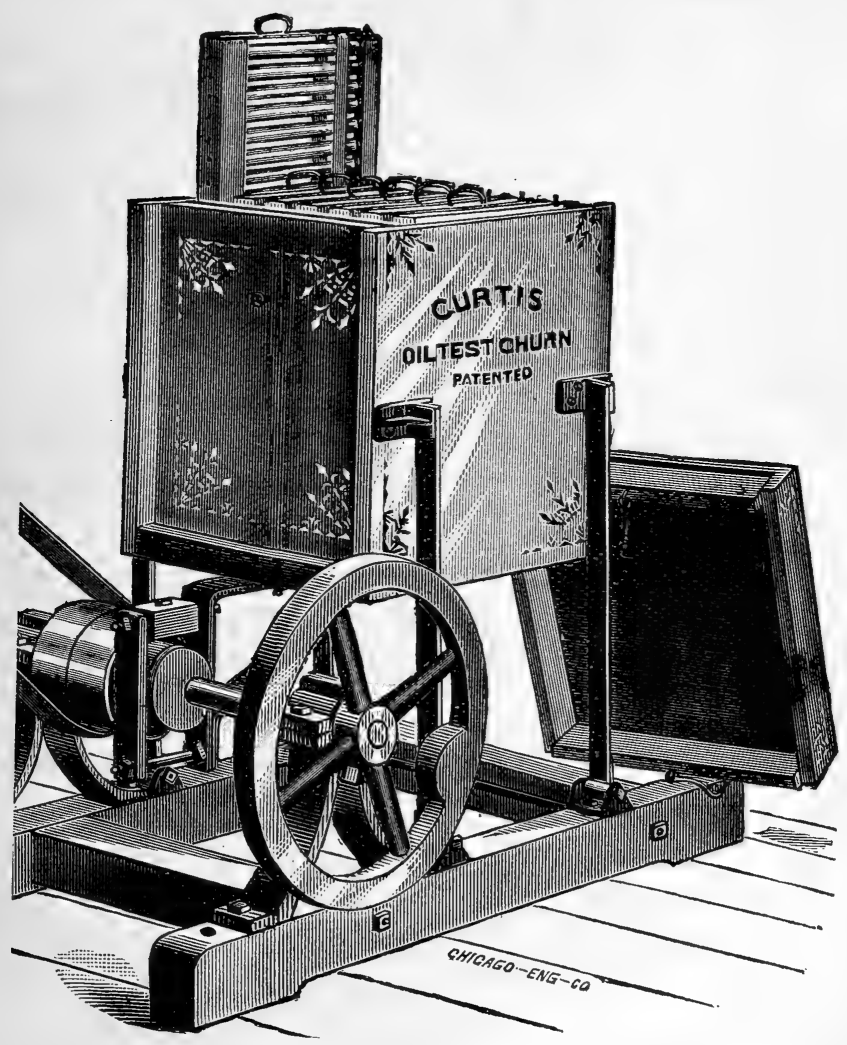

their milk in, and to set the same in many places where they should not. The Eastern or New England creameries have not had one- 
fourth as much to overcome in this line as we have in the West. I know this, as I am a New Hampshire-born man, coming West when sixteen years old. I say to all gathered-cream men that are not using some dairy test that you should do so by all means. If you succeed in doing justice between yourself and your patrons as a whole, you cannot do justice between the different patrons without the test;

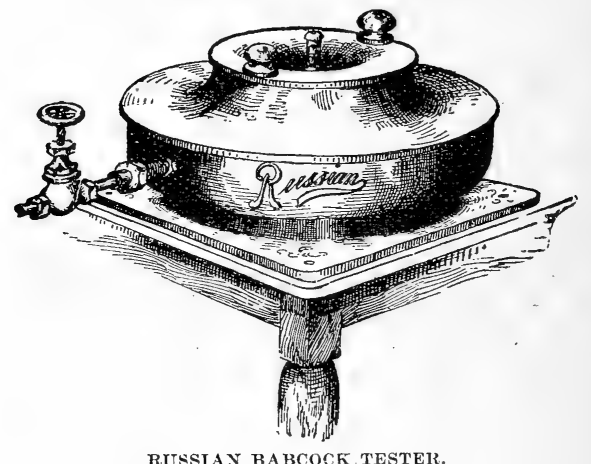

and here is the foundation of all creamery work. An injustice anywhere is sure to breed dissatisfaction and end in justice prevailing or in the business going to pieces. This is inevitable.

The Babcock test.-The Babcock test has come into the field since my firm dropped the gathered-cream work. We use the Babcock machine to test cream that we ship to Chicago, and I see no reason why it is not an improve- 
ment over the old oil-test churn for use in gathered-cream work.

Since writing the foregoing I have received from the Connecticut Agricultural Experiment

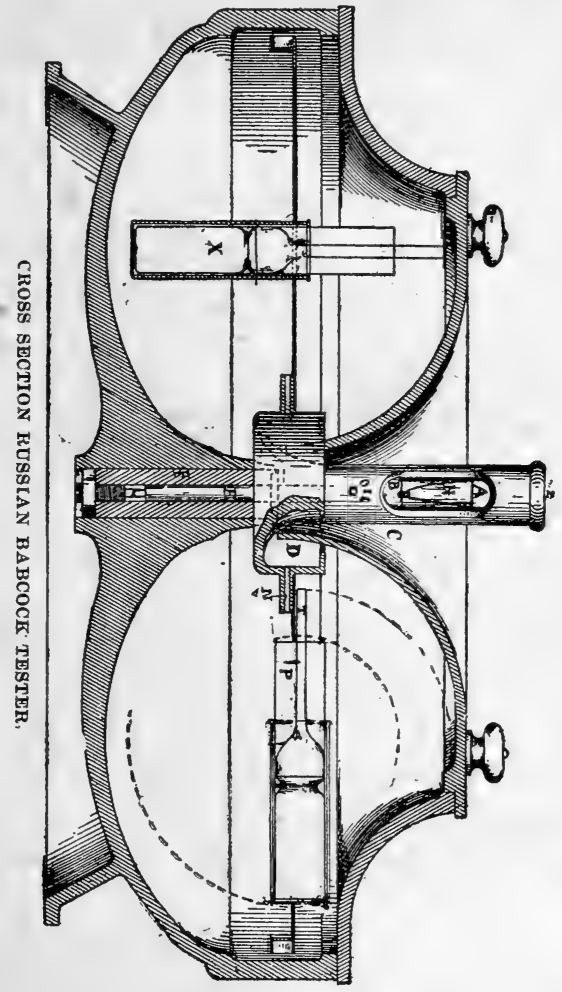

Station, New Haven, Conn., "Bulletin No. 119," on "The Babcock Test as a Basis for Payment in Cream-Gathering Creameries." 
It first shows the defects of the old gauge system, which I have already written about. The apparatus for weighing and sampling the cream is illustrated, and consists of a pail eight inches in diameter and twenty-two inches deep, a spring balance, a sampling tube, collecting bottles for the driver to bring samples of each patron's cream at each trip, and the composite sample bottle, which may be a half-pint jar. Instructions for sampling and weighing are given. Bichromate of potash is recommended as a preservative of the composite samples. An 18 c. c. pipette is used to measure the cream for testing. The test bottle used is graduated from 0 to 30 , having a large neck, it being made to test cream. The acid, the acid measure and the centrifugal machine are the same as used in testing milk, and the work of testing is practically the same as in testing milk.

The bulletin contains six very interesting and instructive tables showing the variations in cream from different patrons, besides much valuable information for persons operating gathered-cream creameries, and they should secure a copy of it if possible. 


\section{CHAPTER XI.}

\section{A TALK WITH CREAMERY EMPLOYÉS.}

There is probably no line of employment where there is more to induce the workmen to slight their work than in creameries. There are no fixed hours of labor, but it is commence early and work until the work is done. It may be necessary to commence at 4 o'clock in the morning and work until $2 \mathrm{p} . \mathrm{m}$. This is frequently the case where one man is doing the work and it is necessary to do the churning and butter-working before the milk arrives. Or the labor may commence at 6 o'clock and end at 4 o'clock p. m. In either case there are no regular hours of labor. Here is where many stumble. The situation is like when we were boys and were told that when we had done a certain amount of work we could go fishing or hunting, or to play at some favorite game. We all remember how hard we would work to get this amount of work done as soon as possible so as to have as long a time as possible to hunt, fish or play, as we preferred. The situation is very similar with many creamery employés, 
and the result is there is too much hustle and hurry. The work many times is not properly done. There is a failure to get the water used in washing hot enough to remove the grease, or if it is at the proper temperature when commencing work it soon cools so that it does not do effectual work, and the desire to get through as soon as possible leads to the use of water not possessing the necessary heat. There is really no time gained here, as hot water does its work so much quicker that time is saved by renewing the water. As soon as water fails to remove dirt and grease stop and renew it and make time by it. I find more men stumbling here than anywhere else in the creamery work. When a person fails to keep the utensils in the creamery clean he is negligent about the patrons' cans, and the milk gets off flavor from this cause and is received in an off condition. There is a general loss of grip on the work all down the line and the result inevitably is a loss of flavor in the butter, a loss of profit and general demoralization. You may think this is overdrawn, but it is not. I have repeatedly seen this very situation. My firm is just now putting in a boiler to replace one that is six years old and that was ruined by the foreman failing to care for it as he was instructed to do and deceiving us in regard to the matter. $\mathrm{He}$ failed to clean the boiler and allowed the mud 
and lime to collect in the bottom until it reached the lower row of flues and blistered the boilers over the fire. We got it patched at the time, but we might better have thrown it away, as we have expended on it altogether nearly enough to purchase a new boiler and now we are compelled to throw it away; and we are putting in place of it a boiler that is twice as old and is nearly as good as new. The first was ruined by carelessness and the other one was cared for properly and is still a good boiler. I write this to show the difference in men.

Scarcely a year passes that we do not drop men from our employment simply because they have not grip enough to do as well as they know how. "They "play boy" with their work and the result is they have to make way for some one who will attend to business. I frequently hear men say they are earning all or more than they get. On the other side I recently heard a young man say he did not expect an advance in salary until he had proven by his work that he was worth to his employer - more than he was receiving. He recently secured an advance of $\$ 25$ per month at a time that many were accepting less salary and some losing their positions entirely. Every true man or woman respects a person that does honorable work well. I have seen ditchers that I felt like 
lifting my hat to, and so it is in all lines of work. A faithful, intelligent workman is sure to reap his reward. If one employer will not do him justice another one will; we all find our level in time; this is inevitable. And whether this level be high or low depends on ourselves to a great degree.

Do all your work about the creamery in a tidy manner; put the dishcloths through the vat gates and do not leave them so that a person's finger inserted in them will show grease or filth. Fix those milk pumps so you can take them to pieces to be cleaned. They are unsafe if not so treated. Clean all utensils so you are not afraid to have your best suit come in contact with them and are not ashamed to show them to a tidy housekeeper. By the way, a tidy housekeeper could give many of us pointers that would be of great value to us. One of the best men I ever had in my employ never left the creamery in the afternoon until he had inspected all the machinery, belting, etc., and knew it was in condition to make a day's run. This man was given employment as long as he could be induced to stay. A man that will do as well as he knows how every day in the year is a jewel, and he is sure to succeed. The utensils in a creamery are short-lived with good care, but with a careless man they are donbly so. Some men handle everything properly 
A TALK WITH CREAMERY EMPLOYES. 253

and others drop or throw everything they handle. The careful man can save to his employer half his salary over the careless man. The time is approaching when more will be required of creamery employés in the way of knowledge of their work, good judgment and skill. We are progressing in this work rapidly and this progress is likely to continue so it will be necessary for men in this line of work to keep alive and up to date.

If you have regard for your future reputation, usefulness and financial success be careful and neat about your work. Do not let an hour's time per day now prevent your securing an advance of $\$ 10$ per month next year. Your employer has a right to expect value received for the salary he pays you. As I have said before, make yourself a necessity. You should take and read at least one live creamery paper, and more than one will pay you well. Remember there are a plenty of men that know more than we do, and a plenty that do not know any more that can give us valuable ideas. Yes, there are many that know much less than we do that have some information that we have not and that we can use to our advantage. As a practical illustration in this line I will give a little information that I picked up in the past few months. A certain creamery that I know well has had a market for its butter for several years 
in an Eastern city. In 1893 a part of the summer make was put in the cold and held until winter. When it was taken out and put on the market it was found that it had not kept well. This was a surprise to the holder and to the creamery proprietor too, as the goods had previously kept well in the cold and made the holder some money; but in 1893 it made quite a large loss and of course in 1894 the goods had to hunt a new customer and the proprietor of the creamery secured a new butter-maker. Here was a money loss to the purchaser of the butter, a loss of a position to the butter-maker and a loss of business to the creamery proprietor, all from failing to do as well as a person knew how. As time passes along more will be expected of creamery employés in the way of intelligence and good judgment. We have a great deal to learn in this line yet. Let us not run away with the idea that we are smarter than other people. We show a weakness when we do it.

Dr. Bernstrom of Stockholm, Sweden, said to me a few years ago that when we made as good butter as they did in Sweden we could crowd them out of the English market. I asked him what was the lowest price they received in the English market for their butter and he said twenty-five cents per pound. The Elgin market was at that time eighteen cents. 
Here was a margin of seven cents between the best Elgin and Swedish butter in England. I advise all who possibly can to take a course in some of our dairy schools. It will pay you. And do not go with the idea that there are only one or two points that you need information upon. I have known men with that idea to be very much surprised with the combined information they came in contact with. It is not alone the knowledge of the instructors, but in addition you get what a skillful teacher can draw out of the class; and a class of men some of whom have had several years' experience contains a remarkable fund of information.

A majority of the butter-makers of the future will have had some experience in dairy-school work. As a pointer here I wish to state a fact: A large per cent of the students at the 1894 Pennsylvania Dairy School in creamery class had positions engaged before attending the creamery course and they were secured in many cases with the understanding that a course should be taken in the dairy school. This was a part of the contract. I wish to talk on one point here that perhaps should have been treated elsewhere. That is the change that is coming upon us, caused by the improved methods of holding butter in the cold-storage warehouses. This is sure to increase the de- 
mand for kutter when the price is low. I have heard butter-makers say they made butter to sell, not to hold. This is foolish talk, as the time is near at hand when summer butter to sell will need to be made so that it will hold well. The fine qualities of butter are not sacrificed when it is made to hold. We add to the value of the butter when we make it so it will hold well. 


\section{APPENDIX.}

\section{AN ACID TEST OF CREAM.}

EXTRACTS FROM ILLINOIS EXPERIMENT STATION "BULLETIN NO. 32," BY E. H. FARRINGTON, M. S.

The sourness of cream is one of the things considered by many dairymen in making butter. They may not agree on the amount of acidity that cream should have when it is ready for churning, but many base their judgment on the taste or appearance of the cream.

The first record of a measurement of the acidity of cream before churning, so far as known to the writer, was reported in 1887 by John Sebelein, in "Versuchs-Stationen," XXXIV, p. 94. He used an alkaline liquid of known strength (onetenth normal) and by adding a few drops of a liquid indicator, phenolphtalein, to a measured quantity of cream $(50 \mathrm{c.}$ c., or about one-tenth of a pint,) the amount of acid in the cream was estimated by measuring the quantity of the alkaline liquid that it was necessary to add to the $50 \mathrm{c}$. c. of cream in order to produce a pink color in the cream tested. The indicator, phenolphtalein, has the property of causing a pink color in some alkaline liquids, but does not change the color of acid solutions. This gives a means of measuring the amount of acid in milk or cream by noting the quantity of an alkaline liquid of known strength that will produce this pink color in a measured amount of cream. The strength of the alkaline liquid and the amount of cream taken for each test are constant, known quantities, always the same in comparative trials of different lots of cream. The amount of acid in the measured quantity of cream is unknown until, by testing it, it is observed how much of the standard alkaline liquid it 
is necessary to use to produce the pink color. A one-tenth normal solution of an alkali is of a definite strength understood by chemists. The alkali may be caustic soda, potash, lime, or baryta. All these are efficient and results will be comparable if a one-ten th normal solution of any one of them is used.

In the fall of 1889 this method of testing the acidity of cream was used by Dr. Manns at the creamery of Gurler Bros., De Kalb, Ill., and also in churnings of cream which

- he made at this station. He found that when cream was churned at a temperature of 58 to $62 \mathrm{deg}$. Fah. too much acid in the cream injured the quality of the butter, and too sweet cream churned at this temperature caused a loss of butter in the buttermilk. The butter was not all churned out unless the cream was sufficiently soured. The butter was of poor quality if the cream was too sour. These trials indicated that, so far as the acidity of the cream had an influence on the flavor of the butter and on the thoroughness of the churning at 58 to 62 deg., the best results were obtained when the acidity of $50 \mathrm{c}$. c. of cream was neutralized by about 40 c. c. of one-tenth normal alkali. This work was published in "Bulletin No. 9" of this station May, 1890. The "per cent of acidity" as given in that bulletin can be converted into c. c. of one-tenth normal alkali by multiplying the "per cent of acidity" by 5,000 and dividing by 87 .

In following up this line of work the writer has developed a method of

Cream testing with alk aline tablets.-A formula has been worked out by which a definite amount of solid alkali can be made into a tablet containing both the alkali and the indicator necessary for testing the acidity of cream or milk.

Each tablet contains a definite amount of alkali which will neutralize as much acid as $4.66 \mathrm{c}$. c. of a one-tenth normal alkaline liquid. A test of a number of the tablets showed them to be very unifor $m$ in the amount of alkali contained in each tablet. The extreme difference amounted to threetenths of one c. c. of the one-tenth normal liquid. One thousand tablets weigh about twelve ounces. Each tablet is about three-eighths of an inch in diameter and one-eighth 
inch thick, and they can be used instead of the one-tenth normal alkaline liquid and the liquid indicator already mentioned. The tablets can be used for testing the acidity of cream in the following way:

Dissolving the tablets.-A 50 c. c. glass cylinder, graduated, and on a foot, is found to be a convenient piece of apparatus to use in preparing the solution of the tablets. It is made of stout glass, not easily broken, and can be obtained of any dealer in chemical apparatus. Put five tablets into this cylinder, add hot or cold soft water until the cylinder is filled up to the 50 mark, then cork the cylinder and shake frequently until the tablets all disappear in solution. If the solution of the tablets is hastened by shaking the bottle or stirring the liquid it should be done in such a way as to prevent any loss. As they do not dissolve immediately they should be put to soak about one-half hour before the cream is to be tested. The strength of the solution does not change perceptibly by standing four or five hours, but there is some change in a tablet solution which is a day or more old. The solid tablet will not change, and the only precaution necessary is to use a fresh solution of the tablets in testing the acidity of the cream. Excepting the flocculent residue or settlings, which will not dissolve in water, the tablets should all disappear in the solution before it is added to the cream to be tested. When the solution is complete the cylinder contains a.reddish-colored liquid, the alkaline strength of which is indicated by the number of tablets which were put into the cylinder.

Testing the cream.-The cream to be tested should be thoroughly mixed. Then measure 25 c. c. of the cream into a glass tumbler or a cup. If the cream is very thick 25 c. c. of clean rain water may be mixed with it in the dish. The sourness of the cream is then ascertained by adding the reddish-colored solution of the tablets to this measured quantity of cream until it retains a pinkish color. When the two liquids, cream and tablet solution, are thoroughly mixed the pink color does not remain permanent until the acid of the cream is completely neutralized by the alkali of the tablets. An excess of the alkali causes the color to increase. The 
acidity of the cream is measured by adding just enough of the alkali to produce a permanent change of color from white to pink. No further addition of the alkali is necessary, as the first change of color indicates the point when the acid is all neutralized. A piece of white paper placed under the tumbler in which the cream is tested will help to show the change of color. It will be found to be more accurate to adopt as the end of the test the point when the first change of color appears and the cream is no longer white, rather than to try to get a certain shade of pink color every time.

The amount of alkali required to produce this change of color shows the sourness of the cream as indicated by this test. A change of color may be produced in 25 c. c. of sweet cream by a solution of one or two tablets. As the sourness of the cream increases $25 \mathrm{c}$. c. of it may require a solution of three, four or five tablets to change the color.

The indications are that a cream which requires a solution of six or more tablets to change its color is too sour. The butter made from such cream will be off flavor. The only general direction that can now be given as applicable to nearly all cream is to churn it when 25 c. c. of the thoroughly mixed cream is not colored by a solution of four tablets but is decidedly colored by a solution of five tablets.

Some dairymen may prefer to churn a less acid cream and adopt the sourness of cream which will give a color with a solution of three tablets.

Comparative trials made by each person of the acidity of the cream and the flavor of the butter made from it will be a satisfactory guide to follow.

This test will show the sourness of each lot of cream so that a uniformity of acidity can be had in each churning. How much acidity each lot of cream should have, or whether cream should be churned sweet or sour, may be a matter of opinion with the butter-maker. This test serves as an aid to show him when the cream is of the sweetness or sourness which he prefers. It will also show when the cream ought to be churned in order to prevent it from spoiling the butter by ripening too far and becoming too sour for the best re. sults. 
The complete outfit. including 1,000 tablets, one 25 c. c. pipette and one 50 c. c. measuring cylinder, costs $\$ 3$ delivered. One thousand tablets ought to make 250 tests of cream.

My firm have used the alkaline tablets in our De Kalb creamery and think them as reliable and more convenient to use than the Manns acid test. I think it will pay all butter-makers to have these tablets and use them as often as is necessary to keep themselves right. They will be a greater help to a person that has had little experience than to one that has had much. They will help to educate a person's taste to the right acidity. 



\section{N D E X.}

\section{PART I.-PRIVATE DAIRYING.}

Abortion, 49, 50 .

Age to breed, 23.

Autumn, why cows should freshen in, 46.

Average cow, the, 9 .

Babcock tester, the, 20.

Babcock test, value of the, 14.

Baker's, Mr. W. D., ration for cows, 54.

Barrel dairy churn (illustration), 96.

Barrels, return milk in. 64 .

Bollert's, Mr. Herman, ration for cows, 56.

Bourquin's, Mr. A., ration for dairy cows, 53.

Box churn, square (illustration), 97.

Boynton's, Mr. W. J., ration for cows, 53.

Bradley's patent pail packages (illustration), 111.

Brand for butter, have a, 113 .

Breeding cows, intelligent, 22.

Breed to select, what, 24.

Busick's, Mrs. Kate M., ration for dairy cows. 53.

Butter color, 99 .

average yield of, par cow, 9

from silage, 35 .

from the test, estimating, 16 .

have a brand for, 113.

individuality of, 113.

ladle, Anderson's (illustration), 106.

loss on poor, 110.

marketing dairy, 110.

once working, 104

packages, kind of, 107.

packer (illustration), 106.

profit on fine, 110.

putting up for market, 108.

salting, working and packing, 103.

shipping box (illustration), 108 .

should not be touched by hands. 102.

spades (illustration), 106.

twice working, 105.

washing the, 100 .

Butter-worker, the Eureka (illustration), 104 .

the Mason (illustration), 105.

lever, (illustration), 107.

Buttermilk, value of as food, 141.

Vermont Station on skim-milk and, 142.

Buying cows, 24, 26.
Caldwell's, Prof. W. H., views on breeds, 25.

Calves, dehorning, 58.

Dr. Goessman on skim-milk for, 137 .

Iowa Station on skim-milk for, 140.

Mississippi Station on skim-milk for, 140 .

Pennsylvania Station on skim-milk for, 140 .

Prof. Plumb on skim-milk for, 138. remedy for scours in, 135 .

rules for feeding, 135 .

should be kept dry; 136.

skim-milk for, 133.

Calving time, the, 44.

Care pays well, 114.

Centrifugal separators, 88 .

Chaff, wet, for weighting the silo, 39.

Churn and worker, washing the, 63. barrel, dairy (illustration), 96 . Davis swing (illustration), 101. rectangular (illustration), 99. room, temperature of, 99 . square box (illustration), 97. straining cream into the, 98 . test for cows, 12 .

Churning at low temperature, 101. different temperatures for, 96 .

Cleanliness in milking, 66.

Clover, when to cut, 3 :.

Commission houses, 112 .

Conflne the cows, how to, 49 .

Cooke, Prof., on feeding pigs, 120.

Cooley creamer, the (illustration), 85.

Cooling, repeated. recommended, 83.

Corn and skim-milk compared, 122. cost of growth of pigs with, 117 . for silage, when to cut, 33 . planting for silage, 35 .

Cottrell's, Mr. M. H., ration for cows, 54.

Cow beef, cost of, 27 .

Cows, a New York experiment in feeding, 45 . breeding, 22

buying, 24 .

churn test for, 12 .

charative profitableness of, 19 .

cost of feeding, 10,27.

cream test for, 12 .

disposing of unprofltable, 27.

Dr. Pierson on feeding, 45.

drying off, 24.

how to confine the 49 . 
Cows, language of the, 32 . need special care, 69 . one better than two, 21. purchasing by Illinois Experiment Station, 25 rations for dairy, 52. standard for, 22 .

test before buying, 26 .

testing the, 15 .

the average. 9 .

tying, 49 .

warm the water for, 39 .

watering in the stahle, 40 .

Cream and fat, percentages of, 13 . deep cold-setting, 95 . effect of heating and cooling on, 83 . holding, 94 .

ripening and churning, 94.

separator, 95

straining into the churn, 98.

test for cows, 12.

test unreliable, 13.

Creamery building, farm (illustration) 81.

Creaming promoted by repeated cooling, 83 .

Dairy butter, marketing, 110. farm, profits from, 115 .

herd, the, 9.

utensils, care of, 62 .

Deep-setting can (illustration), 84 .

Dehorning, 57.

Delaware Station on separators, 88 .

Difference in mulkers, 69 .

Disturbances, effect of, 68 .

Dog power, churning with (illustration), 100.

Doncourt's, Mr. A., ration for cows, 55.

Drew's, Mr. L: S., ration for cows, 55.

Drying off cows, 24 .

Ergot, abortion from, 50 .

Estimating butter from test, 16 .

Eureka butter-worker, the (iliustration), 104.

Exposure, effects of, 58. Farm creamery building (illustration),

Farm skim-milk, 92.

Farmer's work, average in feeding pigs, 120.

Fat and cream, percentages of, 13.

Feed and management, 30 .

Feeding calves, rules for, 135 .

Feeding cows, a New York experiment in, 45 .

cost of, 10 .

Ur. Pierson on, 45.

individual cows, cost of, 27.

Kansas experimental work in, 46. old and young arimals, 125 .

Feeding problem, a, 36 .

Fisher's, Mr. L. C., ration for cows, 55.

Flannel strainers, 81.

Foundation herd of cows, 9 .

Gabrilson's, Mr. C. L., ration for dairy cows, 53.

Goodrich's, Mr. C. P., ration for cows, 55

Gould's, Mr. John, ration' for cows, 55.
Goss', Mr. J. W., ration for dairy cows, 53.

Hands should be kept out of butter, 102.

Hay, when to make. 31.

Heating and cooling, effect of on cream, 83.

Henry's, Mr. E. S., ration for dairy cows, 53.

Henry, Prof., on feeding pigs, 124.

Herd, how to improve the, 10.

Holding cream, 94 .

How to milk, 73.

Hyatt's, Mr. A. X., ration for cows, 55 .

Illinois Station on feeding pigs, 119.

Improving the herd, 10.

Indiana Experiment Station on effects of exposure, 58 .

Individuality, butter has, 114

Kicking, cause for, 67.

Ladle, handling with the, 102.

Lever butter-worker (illustration), 107.

MeClintock's, Mr. John, ration for cows, 55.

Maine experiment work in skimming, 88.

Management and feed, 30.

Market, putting up butter for, 108 .

Marketing dairy butter, 110 .

Mason butter-worker. the (illustration), 105 .

Milk, average of per cow, 20. from cow to cream vat, 81 .

how to, 73.

morning's and night's, compared. 78.

pail, tin (illustration), 81, 82.

quality of, first and last compared, 76.

return. in barrels. 64 .

room, temperature of, 83 .

skimming from Cooley cans (illustration). 86

test, seeking a, 49

variation in, from day to day, 77.

when should be skimmed, 84 .

Milkers, difference in, 69 .

Milking, 65

fast and slow, compared, 75,

for prizes, 71

habit, establish the, 23 .

one teat at a time, 75 .

tests, frequency of, 76 .

Wisconsin Experiment Station on, 74.

Minnesota experiment work in skimming, 88 .

Mississippi Station on milk, 79.

Morning's and night's milk compared, 78.

New York experiment work in skimming, 88.

Nutrients in twenty-four rations; 56.

Oats, can we afford to feed, 43.

Once working. 104

Packages, butter, 107.

Bradley's patent pail (illustration), 111.

glass butter (illustration), 112. 
Packing, salting, and working butter, 103.

Pierson, Dr., on cow-feeding, 45.

Pigs, results from feeding, 117 .

Plumb. Prof. C. S., on effects of exposure, 60 .

Pork, cost of, from corn, 117.

Prizes, milking for, 71 .

Profts from dairy farm, 115.

Quality of first and last milk compared, 76.

Rations for dairy cows, 52.

table of nutrients in twenty-four, 56.

Regularity in milking, 66 .

Rejected tood, 44 .

Return milk in barrels, 64 .

Ripening and churning, 94.

Robertson's, Mr. R., ration for cows, 56.

Salting, worizing, and packing butter, 103.

Samples, care of the, 16 .

Seientists, credit to the, 50 .

Scours in calves, remedy for, 135.

Separator cream, 95.

the "Baby," De Laval (1llustration), 90.

the "Baby," power (illustration), 89.

centrifugal, 88 .

milk good, 141.

Shlpping-box for butter (illustration), 108.

Silage, amount of, to feed, 43.

butter, 35 .

planting corn for, 35 .

surface, exposure of, 34. when to cut corn for, 34 .

Silo, flling the, 38 .

how fast to fill, 38.

weighting, 39 .

Sisson's, Mr. Geo. W., ration for cows, 54.

Skimmer, the cone (illustration), 87.

Skimming, carè in. 87 .

experimental work in, 87.

from the Cooley cans (illustration), 86. milk, 84

Skim-milk, 116

age, effect of in feeding. 128.

and buttermilk compared, 143.

and corn compared, 122

farm, 92 .
Skim-mi!k feeding before and after weaning, 125 .

for calves, 133.

for old and young animals. 125.

Goodrich's, Mr. C. P., experience with feeding, 132 .

Gov. Hoard's experience with feeding, 131.

Massachusetts Station on, 131, 144.

New Hampshire experimental work in feeding, 127.

value of, 11, 116 .

Whitcher's, Prof., conclusions on value of, 130 .

with grain, table showing value of, 129.

Imiths \& Powell's ration for cows, 54.

Sow with pigs, feeding, 121.

Special care for cows, 69.

Spoon ladle, the (illustration), 106.

Stables, importance of warm, 48 .

Strainers, 81.

Submerged plan. the, 85 .

Suggestions a bout feeding, 133.

Temperature, churning at low, 101. for churning, different, 96 .

of churn room, 99.

of milk room, 83 .

Testing, how done, 16. the cows, 15, 17 .

Tin milk pail (illustration), 81.

Tuberculosis, about, 41.

Tubes, milking with, 76 .

Utensils, care of dairy, 62 .

Variation in milk from same cow, 77

Virginia Station on feeding pigs, 119.

Warming water for cows, 39 .

Warm stables, importance of, 48 .

Washing the butter, 100 .

Watering cows, 39.

Wilcox's, Mr. Munzo, ration for cows, 54.

Winslow's, Mr. C. M., ration for cows, 55.

Wire cloth strainer, Curtis' (illustration), 82.

Wisconsin Experiment Station's rations for dairy cows, 52 .

work in skimming; 88 .

on feeding pigs, 118, 123.

Wooden scoop for handling butter, 102

Wooden utensils, preparing, 63 .

Worker and churn. washing the, 63 .

Working, salting and packing butter, 103.

\section{PART II.-CREAMERY MANAGEMENT.}

Absorbing bad odors, 156.

Acidity, look out for, 194.

Acid test of cream; an, 257.

Aerating milk, 147.

Agitating milk when cooling 148.

Alkalire tablets, testing with, 259

Alpha tempering vat (ulustration), 171, $172,173$.

Babcock test, the 246 . at World's Fair, 166.
Babcock test as a basis of payment for cream, 247.

applies to all milk, 160.

difficulties in the, how to overcome, 163.

difficulties, reasons for, 163

difficulty from "black stuff," 162.

gives satisfactory results, 160 .

not automatic, 160 .

points to be watched, 162 . 
Babcock test, Russian, 216, 247. tested and proved, 166. to be looked after. 174.

Bad milk to be returned. 149.

Bair's cream cooler (illustration), 176.

Belts to be looked after, 225.

Bloody milk, effect of, 153 .

Boiler, the, 222 . and engine, capacity of, 234.

Brushes used in cleaning, 221.

Buildings and utensils, care of, $21 \%$.

Butter accumulator (illustration), 181.

Butter at World's Fair, judging, 190. care in packing, 211. coloring with the salt, 198 injured by cheese, 205. keeping quality of unwashed, 190 . marketing, 212.

mottled, cause of, 182. neat packages for, 211 . packages, care of, 210. removing curd from, 200. salting, working and marketing, 204. tubs, 210.

washing, 195.

worker, cleaning the, 220.

worker, Vermont power (illustration), 207.

Buttermilk, test of, for fat, 199.

Calves, skim.milk for, 215 .

Cans and tanks for gathering cream, 242.

Cedar-box creamery churn (illustration), 197.

Channel vat, 170.

Cheese, butter injured by, 205.

Churns, 198

care of, 217, 219.

cedar box, creamery (illustration), 197.

cooling the, 184.

Curtis' improved factory (1llustration), 196.

Davis' swing (illustration), 191.

Disbrow's combined (illustration), $192,193$.

room, temperature of, 188.

salting, 206.

temperature of the, 186 .

Churning at low temperature, 187.

same day gathered, 243. temperature during, 198.

Color added to the salt, 198. have a standard of, 202.

Combined churn and worker, Disbrow's (illustration), 192, 193.

Composite plan of testing, 157. samples, taking, 156

Conveying milk to creamery, 150.

Cooler, Gurler's circulating (illustration), 185.

Cooling cream quickly, 176.

Oooling milk, 147.

Cooling milk quickly, 171.

Covers for milk wagons, 150.

Cream cooler, Danish Weston (illustration), 175.

Cream, cooling, quickly, 176.

gauge, the, 239 .

how to remove from bowl, 177.
Cream, lcok out for the, 194.

Pasteurized, 202.

per cent of fat in, 200.

rich, requires low temperature, 187.

ripening and churning, 182.

strainer (1llustration), 200.

temperature at which to hold, 184.

temperature to ripen, 183

Creamery, cost of, 231 .

employés, a talk with, 249.

location of the, 226 .

plan for a, 228, 229 .

suggestions a bout bullding a, 226 .

Curd from butter, removing, 200.

Curtis' improved factory churn (illustration), 196.

Dairy school work, 178.

Danish Weston cream cooler (illustration), 175 .

Davis' swing churn (illustration), 191.

Decision needed, 155.

Detecting bad odors, 156.

Disbrow's combined churn and worker (illustration), 192, 193.

Drainage, importance of, 230 .

Drain, the creamery, 220.

Driver's case (illustration), 241. measuring pail (illustration), 240 .

Employés, a talk with creamery, 249.

Engine, care of the, 224 .

European example, 203.

Expert at the weigh can, 155.

Farrington's, Dr., bulletin on "An Acid Test of Cream," 257.

Fat, average of in skim-milk, 180. per cent of in buttermilk. 200. per cent of in cream; 200.

Flavor, effect of washing on, 190.

Floating glass thermometer (illustration), 201.

Floor of creamery, 227.

Gas engine, the Charter (illustration): 232.

Gathered-cream and whole-milk butter compared, 243.

and whole milk, comparative value of, 239. work, 238.

Gurler's circulating cooler (illustration), 185.

Heat, danger from too much, 158.

Heating, effect of on separating, 170 .

Heating milk suddenly, 169.

Horizontal engine (illustration), 233.

Ice, the use of, 243 .

Iowa can, the (illustration), 148

Jacketed cream-carrier, Haney's (lllustration), 243.

Key City King (illustration), 187.

Low temperature, advantages of, 189 , 197.

Marketing, salting and working, 204. butter, 212.

Milk absorbing odors, 151. aerating, 147. agitating when cooling, 148. bad, should be returned, 149 . care of, by patrons, 147. conveying to creamery, 150. cooling, 147. 
Milk, effect of bloody, 153 .

off flavor. when received, 195. quick cooling of, 171 .

receiving at the creamery, 154. should not be mixed, 149 . spoiled by bad surroundings, 151 . sudden heating, 169.

tempering and separating, 169.

"Milk thief" (illustration). 15\%.

Milk wagons, covers for, 150.

Mixed, milk should not be, 149 .

Mop heads (illustration), 223

Mottled butter, cause of, 182.

Mutual interests of patrons and proprietors, 216

Neat packages for butter; 211.

Neglect of boilers, results of, 224 .

Odors a bsorbed by milk, 151 . salt absorbs, 204:

Oll-test churn, Curtis' patent (1llustration), 245 .

Packages, care of, 210.

Packing, care in, 211.

Pasteurized cream, 202.

Patrons and proprietors considered, 216.

tact required in dealing with, 154 .

Pennsylvania Dairy School's tests, 199.

Perforated tin cream strainer (1llustration), 200.

Ploneer work, gathering cream is, 241.

Plan, criticisms of, 230 . for a creamery, $228,229$.

Power required, tests of, 179.

Preserving samples, 158.

Quick cooling of mllk, 171.

Recelving milk at the creamery, 154.

Refrigerator for tank, Curtis' patent (illustration), 242.

Ripening and churning cream, 182.

Ripening cream, use of a "starter" in, 183.

Rotary force pump, improved (illustration), 235 :

Russian separator, Sharples (illustration), 174

Safety valve to be looked after dally, 224.

Salt absorbs odors, 204.

estimating for, 207.

how much, 206 .

sift the, 206.

Salting churn, 206.

Salting, working and marketing, 204.

Samples, preserving, 153. taking composite, 156 .

Sample tube, Scovell's (illustration), 157.

Scalding skim-milk, 215.

School work, dairy, 178.

Scientists, Babcock test satisfactory to, 160 .

Scovell's sample tube (illustration), 157.

Separator, capacity of, 177. care of the, 171 .
Separators, difference in, 178.

Sharples Russian separator (illustration), 174.

Skim-milk at creamery, care of, 214

average of fat in, 180.

clean vats for, 214 .

for calves, 215.

scalding, 215.

sweet and sour, 214.

Vermont experiment with, 214.

Skimming, clean vs. close, 174 .

Skim stations, 235.

Spring wagons necessary. 150.

Standard of color, have a, 202 .

Star cooler and aerator (illustration), 147.

"Starter," a, in ripening cream, 183.

Station work, value of, 180.

Strainer, cream vat (illustration), 239. dipper (illustration), 189.

perforated tin cream (illustration), 200.

Smoke-stack, construction of the, 234.

Submerged can, 244.

Suggestions to those building creameries, 226 .

Surplus and shortage of gathered cream, 238.

Temperature, advantages of $10 \mathrm{w}, 189$, 197.

at which to hold cream, 184.

churning at low, $18 \%$.

during churning, 198.

of the churn, 186 .

of the churn room, 188.

to ripen cream, 183.

Tempering and separating, 169 .

Testing milk, composite plan of, 157 .

Test plan for gathered cream, 241.

Tests at World's Fair, flgures from the, 167.

Tests of power required, 179.

Thermometer, floating glass (1llustration), 201.

have a tested, 201.

Tinware, care of the, 217.

Trap for the sewer, 228.

Unnecessary losses, 150.

Unwashed butter, keeping quality of, 190.

Vat for cans, 148.

the cream, 227.

leaky, 222.

tempering, 231.

Wallace's, Mr. Henry C., experiments, 180.

Washing butter, 195 . effect of on flavor, 190.

Wash sink, 218.

Water heater, Barber's pipe, nolseless, 219.

Weigh can (1llustration), 155 the man at the, 158.

Working, how much? 209. once or twice, 208.

Working, salting and marketing, 204. 


\section{Dairy, Creamery}

and

\section{Cheese Factory}

Apparatus

and

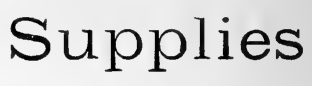

Of every description. We carry in stock everything pertaining to the trade and can supply your wants promptly, from the smallest dairy to the largest and most extensive factory. We have all makes, styles and sizes of separators, both hand and power; boilers and engines, all sizès; gas and gasoline engines; shafting, hangers, pulleys and belting; vats, churns, butter-workers and molds.

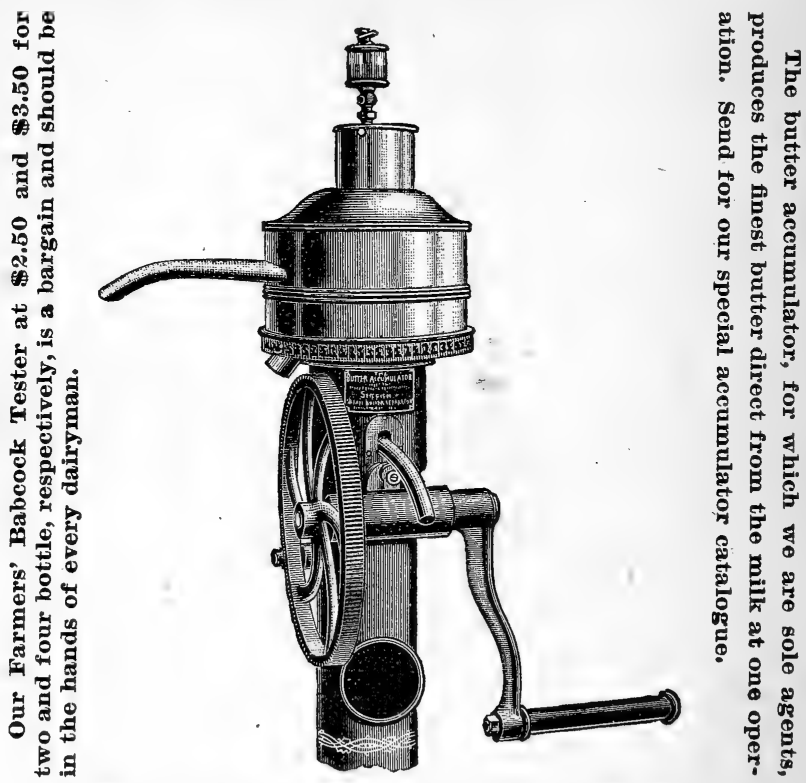

Glassware and tinware at specially close prices. We are the largest manu facturers of butter and cheese packages in the world and in buying from us you get them at first hands and save subsequent profits. We make a specialty of mall-order business and guarantee you prompt shipments and careful service. Should be pleased to mail you our large, free, illustrated catalogue. Address

\section{CREAMERY PACKAGE MFG. CO.,}

1, 3 and $5 \mathrm{~W}$. Washington Street, Chicago, III. 


\section{The Sharples Russian Separator}

THE BOWL ALONE REVOLVES.
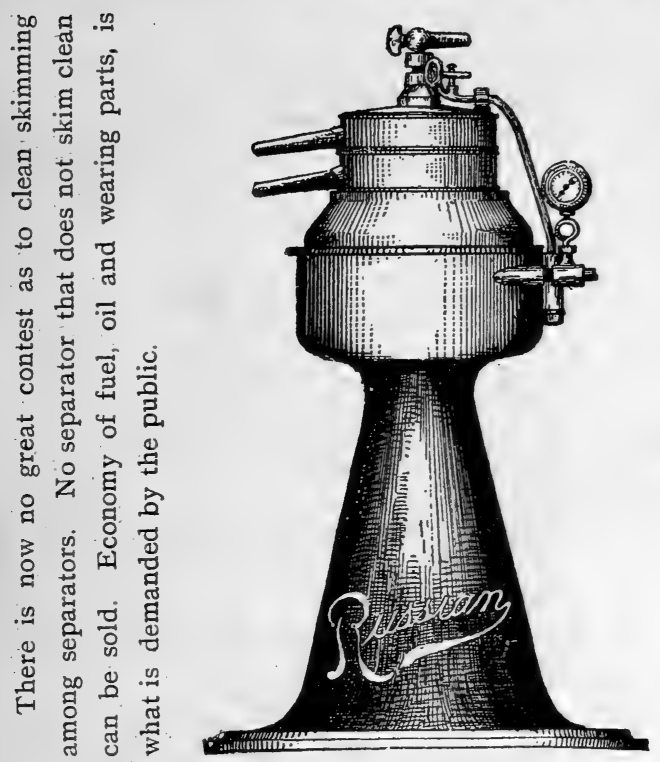

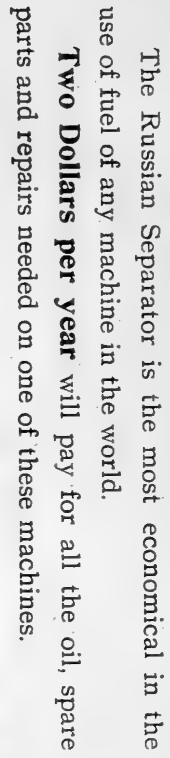

These machines have come into general use in the great Elgin district, and are deservedly the most popular on the market. The bowl is very simple, and the machine easy to operate. Send for circulars.

THE RUSSIAN BABCOCK TEST

IS THE

Only First=Class Test on the Market. IT IS NOT CHEAP, BUT GOOD.

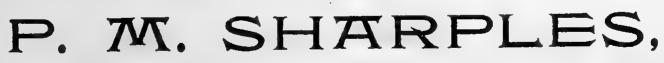

ELGIN, ILL.

IKEST CHESTER, PA. 


\section{THE DE LAVAL "ALPHA" CREAM SEPARATORS.}

These separators are used by all the older, larger and more careful users of cream separators throughout the world. They excel other makes of such machines in essentially the same degree as do such other machines the older gravity systems. They do all that any other machine can do, and enough more to - practically save their cost each year of use.

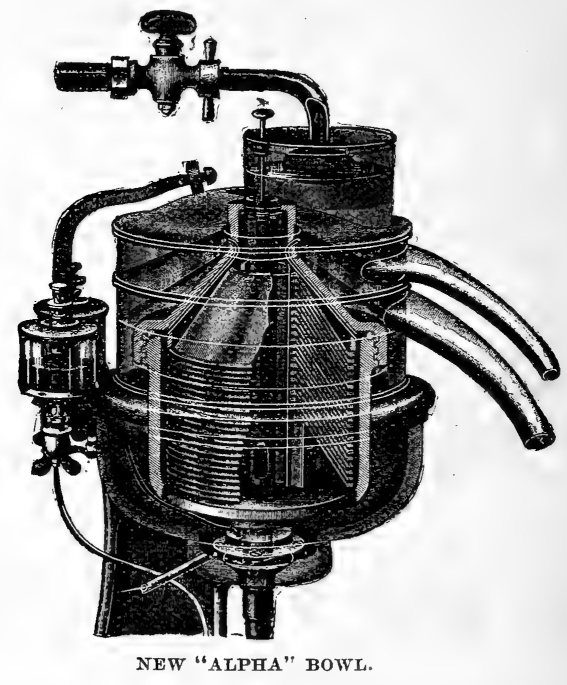

The De Laval separators were selected and used exclusively in the practical working dairy of the late World's Fair. They received the only rezularly' granted award in the Exhibition Department. Their sales now exceed 60,000 machines-or more than ten times all other makes combined. They are sold subject to the guarantee of their unqualified superiority.

\section{THE DE LAVAL SEPARATOR CO.,}

General Offices: 74 Cortlandt St., N. Y. Branch Offices and Shops: Elgin, Ill.; Montreal, Can. 


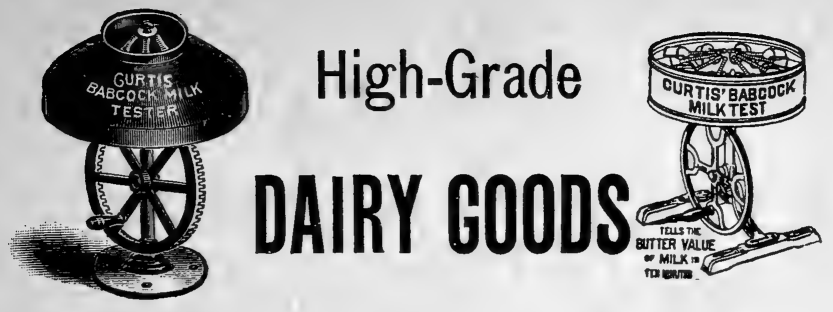

Curtis Channel Bottom Vats.

Curtis Improved Factory Churns.

Curtis Trunk Churns.

Rectangular Churns.

Curtis Babcock Milk Testers.

Lever Butter Workers.

National Butter Workers.

Mason Butter Workers.

$=$ IN FACT -

\section{WE SELL EVERYTHING}

- -

Dairy, Creamery and Cheese Factory.

SERD For FrEB CATALOUEES.

CORNISH, CURTIS \& GREENE MANF'G CO,

Branch House,

Fort Atkinson, Wis.

St. Paul, Minin. 


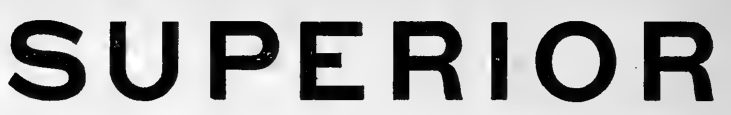

Dairy and Creamery

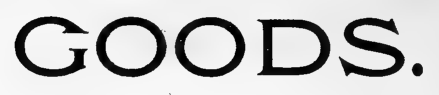

$\frac{\infty}{8}$
$\frac{8}{2}$

EVERYTHING PERTAINING TO THE EVERYTHING MANUFACTURE OF BUTTER AND CHEESE.

Separators, Engines and Boilers, Butter Workers,

Cream, Milk and Water Vats, BAвсоск

Milk Testers, Cabinet Creameries,

Churns, Butter Printers

and Carriers.

ALI STYLES OF

BUTTER PACKAGES AND SUPPLIES.

OUR GOODS ARE OF THE

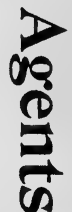

웅

Latest Up=to=Date Pattern, AND FOR

QUALITY OF MATERIAL AND WORKMANSHIP

ARE WITHOUT AN EQUAL,

As the largest and finest Creaméries in the United States and Canada will bear witness.

Send for free Catalogue.

\section{MOSELEY \& STODDARD MFG, CO.}

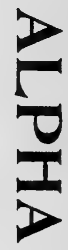

RUTLAND, VT. 


\section{THE DAIRYMAN'S COMPASS}

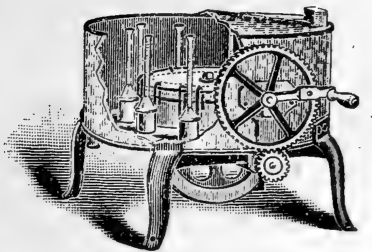

to guide him on his "milky. way"

- IS THE -

V. F. M. BABCOCK TESTER.

Buy one and know

"where you are at."

We have written a book which tells all about it and how to use it.

\section{We Furnish Apparatus Whose Work Will} Stand Testing,

\section{VIZ:- \\ CENTRIFUGAL \\ SEPARATORS,}

Which will take out ALL the

cream from your milk,

"While you WAIT."

Simple,

Well made,

Thorough in their work.

\section{. . OR . . \\ COOLEY CREAMERS,}

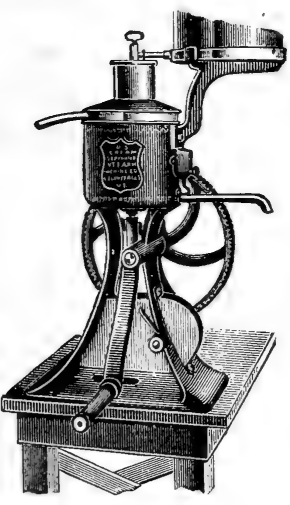

The best gravity creaming apparatus in the World. Proven by

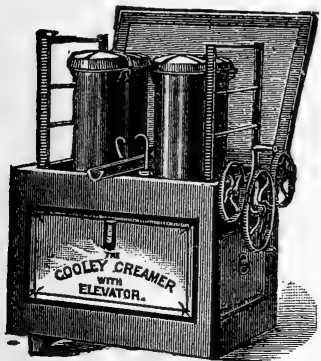
tests of careful government experimenters. Proven in the every day use of thousands of dairymen.

Procure and read our circulars.

WE FURNISH EVERYTHING for the dairy, creamery, or sugar bush and shall be glad to send circulars of anything you may wish.

\section{VERMONT FARM MACHINE CO,,




\section{A. H. BARBER, PRODUCE COMMISSION MERCHANT.}

SPECIALTIES:

Butter, Cheese and Eggs. MANUFACTURERS AND DEALERS

Creamery Apparatus and Supplies. WESTERN AGENTS

- FOR-

ALPHA Separators $-\mathbf{A N D}-$

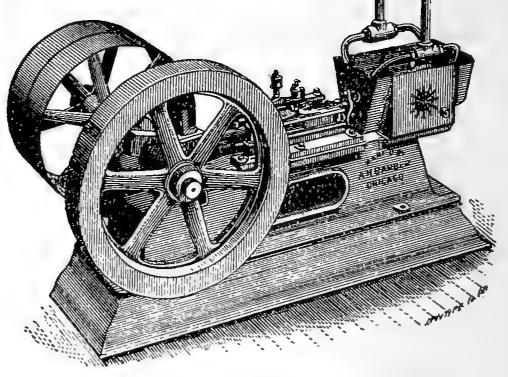
WELLS, RICHARDSON \& CO.'S BUTTER AND CHEESE COLOR. Barber's Ice or Refrigerating Machine, Creameries, Butter Rooms, Meat Markets, Cold Storage, Etc.

229 SOUTH WATER ST. - - CHICAGO, ILL. 


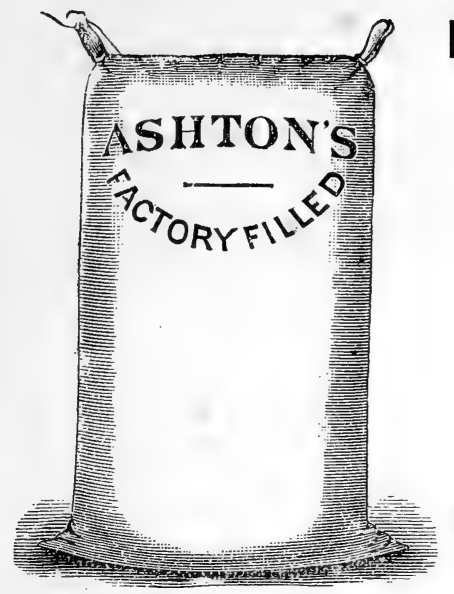

FIRST COST cuts so important a figure with many people that they

\section{LOSE}

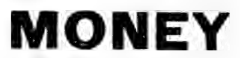

by getting the poorest, because the lowest priced goods. The article that saves you money

\section{IN THE LONG RUN}

is what you want to get.

\section{Asshton's and Higgin's Eupeka Salts}

are the cheapest Salts to buy because they are

\section{PURER, STRONGER} $\therefore$ and..

\section{GO FARTHER}

than any other Dairy

Salts on the market.

For Seventy-five years the leading brands of Dairy Salts in the World.

Sold by leading grocers everywhere. . .

Francis D. MOULTon \& Co, GENERAL AGENTS, 29 Broadway, - NEW YORK.

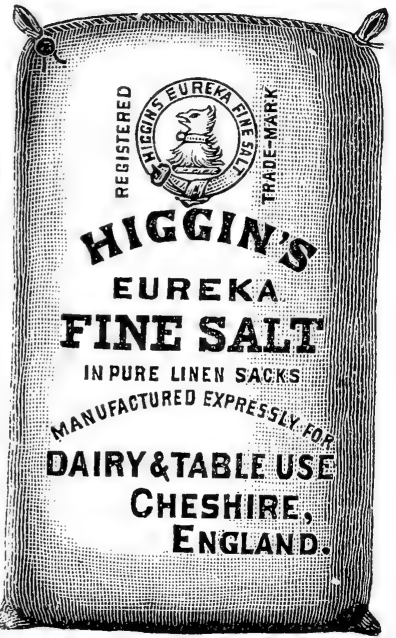




\section{STANDARD BOOKS For Stock-Owners.}

BARN BUILDING, $\begin{aligned} & \text { EDITED BY J. H. SANDERS, a collection } \\ & \text { of plans of general farm barns, cattle barns, }\end{aligned}$ horse barns, swine pens, sheep folds, etc., from drawings of bulldings actually built and in use by successful farmers and stockmen; from which many useful and practical hints may by drawn. New edition; 285 pages; cloth. Price, \$1.50.

\section{BREEDS OF LIVE STOCK, BY J. H. SANDERS. All} proved farm animals described and illustrated by elegant wood engravings by the best artists. 475 large pages. Cloth. Only $\$ 2$ by express, prepaid.

CATTLE-BREEDING, BY mere Farm, Lexington, Ky.-acknowledged by the highest authorities of America and Europe to be the most thorough setting forth of the THEORY AND PRA(TICE OF STOCK-BREEDING ever written. 390 pages. Cloth. Price by mail, post-paid, to any address, $\$ 2$.

HORSE-BREEDING, ${ }_{\text {BREEDER'S GAZETTE, for years editor of }}^{\text {JP. H. SANDERS, foupd }}$ the old National Live-Stock Journal, ex-associate editor of the Spirit of the Times, ex-editor of the Percheron and Breeders' Trotting Stud Books, etc. This is by all odds the most successful book on this subject ever issued. It has passed through ten editions and was translated into the German by H. von Nathusius, the great European authority on scientific breeding. All about the breeds and management of stallions, brood mares and foals. Treatment of diseases incident to parturition, how to tell age by the teeth, etc 428 pages. Cloth. Last edition, revised, enlarged, illustrated. By mail, post-paid, \$1.50.

\section{The King of All Farm Papers} $\rightarrow-$

\section{THE BREEDER'S GAZETTE,}

$A^{N}$ illustrated weekly, covering the whole fleld of stock-breeding, feeding, $A_{\text {dairying, etc.; numbering among its contributors such authorities as Prof. }}$ W. A. Henry, Director of the Wisconsin Agricultural Experiment Station; H. B. Gurler, C. P. Goodrich, A. X. Hyatt, et al. Write for free specimen copy.

All of the above published by the

J. H. SANDERS PUB. CO., Chicago, III. 



\section{(1.5) (1)}

(1)

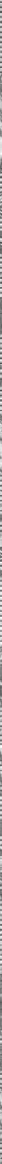


a

니ำ

(2)

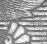

3 ,

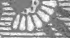

(1)

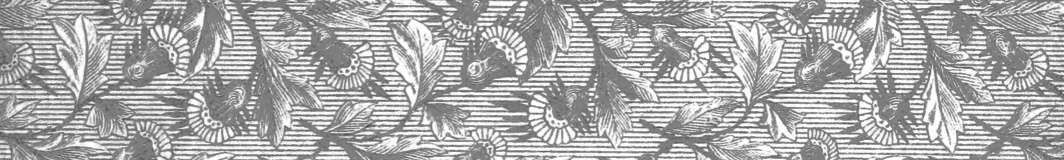

(19)

3.

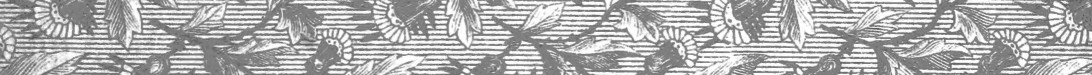
(6)

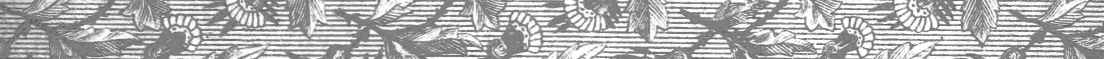

12)

orix (n)

73 .

군

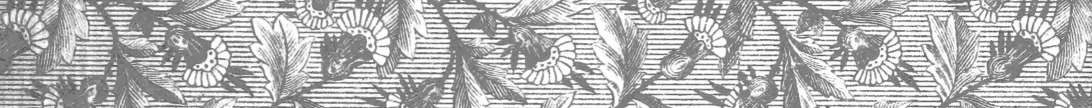

Q60.

(5)

2 .

(5) 글

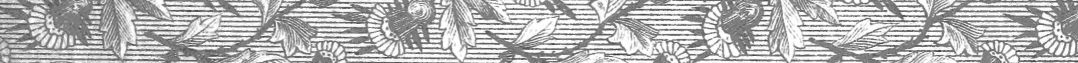
$3 \sum$ "

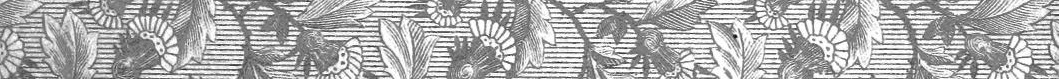




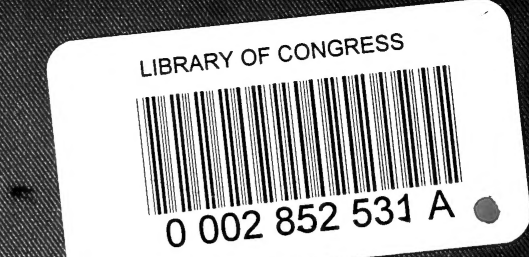

